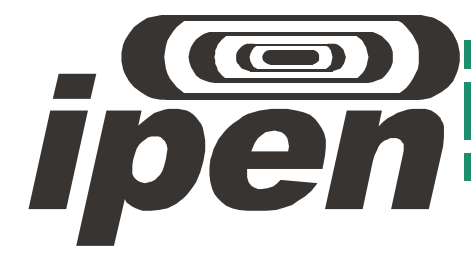

AUTARQUIA ASSOCIADA À UNIVERSIDADE DE SÃO PAULO

\title{
AVALIAÇÃO ECOTOXICOLÓGICA DOS PERCOLADOS DAS COLUNAS DE CINZA DE CARVÃO E DE SOLOS COM CINZA DE CARVÃO UTILIZANDO Lactuca sativa e Daphnia similis COMO ORGANISMOS TESTE
}

Flávia Junqueira de Castro

Dissertação apresentada como parte
dos requisitos para obtenção do Grau
de Mestre em Ciências na Área
de Tecnologia Nuclear - Materiais
Orientadora:
Profa. Dra. lara Maria Carneiro de Camargo


INSTITUTO DE PESQUISAS ENERGÉTICAS E NUCLEARES

Autarquia associada à Universidade de São Paulo

\title{
AVALIAÇÃO ECOTOXICOLÓGICA DOS PERCOLADOS DAS COLUNAS DE CINZA DE CARVÃO E DE SOLOS COM CINZA DE CARVÃO UTILIZANDO Lactuca sativa E Daphnia similis COMO ORGANISMOS TESTE
}

\author{
FLÁVIA JUNQUEIRA DE CASTRO
}

Dissertação apresentada como parte dos requisitos para obtenção do Grau de Mestre em Ciências na Área de Tecnologia Nuclear - Materiais.

Orientadora:

Dra. lara Maria Carneiro de Camargo

Versão corrigida

Versão original se encontra no IPEN

São Paulo 
Dedicatóría

Aos meus país, Roseli e Luiz Evaldo,

e a minha írmã Fernanda, por todo amor e paciêncía. 
Epigrafe

"O futuro dependerá daquílo que fazemos no presente" Mahatma Gandhi 


\section{Agradecimentos}

À Nossa Senhora e à Deus por me ajudar a alcançar mais essa conquista.

Ao meu pai e a minha mãe por seus conselhos por me ouvir sempre que precisei, pela paciência, compreensão e confiança, mas de maneira especial por todo amor.

À minha irmã Nanda por ser minha grande amiga sempre.

Ao meu tio Regis e minha tia Selma pelo carinho.

Aos meus amigos Amanda Büttner, Aline Mendonça, Bruna Graber, Bruna Junqueira, Carolina Martinelle, Heleno Castro, Mônica Santiago e Natália Junqueira por me ouvir e incentivar sempre.

À Dra. Iara Maria Carneiro de Camargo pela oportunidade, paciência e orientação.

À FAPESP pelo auxilio financeiro ao projeto.

À CAPES pela bolsa de mestrado.

Ao Dr. Augusto Cesar, Dr. Camilo Seabra, Msc. Fábio Puscesddu, Msc. Fernando Cortez e Dr. Rodrigo Choueri, pelo apoio, atenção, incentivo, amizade e contribuição para realização deste trabalho.

À Sandra R. Mattiolo por sua contribuição para a realização deste trabalho.

À Camila Lange por sua amizade e contribuição para a realização deste trabalho.

À Lucilena Rebelo por todos os bons conselhos, atenção, carinho e amizade.

Às minhas amigas do laboratório de ecotoxicologia do CQMA: Vanessa Lameira, Giovana Gimiliani e Diana Dias que ajudaram muito para a realização deste trabalho.

Aos meus amigos e colegas Carina Pitwak, Douglas Silva, Juliana Ikebe, Juliana Izidoro, Mainara Faustino, Marina Victoretti, Patricia Cunico, Renan Azevedo e Tarcila Bertolini pelo apoio e momentos de descontração.

À Bruna Oliveira por sua amizade e conversas depois de cada aula.

À Gisela Martini por nossas conversas, amizade, apoio e incentivo sempre.

À Caroline Oliveira e à Juliana Silva pela amizade, momentos de descontração, conselhos, incentivos, preocupação, cuidado e carinho.

Aos funcionários do IPEN e do CQMA pela atenção e disponibilidade e à todos que de alguma forma contribuíram para minha formação. 


\title{
AVALIAÇÃO ECOTOXICOLÓGICA DOS PERCOLADOS DAS COLUNAS DE CINZA DE CARVÃO E DE SOLOS COM CINZA DE CARVÃO UTILIZANDO Lactuca sativa E Daphnia similis COMO ORGANISMOS TESTE
}

\section{Flávia Junqueira de Castro}

\begin{abstract}
RESUMO
As cinzas resultantes da queima de carvão por usinas termelétricas tem sido uma fonte de contaminação constante devido a seu descarte sobre o solo de forma inadequada. Os elementos tóxicos presentes na cinza de carvão quando lixiviados da cinza para o solo podem ficar biodisponíveis e serem absorvidos por plantas, consumidos por animais ou ainda transportados para diversas matrizes ambientais, tais como, águas subterrâneas e águas superficiais. Ensaio de germinação e desenvolvimento das radículas de Lactuca sativa e ensaio de toxicidade aguda com Daphnia similis foram realizados para avaliar a toxicidade dos percolados de colunas de cinza de carvão e de solo com cinza de carvão. De acordo com os valores obtidos por meio dos ensaios de germinação e desenvolvimento das radículas de $L$. sativa foram observados efeitos tóxicos à germinação das sementes de $L$. sativa nos percolados da coluna de cinza de carvão. Os valores médios de $\mathrm{Cl}_{50}(120 \mathrm{~h})$ destes percolados variaram de 27,6 a $90,6 \%$ e os valores do índice de germinação (IG) variaram de 6,7 a 40,8. Nos ensaios de toxicidade aguda com os organismos teste $D$. similis também foram observados efeitos tóxicos à mobilidade e/ou sobrevivência dos organismos expostos aos percolados da coluna de cinza de carvão. Os valores obtidos para CE50(48h) nestes percolados variaram de 25,6 a 84,1\%. Os percolados das colunas de solo com cinza de carvão não apresentaram toxicidade tanto à $L$. sativa como à $D$. similis. Os resultados obtidos por meio destes ensaios ecotoxicológicos para os percolados das colunas de cinza de carvão e de solo com cinza de carvão indicam que o solo das colunas retiveram as substâncias tóxicas lixiviadas da cinza de carvão, ou seja, os solos utilizados nestas colunas atuaram como filtros.
\end{abstract}




\title{
ECOTOXICOLOGICAL EVALUATION OF LEACHATES FROM COLUMNS OF COAL FLY ASH AND SOIL WITH COAL FLY ASH USING Lactuca sativa AND Daphnia similis AS TEST ORGANISM
}

\section{Flávia Junqueira de Castro}

\begin{abstract}
The coal fly ash of power plants has been a constant source of contamination due to the improperly disposed on the soil. The toxic elements leached from coal fly ash when in contact with soil could become bioavailable and be absorbed by plants, consumed by animals or transported to different environmental matrices, such as groundwater and surface water. Seed germination and root elongation tests with Lactuca sativa and acute toxicity tests with Daphnia similis were done to evaluate the toxicity of the leachate from coal fly ash and soil with coal fly ash columns. According to the values obtained for the seed germination and root elongation tests were observed toxic effects to seed germination of $L$. sativa for the leachates from coal fly ash column. The mean values of $1 \mathrm{C} 50_{(120 h)}$ for these leachates ranged from 27.6 to $90.6 \%$ and the germination index values (IG) ranged from 6.7 to 40.8 . In the acute toxicity tests with test organisms $D$. similis were also observed toxic effects to mobility and/or survival of organisms exposed to leachates of the coal fly ash column. The values obtained for $E C 50_{(48 h)}$ for these leachates range from 25.6 to $84.1 \%$. The leachates of soil with coal fly ash columns not presented toxicity to both test organisms, L. sativa and D. similis. The data obtained by these ecotoxicological tests to the leachates of soil coal fly ash and soil with coal fly ash columns indicate that the soil of the columns have retained the toxic substances leached from the coal fly ash, thus the soils used in these columns have acted as filters.
\end{abstract}




\section{SUMÁRIO}

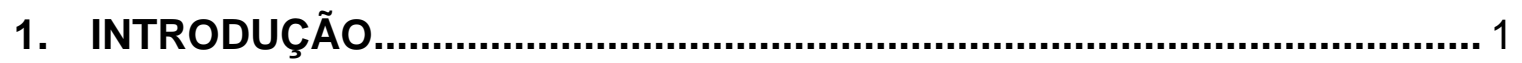

2. OBJETIVO

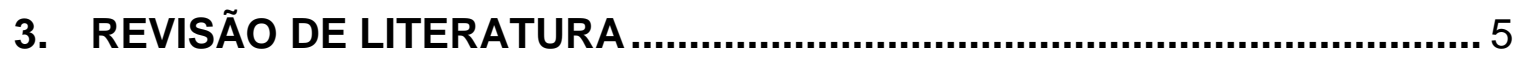

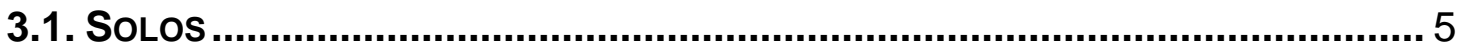

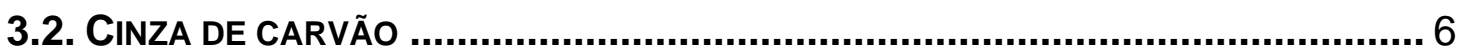

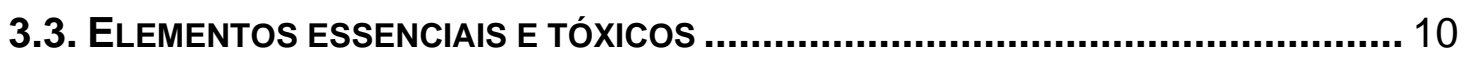

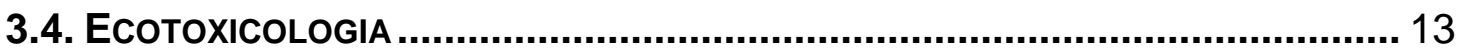

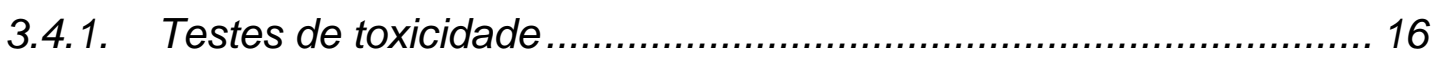

3.4.2. Organismos teste..................................................................... 17

3.4.3. Ensaio de germinação e desenvolvimento das radículas com

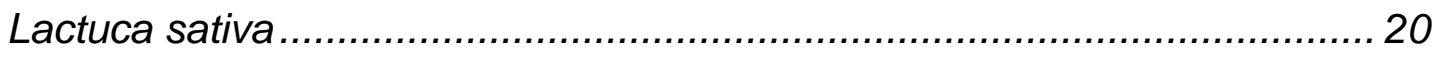

3.4.4. Ensaio de toxicidade aguda com Daphnia similis ......................... 22

3.5. ESTUDOS ECOTOXICOLÓGICOS PARA AVALIAÇÃo DE ELEMENTOS TÓXICOS .... 23

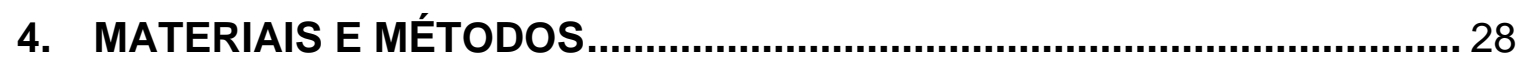

4.1. ObTenÇÃo dos PeRcolados das Colunas de cinza de CARVÃo E de SOlO

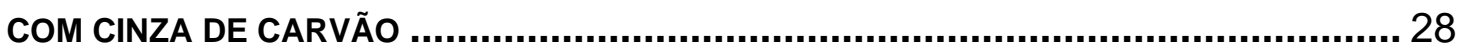

4.2. ENSAIO DE GERMINAÇÃO E DESENVOLVIMENTO DAS RADíCULAS DE LACTUCA

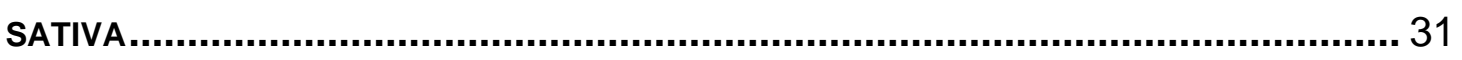

4.3. ENSAIO DE TOXICIDADE AGUDA COM DAPHNIA SIMILIS ................................ 34

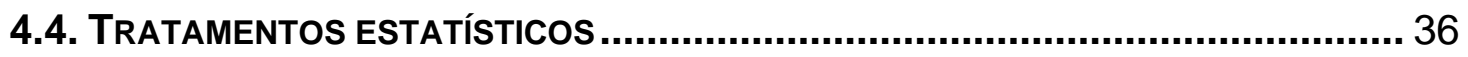

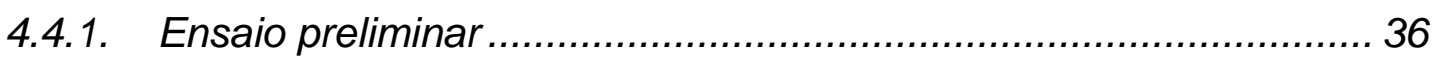

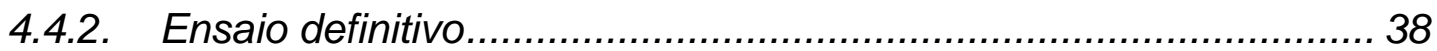

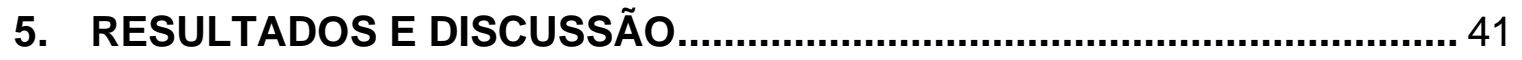

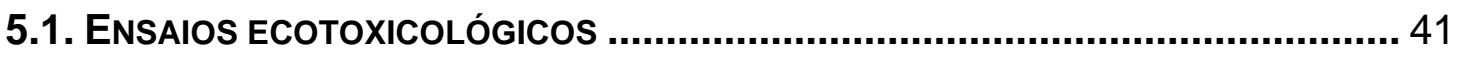

5.1.1. Ensaios de germinação e desenvolvimento das radículas de $L$. sativa 41

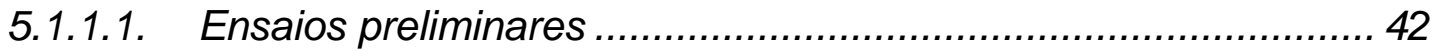

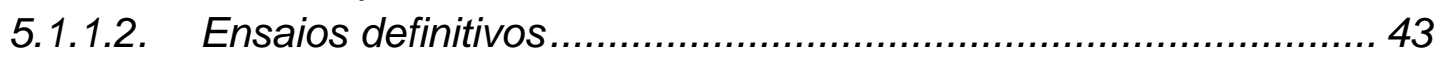

5.1.1.3. Desenvolvimento das radículas de Lactuca sativa ..................... 49

5.1.2. Ensaios de toxicidade aguda com Daphnia similis ....................... 59

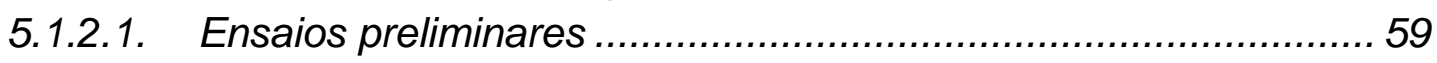

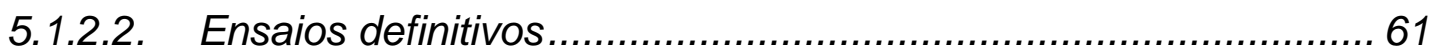

5.2. CoEfICIENTE DE CORRELAÇÃO ENTRE OS VALORES OBTIDOS PARA Cl50 $0_{(120 H)} \mathrm{E}$ CE50 ${ }_{(48 H)}$ E OS PARÂMETROS QUíMICOS DOS PERCOLADOS DA COLUNA DE CINZA DE CARVÃO. 63

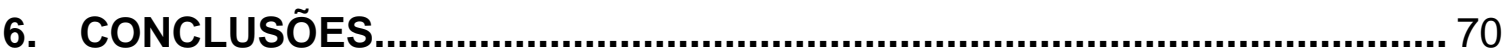

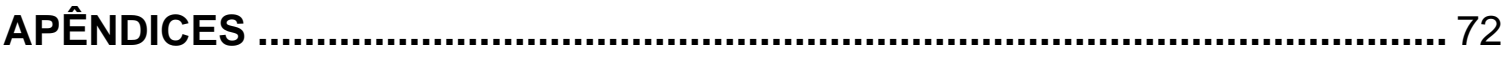


REFERÊNCIAS BIBLIOGRÁFICAS. 


\section{LISTA DE TABELAS}

TABELA 1 - Produção máxima de cinza de carvão nas usinas termelétricas brasileiras em toneladas por ano

TABELA 2 - Concentração ( $\mu \mathrm{g} g$-1) média dos elementos presentes na cinza leve das usinas termelétricas brasileiras .............................................. 10

TABELA 3 - Toxicidade e funções biológicas de elementos importantes ........... 12 TABELA 4 - Organismos teste, efeito e espécie utilizados em testes de toxicidade no Brasil ..................................................................... 19

TABELA 5 - Indicação de ensaios de toxicidade e organismos teste para diferentes tipos de amostras

TABELA 6 - Condições gerais utilizadas no ensaio de germinação e desenvolvimento da $L$. sativa e critérios de aceitabilidade ............................ 32 TABELA 7 - Condições gerais do ensaio de toxicidade aguda com $D$. similis e critérios de aceitabilidade 34

TABELA 8 - Toxicidade dos percolados C, SCC e SPC (concentração 100\%) obtida nos ensaios preliminares, utilizando como organismos teste $L$. sativa.... 42 TABELA 9 - Média do comprimento das radículas das sementes germinadas nos percolados C, SPC e SCC e na água deionizada obtida nos ensaios preliminares 50

TABELA 10 - Média do comprimento das radículas das sementes germinadas nos percolados 28, 56 e 84 da coluna de cinza de carvão e na água deionizada obtida nos ensaios definitivos 58

TABELA 11 - Toxicidade dos percolados C, SCC e SPC (concentração 100\%) obtida nos ensaios preliminares utilizando como organismos teste $D$. similis .... 60 TABELA 12 - Coeficiente de correlação (r) entre CI50(120h) e CE50(48h) e os parâmetros químicos dos percolados da coluna de cinza de carvão 64 


\section{LISTA DE FIGURAS}

FIGURA 1 - GERAÇÃO DE CINZAS DE CARVÃO DE UMA USINA TERMELÉTRICA E TRANSPORTE DE LIXIVIADOS E PARTICULADOS DA CINZA PARA MATRIZES AMBIENTAIS .... 8 FIGURA 2 - (A) USINA TERMELÉTRICA DE FIgUEIRA, PARANÁ; (B) DEPÓSITO DE CINZAS DE CARVÃO AO REDOR DA USINA DE FIGUEIRA .............................................. 9 FIGURA 3 - CONCEITO DE ECOTOXICOLOGIA ............................................. 14 FIGURA 4 - ETAPAS COMPREENDIDAS NA ECOTOXICOLOGIA DENOMINADA DE CADEIA DA CASUALIDADE 15

FIGURA 5 - EXEMPLO DE UMA CADEIA ALIMENTAR DE UM ECOSSISTEMA AQUÁTICO CONSTITUÍDO POR TRÊS NÍVEIS TRÓFICOS (NT) 18

FIGURA 6 - SEMENTE GERMINADA DE L. SATIVA COM SUA RADÍCULA DESENVOLVIDA 21 FIGURA 7 - DAPHNIA SIMILIS. 22

FIGURA 8 - (A) ESQUEMA EXPERIMENTAL DO SISTEMA DE PERCOLAÇÃO DA COLUNA DE SOLO COM CINZA DE CARVÃO; (B) FOTO DO SISTEMA DE PERCOLAÇÃO DAS COLUNAS DE SOLO FRANCO ARENOSO COM CINZA DE CARVÃO. 30

FIGURA 9 - PERCOLAdOS C, SPC E SCC GERADOS AO LONGO DE 336 DIAS 31 FIGURA 10 - FOTOS DO ENSAIO DE GERMINAÇÃO E DESENVOLVIMENTO DAS RADÍCULAS DE L. SATIVA 33

FIGURA 11 - FOTOS DO ENSAIO DE TOXICIDADE AGUDA COM D. SIMILIS. 35 FIGURA 12 - FLUXOGRAMA PARA ANÁLISE ESTATíSTICA DOS DADOS DO ENSAIO PRELIMINAR COM UMA ÚNICA CONCENTRAÇÃO E O CONTROLE NEGATIVO.

FIGURA 13 - FLUXOGRAMA PARA ANÁLISE ESTATÍSTICA DOS DADOS DO COMPRIMENTO DAS RADÍCULAS DAS AMOSTRAS DOS PERCOLADOS E DO CONTROLE NEGATIVO 38 FIGURA 14 - FLUXOGRAMA PARA ANÁLISE ESTATÍSTICA DOS DADOS DOS EFEITOS SUBLETAIS PARA O CRESCIMENTO DAS RADÍCULAS DE L. SATIVA 39 FIGURA 15 - $\mathrm{Cl}^{5} 0_{(120 \mathrm{H})}$ DOS PERCOLADOS DA COLUNA DE CINZA DE CARVÃO EMPREGANDO COMO ORGANISMO TESTE SEMENTES DE L. SATIVA $\mapsto$ : INTERVALO DE CONFIANÇA

FIGURA 16 - ÍNDICE DE GEMINAÇÃO (IG) DO PERCOLADO 28 DA COLUNA DE CINZA DE CARVÃO

FIGURA 17 - ÍNDICE DE GEMINAÇÃO (IG) DO PERCOLADO 56 DA COLUNA DE CINZA DE CARVÃO 
FIGURA 18 - ÍNDICE DE GEMINAÇÃO (IG) DO PERCOLADO 84 DA COLUNA DE CINZA DE CARVÃO

FIGURA 19 - CONCENTRAÇÃO DOS ELEMENTOS MAJORITÁRIOS NOS PERCOLADOS SCC E SPC

FIGURA 20 - CONCENTRAÇÃO DOS ELEMENTOS As E ZN NOS PERCOLAdOS SCC E SPC 54

FIGURA 21 - CONCENTRAÇÃO DOS ÂNIONS NOS PERCOLADOS SCC E SPC 55 FIGURA 22 - CONCENTRAÇÃO DE CARBONO ORGÂNICO, CARBONO INORGÂNICO E CARBONO TOTAL NOS PERCOLADOS SCC E SPC 56 FIGURA 23 - PH DOS PERCOLADOS SPC E SCC 57 FIGURA 24 - CE50(48H) DOS PERCOLADOS DA COLUNA DE CINZA DE CARVÃO UTILIZANDO COMO ORGANISMOS TESTE $D$. SIMILIS $\mapsto$ : INTERVALO DE CONFIANÇA ........61 FIGURA 25 - CONCENTRAÇÃo dos ELEMENTOS As, Zn, CD E Mo NO PERCOLAdO C63 FIGURA 26 - CONCENTRAÇÃO dOS ELEMENTOS NA, CA, K E Mg NO PERCOLAdO C. 65 FIGURA 27 - CONCENTRAÇÃO DOS ÂNIONS NO PERCOLADO C ............................6 66

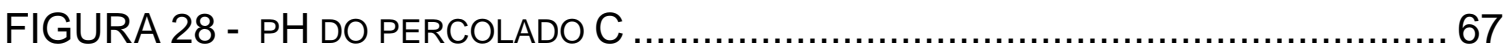
FIGURA 29 - CONCENTRAÇÃO DE CARBONO ORGÂNICO, CARBONO INORGÂNICO E CARBONO TOTAL NO PERCOLADO C 


\section{LISTA DE ABREVIATURAS E SIGLAS}

ABMC - Associação Brasileira do Carvão Mineral

ABNT - Associação Brasileira de Normas Técnicas

AIE - Agência Internacional de Energia

ANEEL - Agência Nacional de Energia Elétrica

ASTM - American Society for Testing and Materials

CENO - Concentração de efeito não observado

CEO - Concentração de efeito observado

CETESB - Companhia de Tecnologia de Saneamento Ambiental do Estado de São Paulo

CE50 (48h) - Concentração efetiva de mortalidade e/ou imobilidade a $50 \%$ dos organismos teste

$\mathrm{Cl} \mathrm{O}_{(120 h)}$ - Concentração de inibição em $50 \%$ dos organismos teste

CONAMA - Conselho Nacional do Meio Ambiente

CQMA - Centro de Química e Meio Ambiente

EMBRAPA - Empresa Brasileira de Pesquisa Agropecuária

FAPESP - Fundação de Amparo à Pesquisa do Estado de São Paulo

ICSU - Committe of the International Council of Scientific Unions

IG - Índice de Germinação

IPEN/CNEN- SP - Instituto de Pesquisas Energéticas e Nucleares / Comissão Nacional de Energia Nuclear - São Paulo

ISO - International Organization for Standardization

MME - Matriz Energética Nacional 2030

OECD - Organization for Economic Cooperation and Development

US EPA - United States Environmental Protection Agency 


\section{INTRODUÇÃO}

O carvão mineral, mesmo com a crescente utilização das fontes de energia renováveis e das matrizes energéticas não renováveis, ainda nos dias de hoje é responsável por grande parte da eletricidade utilizada em todo o mundo. A utilização das usinas termelétricas a base de carvão mineral tem sido cada vez maior com o aumento da demanda energética mundial especialmente em países em desenvolvimento, como Índia e China. De acordo com a Agência Internacional de Energia estima-se que em dez anos esta será a principal fonte de energia elétrica do mundo (AIE, 2011; AIE, 2012).

Atualmente, ainda que grande parte da demanda energética no Brasil seja proveniente de usinas hidrelétricas $(65,29 \%)$, as usinas termelétricas a base de carvão são responsáveis por 1,52\% da eletricidade utilizada no país, cerca de 1.944.052 kW de potência (ANEEL, 2011). Apesar das usinas termelétricas apresentarem uma representatividade na produção energética do país relativamente baixa, só no ano de 2011 foi produzido um total de 12.067.652 toneladas de cinzas de carvão e deste total menos de 50\% foi reaproveitado (ABMC, 2011).

Estas cinzas de carvão geradas por usinas terméletricas são classificadas como resíduos sólidos e de um modo geral, são descartadas diretamente sobre o solo a céu aberto, apresentando um potencial para causar danos ao meio ambiente (Gaivizzo et al., 2002; Rohde et al., 2006).

As cinzas de carvão são compostas basicamente por $\mathrm{Si}, \mathrm{Al}, \mathrm{Fe}, \mathrm{P}$, $\mathrm{Ca}, \mathrm{Mg}, \mathrm{Ti}, \mathrm{Na} \mathrm{K}$ e S em menores quantidades por Ag, As, Au, B, Ba, Be, Cd, $\mathrm{Ce}, \mathrm{Co}, \mathrm{Cr}, \mathrm{Cu}, \mathrm{Ga}, \mathrm{Ge}, \mathrm{Li}, \mathrm{Mn}, \mathrm{Mo}, \mathrm{Nb}, \mathrm{Ni}, \mathrm{Pb}, \mathrm{Pt}, \mathrm{Rb}, \mathrm{Sb}, \mathrm{Se}, \mathrm{Sr}, \mathrm{Ti}, \mathrm{U}, \mathrm{V}, \mathrm{Y}$, Zn e Zr (Rohde, 2006; Depoi et al., 2008). Os elementos presentes nas cinzas de carvão quando lixiviados para o solo podem ficar ambientalmente disponíveis e vir a ser absorvidos por plantas, consumidos por animais, ou ainda transportados para diferentes matrizes ambientais, tais como, águas superficiais e águas subterrâneas (Lu et al., 2009). 
Alguns elementos tóxicos como $\mathrm{Cd}$ e $\mathrm{Pb}$ apresentam potencial para se bioacumular e/ou biomagnificar em organismos aquáticos, podendo subsequentemente serem consumidos por organismos de níveis tróficos maiores, incluindo o homem (Adams et al., 2002).

Diante da possível contaminação de diferentes matrizes ambientais devido ao descarte inadequado das cinzas de carvão que apresentam toxicidade potencial a diferentes organismos, a utilização de testes de toxicidade se torna uma ferramenta importante. Estes testes são realizados em laboratório sob condições experimentais específicas e controladas, nos quais são determinadas as concentrações e os potenciais efeitos tóxicos que 0 resíduo analisado pode causar sobre os organismos teste (Costa et al., 2008).

Os ensaios de toxicidade com sementes de plantas são bioensaios nos quais sementes são imersas em uma ou mais substâncias potencialmente tóxicas durante o período inicial de sua germinação, quando estas substâncias podem ser absorvidas e acumuladas no tecido vegetal (Chang et al., 1992; Sobrero et al., 2004).

Estes ensaios são relativamente simples de baixo custo e vêm sendo empregados em estudos realizados em países como Canadá, França, Alemanha, Espanha, Holanda, entre outros, para avaliar os efeitos tóxicos causados por substâncias diversas, mas especialmente por elementos tóxicos devido à sensibilidade que estes organismos teste apresentam (Wong et al., 1982; Cook et al., 2002; Rooney et al., 2007; Chapman et al., 2010).

Estes ensaios apresentam ainda como vantagem a avaliação de amostras líquidas sem necessidade de uma filtração prévia, permitindo que se realizem análises de amostras turvas (Sobrero et al., 2004).

\footnotetext{
A espécie Lactuca sativa (Asterales Lactuca) vem sendo empregada como organismo teste em ensaios de germinação e desenvolvimento das radículas especialmente para avaliar amostras de solo e
} 
água, devido ao fato desta espécie apresentar respostas rápidas a danos ambientais (Cook et al., 2002; Ferreira, 2007; Chapman et al., 2010).

Avaliações ecotoxicológicas realizadas no Brasil têm empregado o microcrustáceo Daphnia similis (Cladocera, Crustacea) em testes de toxicidade aguda, uma vez que este organismo é sensível a diferentes contaminantes, além de ser uma espécie de fácil cultivo e manutenção em laboratório (Domingues et al., 2008; Costa et al., 2008; Rodgher et al., 2010).

Estudos ecotoxicológicos relacionados com avaliação da toxicidade de lixiviados de solos contaminados com metais tóxicos e hidrocarbonetos (Cook et al., 2002; Chapman et al., 2010) e de solos e lixiviados de solos com cinza de carvão (Martens et al., 1976; Adriano et al., 1980), utilizando como organismos teste sementes de hortaliças e crustáceos, têm sido realizados.

No Brasil poucos trabalhos relacionados com a avaliação da toxicidade da cinza de carvão têm sido publicados. Printes et al. (2000) avaliaram a toxicidade aguda e crônica de águas superficiais e sedimentos contaminados com cinza de carvão da região Carbonífera do Baixo Jacuí, Rio Grande do Sul, empregando organismos aquáticos.

A avaliação da toxicidade de lixiviados de cinzas de carvão e de solos com cinza de carvão é importante, pois pode fornecer indicações sobre o risco ambiental que os contaminantes presentes nas cinzas de carvão representam a biota de diferentes ecossistemas. De acordo com El Mogazi et al. (1988) é importante avaliar a toxicidade potencial de lixiviados da cinza de carvão nas plantas, uma vez que, estes organismos podem ter seu desenvolvimento alterado devido ao aumento dos elementos provenientes deste resíduo descartado inadequadamente no solo. 


\section{OBJETIVO}

Avaliar a toxicidade dos percolados das colunas de cinza de carvão e de solos com cinza de carvão utilizando a Lactuca sativa e a Daphnia similis como organismos teste. 


\section{REVISÃO DE LITERATURA}

\subsection{Solos}

Importantes matrizes ambientais como as águas superficiais e subterrâneas dependem diretamente da qualidade do solo para manter suas propriedades naturais, uma vez que o solo tem influência direta sobre os principais fluxos de água entre a hidrosfera, litosfera, biosfera e atmosfera (Lepsch, 2002).

O solo representa a parte superficial da crosta terrestre, tendo sido formado ao longo dos anos, por meio do intemperismo de rochas derivado de fenômenos biológicos, geológicos, hidrológicos, climáticos e da decomposição da matéria orgânica (Sposito, 1989; Mazoyer et al., 2010).

O solo é dividido em fases líquida (água), gasosa (ar) e sólida. A fase sólida é composta por substâncias minerais, pequenos fragmentos de rochas e de minerais, matéria orgânica proveniente da decomposição de vegetais e de animais (Brady,1989).

Os grãos do solo podem ser distribuídos quanto ao diâmetro em frações de areia $(0,06-2,0 \mathrm{~mm})$, silte $(0,002-0,06 \mathrm{~mm})$, argila $(<0,002 \mathrm{~mm}) \mathrm{e}$ cascalho (> 2,0 mm) (Brady, 1989).

A textura do solo pode ser classificada com base nos teores de areia, silte e argila presentes no solo. Os solos podem ser agrupados de forma simplificada em três classes de textura: solos de textura arenosa, que tem teores de areia superiores a 70\%, sendo solos mais permeáveis; solos de textura média apresenta certo equilíbrio entre os teores de areia, silte e argila, que apresentam boa drenagem e capacidade de retenção de água; solos de textura argilosa que tem teores de argila superiores a $35 \%$, estes solos tem baixa permeabilidade (EMBRAPA, 2006). 
A textura do solo é propriedade física deste meio que menos sofre alterações ao longo do tempo, e tem grande relevância ecológica devido a sua influência direta sofre o fluxo hídrico no solo, de modo que alterações em suas propriedades podem ser responsáveis pela poluição de matrizes aquáticas causando danos aos organismos aquáticos, podendo também resultar na alteração da biota do solo, como a má formação de raízes (EMBRAPA, 2006).

Os principais elementos presentes no solo são fósforo, sódio, alumínio, potássio, cálcio, magnésio, enxofre, cobalto, zinco, níquel, molibdênio, cobre, ferro, manganês, boro e sílica, de acordo com Lepsch (2002). Grande parte destes elementos presentes naturalmente no solo são elementos essenciais ao desenvolvimento da biota, entretanto, em concentrações elevadas estes elementos apresentam potencial para causar efeitos adversos sobre os organismos que habitam esta matriz (McBride, 1994).

Atividades humanas que envolvem a utilização do solo como aterro sanitário, áreas de descarte de resíduos e mineração têm causado o aumento da concentração de elementos tóxicos no solo e na solução do solo. A toxicidade do solo e da solução do solo pode depender das propriedades das matrizes e dos elementos nestes presentes (Mozeto et al., 2008; Cirino, 2009).

\subsection{Cinza de carvão}

O carvão mineral ainda tem sido um dos combustíveis fósseis mais utilizados na geração de energia elétrica em todo mundo, apesar de ser potencialmente poluente. Atualmente, a combustão do carvão mineral por usinas termelétricas é responsável por suprir aproximadamente $40 \%$ da demanda energética mundial (World Energy Council, 2007; ANEEL, 2011). Segundo a Agência Internacional de Energia (2012) em dez anos o carvão mineral deverá ser a principal fonte de produção energética do mundo.

De acordo com a Agência Nacional de Energia Elétrica (ANEEL, 2011), diversos países dentre eles os Estados Unidos, China, Índia, Alemanha, 
Japão e África do Sul, tem no carvão mineral sua principal fonte de geração de energia, e devido a grande disponibilidade deste recurso, somados à necessidade de expansão dos sistemas elétricos e a restrição de outras fontes energéticas, as usinas termelétricas continuarão sendo uma das principais fontes de geração de energia no mundo.

O Brasil tem a décima maior reserva de carvão mineral do mundo (32 bilhões de toneladas). Esta reserva de carvão se encontra distribuída entre os estados do Rio Grande do Sul, Santa Catarina e Paraná, onde estão localizadas as principais usinas termelétricas brasileiras (Izidoro, 2008).

No Brasil, a combustão do carvão mineral por usinas termelétricas tem sido pouco explorada representando apenas 1,5\% da matriz energética do país, sendo a maior parte da demanda energética do país suprida por meio de usinas hidroelétricas. Entretanto, frente à necessidade de diversificar a matriz energética do país a expansão das usinas termelétricas está entre as soluções estipuladas pelo governo no plano Matriz Energética Nacional 2030 (MME, 2007; ANEEL, 2011).

Para gerar energia elétrica o carvão passa por um processo de combustão nas usinas termelétricas e durante esse processo são produzidos resíduos sólidos tais como cinzas de fundo (cinzas pesadas) e volantes (cinzas leves). As cinzas de fundo são depositadas na base dos fornos da usina e as cinzas volantes são arrastadas pelos gases de combustão sendo boa parte retida por filtros (Rohde et al., 2006).

Parte da cinza de carvão gerada na etapa final do processo de produção de energia é descartada sobre o solo a céu aberto devido à ausência de uma destinação final adequada para as cinzas de carvão (Prochnow et al., 2000). Na FIG.1 foi mostrado o depósito de cinzas de carvão sobre o solo de forma inadequada, no qual os particulados da cinza podem ser transportados para a atmosfera e água superficial e os lixiviados da cinza para o solo e água subterrânea podendo contaminar estas matrizes ambientais. 


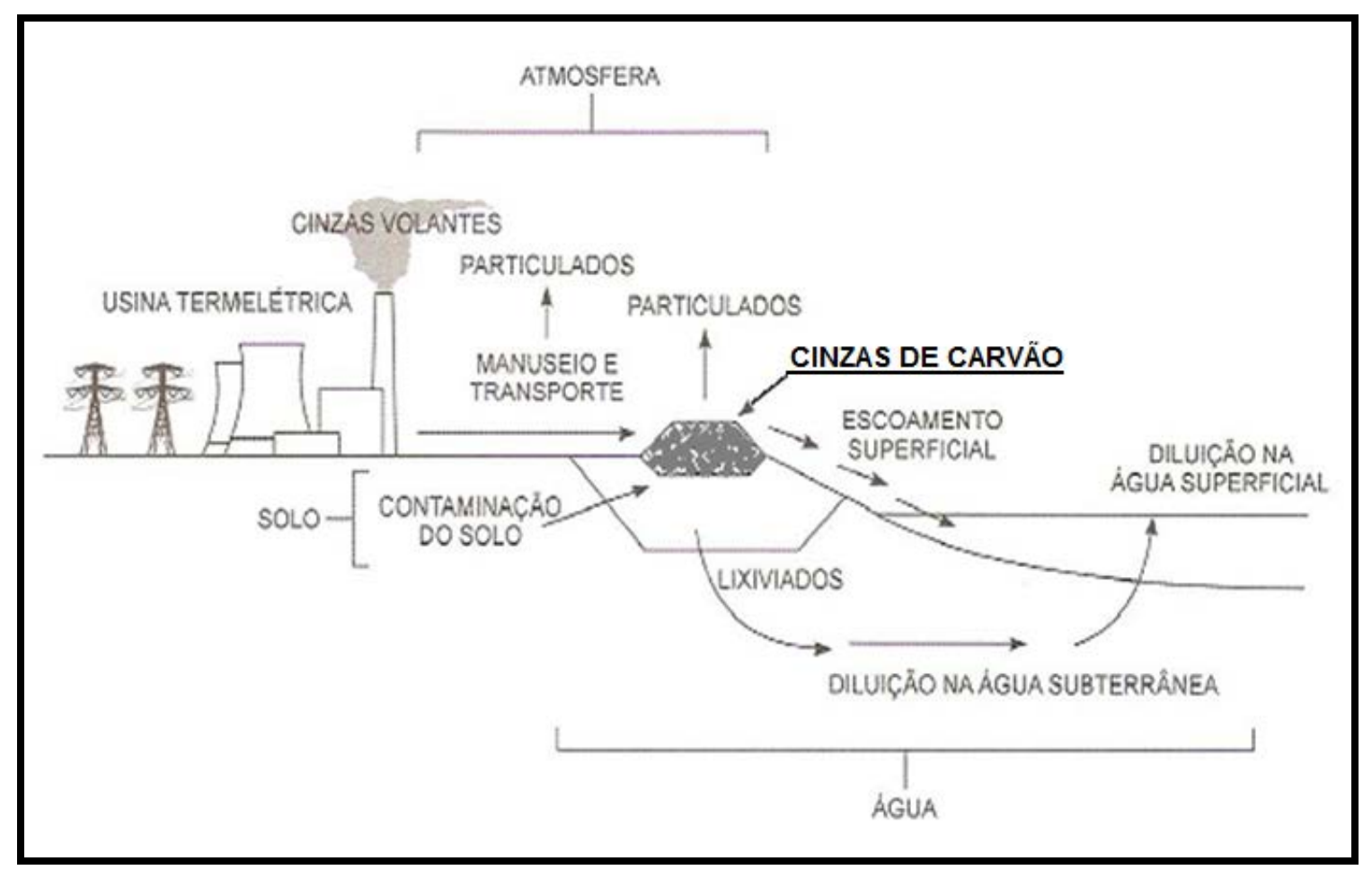

FIGURA 1 - Geração de cinzas de carvão de uma usina termelétrica e transporte de lixiviados e particulados da cinza para matrizes ambientais Fonte: adaptado de Rohde et al., 2006.

Estima-se que no Brasil são geradas anualmente por usinas termelétricas e outras unidades industriais cerca de quatro milhões de toneladas de cinzas de carvão, das quais aproximadamente apenas $50 \%$ são reaproveitadas como, por exemplo, na fabricação de cimentos e concretos Portland (Rohde et al., 2006). Na TAB.1 foi apresentada a produção anual de cinza de carvão das usinas termelétricas brasileiras.

TABELA 1 - Produção máxima de cinza de carvão nas usinas termelétricas brasileiras em toneladas por ano

\begin{tabular}{lrrr}
\hline & \multicolumn{3}{c}{ Resíduos sólidos (t) } \\
\cline { 2 - 4 } Usina termelétrica & Cinza volante & Cinza pesada & Escória \\
\hline Presidente Médici A/B & 1.500 .000 & 375.000 & - \\
São Jerônimo & 5.000 & - & 50.000 \\
Charqueadas & 295.058 & 126.453 & - \\
Jorge Lacerda I, II, III e IV & 1.500 .000 & 500.000 & - \\
Figueira & 50.000 & 5.000 & - \\
\hline Fonte: Rohde et al., 2006. & & &
\end{tabular}


Estas cinzas de carvão geradas por usinas termelétricas são classificadas como resíduos sólidos que apresentam toxicidade e propriedades químicas capazes de causar danos ao meio ambiente. De acordo com a Constituição Federal do Brasil (1988), é de responsabilidade do gerador garantir o armazenamento, manuseio, bem como o transporte e a destinação final adequada, uma vez que estes resíduos devem ser descartados em aterros sanitários (Rohde et al., 2006).

$\mathrm{Na}$ FIG.2 foram apresentadas fotos da usina termelétrica de Figueira, Paraná, e o depósito de cinzas de carvão na proximidade da usina.

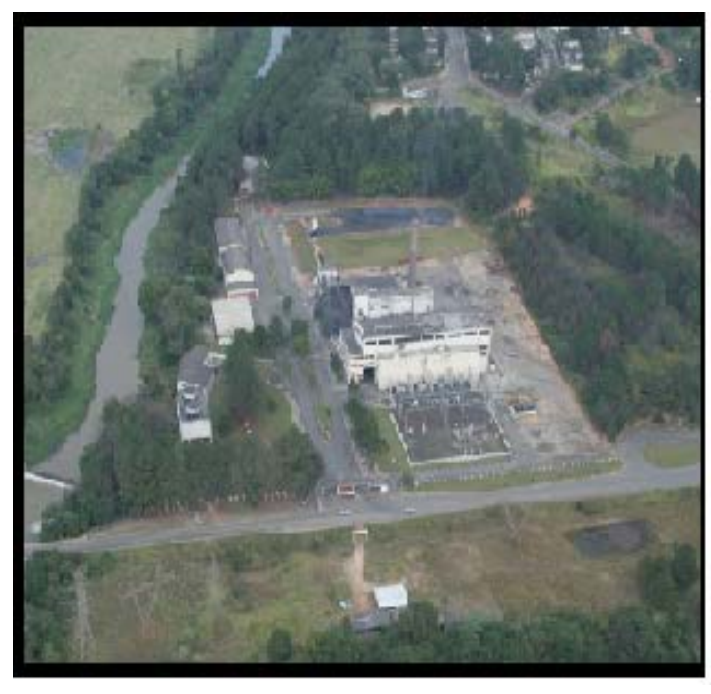

(a)

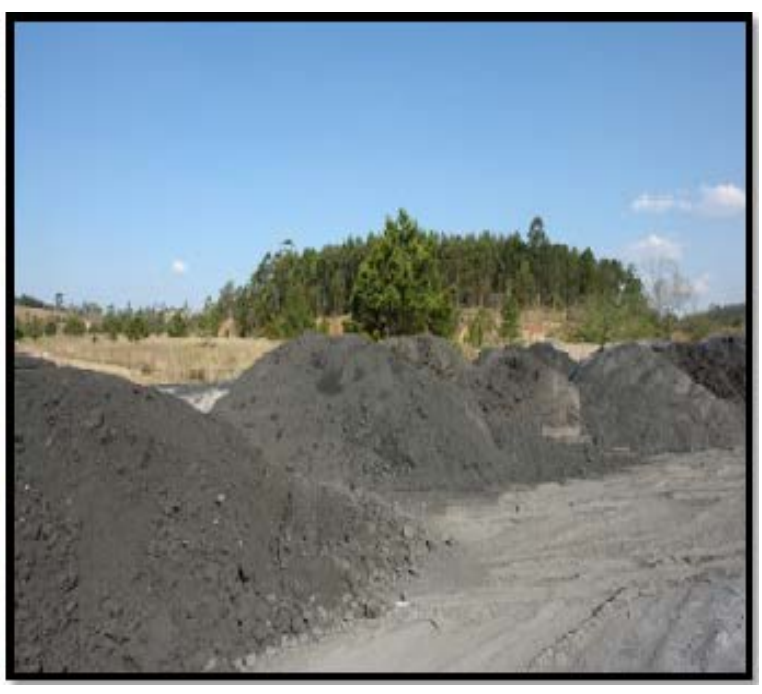

(b)

FIGURA 2 - (a) Usina termelétrica de Figueira, Paraná; (b) Depósito de cinzas de carvão ao redor da usina de Figueira

Fonte:(a) Carbonífera do Cambuí 2008; (b) Izidoro et al.,2008

A combustão do carvão para geração de energia elétrica tem sido considerada como uma das fontes mais poluidoras uma vez que todo 0 processo de produção de energia tem potencial para causar danos a diversas matrizes ambientais devido à presença de elementos tóxicos como $\mathrm{As}, \mathrm{Cd}, \mathrm{Co}$, $\mathrm{Cr}, \mathrm{Cu}$, Mo e Pb no carvão e nas cinzas de carvão (Rohde et al., 2006; Depoi et al., 2008).

De acordo com Depoi (2008), as cinzas volantes geradas pela usina termelétrica de Figueira (FIG. 2) que fica localizada no Estado do Paraná, é a 
que apresenta as maiores concentrações de alguns elementos tóxicos tais como, arsênio, chumbo, zinco, cádmio, molibdênio quando comparada as demais usinas termelétricas brasileiras. $\mathrm{Na}$ TAB.2 foram apresentados os valores médios de concentração dos elementos presentes na cinza leve das usinas termelétricas brasileiras, obtidos no estudo realizado por Depoi (2008).

TABELA 2 - Concentração ( $\mu \mathrm{g} \mathrm{g}^{-1}$ ) média dos elementos presentes na cinza leve das usinas termelétricas brasileiras

\begin{tabular}{lccccccccccccc}
\hline Termelétrica & Pb & As & Au & Ba & Be & Cd & Co & Cr & Cu & Zn & Ge & Mn & Mo \\
\hline Figueira & 3477 & 1820 & 0,08 & 660 & 6,67 & 16,4 & 18,1 & 111 & 52,6 & 2224 & 68,7 & 305 & 385 \\
Candiota & 26,2 & 11,9 & 0,09 & 372 & 3,27 & 0,55 & 13,9 & 41,8 & 20,7 & 83,6 & 3,78 & 294 & 3,93 \\
Charqueadas & 57,3 & 35,6 & 0,14 & 296 & 6,58 & 0,77 & 12,6 & 82,1 & 29,1 & 134 & 33,8 & 66,1 & 4,95 \\
$\begin{array}{l}\text { Capivari de } \\
\text { baixo }\end{array}$ & 52,5 & 44,9 & 0,09 & 430 & 2,83 & 1,29 & 9,00 & 84,1 & 28,1 & 213 & 17,6 & 141 & 5,86 \\
\hline Fonte- - Depoi (2008) & & & & & & & & & & & & &
\end{tabular}

\subsection{Elementos essenciais e tóxicos}

Elementos como $\mathrm{Co}, \mathrm{Cu}, \mathrm{Se}, \mathrm{Zn}$, que ocorrem naturalmente em diversas matrizes ambientais, em baixas concentrações são essenciais para o metabolismo de plantas e animais, associados com processos respiratórios, formação de proteínas, ativadores de complexos enzimáticos. Porém em altas concentrações esses elementos e outros tais como As, Cd, Cr, $\mathrm{Hg}, \mathrm{Pb}$ podem se tornar tóxicos e prejudiciais podendo interferir na ação das enzimas em plantas, organismos aquáticos e seres humanos (Ward, 1995; Fairbrother et al, 2007a; Mozeto et al., 2008).

A toxicidade dos elementos pode variar de acordo com diversos fatores, como as características dos organismos e a via de exposição dos elementos (por ingestão, absorção, inalação), o tipo e forma que os elementos se encontram (Water Quality Committee, 2010). Quando os elementos se encontram em matrizes aquáticas, tais como águas superficiais, águas subterrâneas, águas intersticiais, percolados, podem se apresentar em diversas formas de distribuição como: íons livres e dissolvidos; complexados, pela matéria orgânica dissolvida; complexos solúveis com a fração de lipídeos 
presentes na água; sorvidos por partículas coloidais e por particulados orgânicos e inorgânicos suspensos na água insolúvel como sulfetos e carbonatos. As diversas formas irão influenciar diretamente na maior ou menor biodisponibilidade dos elementos e consequentemente em maior ou menor toxicidade aos organismos (Mozeto et al., 2008).

De forma geral, quando os elementos se encontram em formas de íons livres são considerados mais biodisponíveis e, portanto, a forma que apresenta maior potencial tóxico (Water Quality Committee, 2010).

A forma iônica que os elementos se encontram no meio ambiente influencia diretamente em sua absorção por plantas e micro-organismos. Os nutrientes minerais (micronutrientes e macronutrientes), que são indispensáveis para o ciclo de vida dos vegetais, são absorvidos na forma iônica $\mathrm{K}^{+}, \mathrm{Ca}^{2+}, \mathrm{Mg}^{2+}, \mathrm{Fe}^{2+}, \mathrm{Mn}^{2+}, \mathrm{Zn}^{2+}, \mathrm{Cu}^{2+}, \mathrm{Mo}^{6+}, \mathrm{Ni}^{2+}$. Entretanto, se estes mesmos íons forem absorvidos em excesso podem causar toxicidade para as plantas (Furlani et al., 2004).

Do mesmo modo como ocorrem com os vegetais, estes elementos quando absorvidos em concentrações acima das toleradas por organismos de diferentes espécies podem causar toxicidade aguda, alterações nos processos metabólicos e mudanças fisiológicas, resultando em danos em longo prazo aos organismos, devido ao potencial que esses elementos apresentam de se bioacumular e/ou biomagnificar nos níveis tróficos (Fairbrother et al., 2007b).

O mecanismo da ação tóxica e o metabolismo destes elementos tóxicos em geral são diferentes em plantas e animais, uma vez que estes podem causar impactos sobre tecidos específicos em cada espécie. Muitas vezes, a toxicidade destes elementos ocorre por meio de processos bioquímicos envolvendo componentes celulares, tais como membranas e organelas celulares (Fairbrother et al., 2007b).

A toxicidade e as funções biológicas dos elementos importantes para plantas e mamíferos foram apresentas na TAB.3. 
TABELA 3 - Toxicidade e funções biológicas de elementos importantes

\begin{tabular}{|c|c|c|c|}
\hline Elemento & Função Biológica & $\underset{(*)}{\text { Fitotoxicidade }}$ & $\overline{\text { Toxicidade a mamíferos }}$ \\
\hline Ag & Não conhecida & $A(5-10)$ & A \\
\hline Al & Pode ativar a desidrogenasse succínica & M (50-200) & B \\
\hline As & Constitui fosfolipídios em algas & M A (5-20) & A \\
\hline B & Essencial às plantas, constitui o fosfocluconato & M (50-200) & B \\
\hline $\mathrm{Ba}$ & Não conhecida & $B(500)$ & A (formas solúveis) \\
\hline $\mathrm{Be}$ & Não conhecida & M A (10-50) & A \\
\hline $\mathrm{Cd}$ & Não conhecida & M A (5-30) & A \\
\hline Co & $\begin{array}{l}\text { Essencial para mamíferos, cofator de várias } \\
\text { enzimas. Em plantas, atua na fixação } \\
\text { simbiótica do } \mathrm{N}_{2}\end{array}$ & M A (15-50) & M \\
\hline $\mathrm{Cr}$ & $\begin{array}{l}\text { Envolvido no metabolismo de açúcares em } \\
\text { mamíferos }\end{array}$ & M A (5-30) & $\mathrm{A}\left(\mathrm{Cr}^{6+}\right)\left(\mathrm{Cr}^{3+}\right)$ \\
\hline $\mathrm{Cu}$ & $\begin{array}{l}\text { Essencial a todos os organismos, atua no } \\
\text { transporte de } \mathrm{O}_{2} \text { e como cofator de enzimas } \\
\text { redox }\end{array}$ & M A (20-100) & M \\
\hline $\mathbf{F}$ & Fortalece os dentes em mamíferos & B M (50-500) & M \\
\hline $\mathrm{Fe}$ & $\begin{array}{l}\text { Essencial a todos os organismos, cofator de } \\
\text { várias enzimas }\end{array}$ & $B(>1000)$ & B \\
\hline $\mathrm{Hg}$ & Não conhecida & $H(1-3)$ & A (formas solúveis) \\
\hline Mn & $\begin{array}{l}\text { Essencial a todos os organismos, cofator de } \\
\text { várias enzimas, e em plantas atua na divisão } \\
\text { da molécula de } \mathrm{H}_{2} \mathrm{O} \text { no processo de } \\
\text { fotossíntese }\end{array}$ & B M (300-500) & M \\
\hline Mo & $\begin{array}{l}\text { Essencial a todos os organismos, cofator } \\
\text { enzimático na fixação do } \mathrm{N}_{2} \text { e na redução de } \\
\mathrm{NO}_{3}^{-}\end{array}$ & $M(10-50)$ & M \\
\hline $\mathrm{Ni}$ & $\begin{array}{l}\text { Essencial as plantas, e não tem a função } \\
\text { conhecida em mamíferos }\end{array}$ & M A (10-100) & M \\
\hline $\mathrm{Pb}$ & Não conhecida & M (30-300) & A \\
\hline Sb & Não conhecida & M (150) & A \\
\hline Se & $\begin{array}{l}\text { Essencial a todos os mamíferos e a algumas } \\
\text { plantas }\end{array}$ & M A (5-30) & A \\
\hline TI & Não conhecida & M A (20) & A \\
\hline $\mathbf{v}$ & Essencial as algas verdes & A (5-10) & A \\
\hline Zn & $\begin{array}{l}\text { Essencial a todos os organismos, cofator de } \\
\text { várias enzimas }\end{array}$ & B M (100-400) & B M \\
\hline
\end{tabular}


É importante ressaltar que além dos efeitos de bioacumulação e biomagnificação, a presença de mais de um elemento em uma mesma matriz pode causar efeitos sinérgicos, ou seja, quando a presença de um elemento pode resultar no aumento da absorção de outro (Faquin, 1997; Aragão et al., 2008).

\subsection{Ecotoxicologia}

A ecotoxicologia é a ciência que avalia os efeitos de substâncias tóxicas sobre os ecossistemas, resultantes do descarte de substâncias químicas e de resíduos em matrizes ambientais. Esta ciência tem como objetivo proteger ecossistemas inteiros e prever futuros impactos (Hoffman et al., 2002).

O termo Ecotoxicologia foi sugerido pela primeira vez durante uma reunião do Committe of the International Council of Scientific Unions (ICSU), realizada em Estocolmo, pelo toxicologista francês René Truhaut no ano de 1969. O termo ecotoxicologia foi definido após uma série de reuniões como sendo "a ciência que estuda os efeitos das substâncias naturais ou sintéticas sobre os organismos vivos, populações e comunidades, animais ou vegetais, terrestres ou aquáticos, que constituem a biosfera, incluindo assim a interação das substâncias com o meio nos quais os organismos vivem num contexto interligado" (FIG. 3) (Plaa, 1982). 


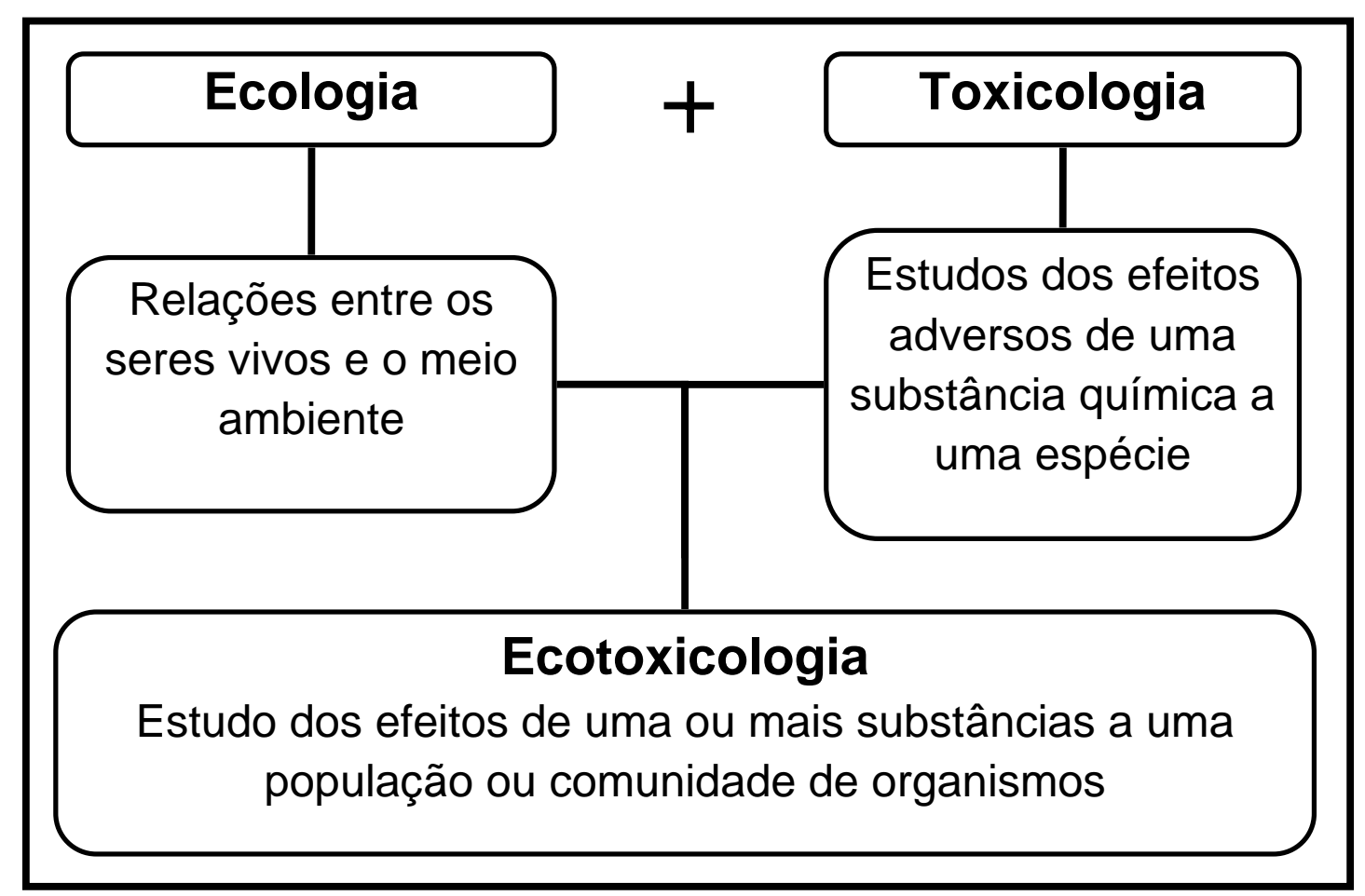

FIGURA 3 - Conceito de Ecotoxicologia

Fonte: adaptado de Blaise, 1984

Um dos desafios da Ecotoxicologia é identificar potenciais fontes de contaminantes no meio ambiente, bem como conhecer as possíveis interações, transformações e destino que estes contaminantes podem ter no ambiente para realizar uma predição segura dos efeitos tóxicos que estes contaminantes podem causar a diferentes ecossistemas (Hoffman et al., 2002; Zagatto et al., 2008). Além disto, é importante ter conhecimento dos riscos potenciais a que a exposição a estes poluentes oferece a biota. Na FIG.4 foram apresentadas as etapas compreendidas na ecotoxicologia denominada de cadeia da casualidade de acordo com Costa et al.(2008). 


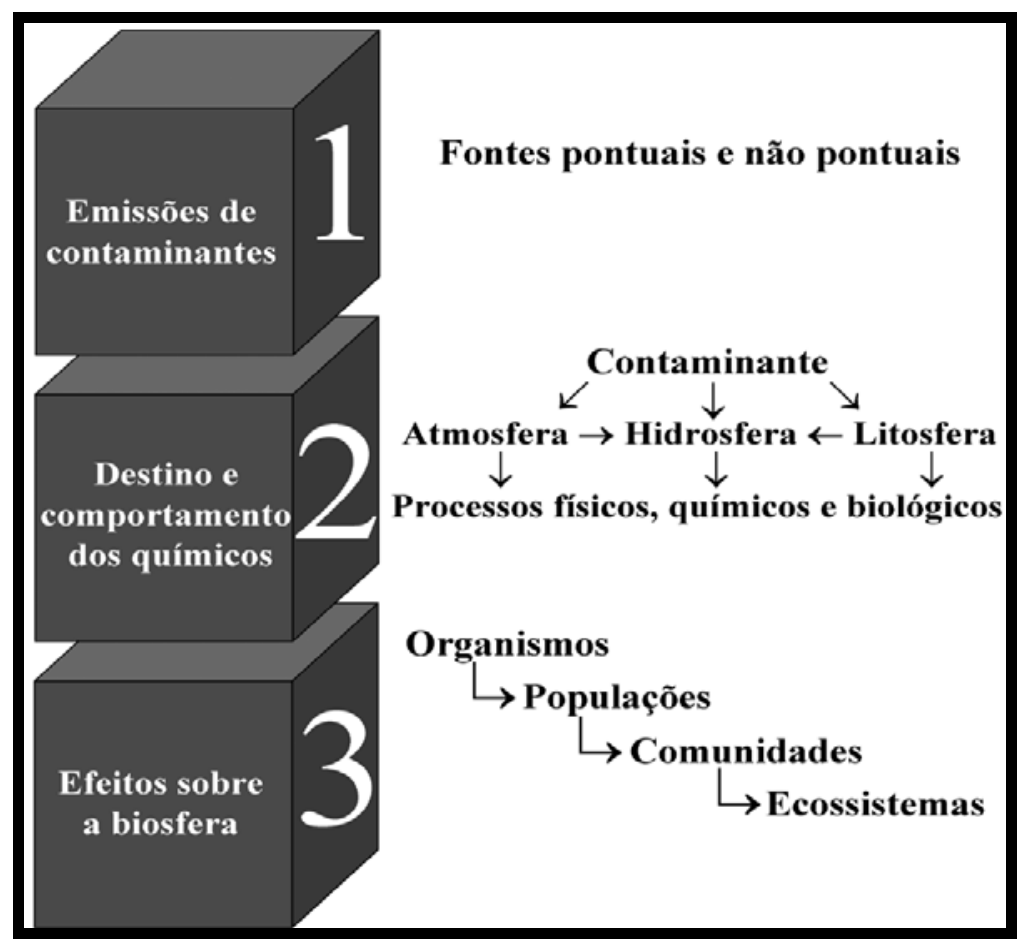

FIGURA 4 - Etapas compreendidas na ecotoxicologia denominada de cadeia da casualidade

Fonte: Costa et al ., 2008.

A Ecotoxicologia tem buscado definir limites aceitáveis de toxicidade por meio de protocolos padronizados de testes de toxicidade que possam vir a ser utilizados como limite guia para tomadas de decisões (Hoffman et al., 2002). Contudo a utilização de testes de toxicidade padronizados oferecem ainda outras vantagens, uma vez que facilita a comparação de dados obtidos entre laboratórios, contribuindo na utilização de dados já publicados e permitindo a reprodutibilidade dos ensaios (Zagatto, 2008).

No Brasil, uma das primeiras iniciativas para desenvolver uma metodologia na área de Ecotoxicologia ocorreu no ano de 1975, com a participação da Companhia de Tecnologia de Saneamento Ambiental do Estado de São Paulo (CETESB) em um programa de padronização internacional de testes de toxicidade aguda para peixes, desenvolvido pelo Comitê Técnico das Águas TC147 da International Organization for Standardization (ISO). Atualmente, vários já são os ensaios padronizados por organizações e associações nacionais e internacionais (Zagatto, 2008). 


\subsubsection{Testes de toxicidade}

Testes de toxicidade são utilizados para avaliar os potenciais efeitos adversos de substâncias tóxicas sobre organismos de diferentes ecossistemas. Os testes de toxicidade e as análises físicas e químicas que identificam e quantificam as concentrações das substâncias tóxicas em amostras ambientais são análises complementares para avaliar o risco ambiental destas substâncias (Seco et al., 2003; Costa et al., 2008).

Os testes de toxicidade vêm sendo cada vez mais utilizados para fins diversos, tais como, determinar a toxicidade de compostos químicos, efluentes líquidos e percolados de resíduos sólidos, estabelecer limites máximos para lançamentos de descarte de contaminantes, realizar o monitoramento ambiental (Nascimento et al., 2008).

Diferentes órgãos internacionais, como Environmental Protection Agency (US EPA), American Society for Testing and Materials (ASTM), Organization for Economic Cooperation and Development (OECD), vêm buscando a padronização de novos ensaios de toxicidade com espécies diversas, que apresentam respostas significativas à exposição a compostos tóxicos, visando por meio destes novos ensaios oferecer uma proteção ambiental mais abrangente (Aragão et al., 2008).

Testes de toxicidade podem ser classificados como agudos e crônicos e estes diferem, sobretudo quanto ao tempo de exposição do organismo ao contaminante e a forma como os resultados finais são avaliados (Adams et al., 2002).

Os testes de toxicidade aguda têm como finalidade avaliar a ocorrência de efeitos severos e rápidos sobre os organismos, como a mortalidade e/ou imobilidade de 50\% dos organismos expostos, uma vez que este critério é facilmente determinado, apresenta um importante significado ecológico para o ambiente e pode ser avaliado em curto prazo (Adams et al., 2002; Yu, 2004; Aragão et al., 2008). De forma geral, os testes de toxicidade 
aguda permitem estimar a dose ou a concentração que uma dada substância tóxica poderia provocar um efeito tóxico específico mensurável a um organismo teste ou população em um tempo de exposição relativamente curto em relação à vida do organismo (Adams et al., 2002; Aragão et al., 2008).

Nos testes de toxicidade aguda os resultados obtidos podem ser avaliados por meio dos valores de CI50 concentração de inibição a 50\% dos organismos expostos e CE50 concentração efetiva que causa efeito à 50\% dos organismos expostos (Aragão et al., 2008; Costa et al., 2008).

Entretanto, o fato de uma substância química não produzir efeitos adversos de mortalidade e/ou imobilidade aos organismos teste não indica necessariamente que esta substância não seja tóxica (Aragão et al., 2008).

Os testes de toxicidade crônica têm como objetivo avaliar os efeitos subletais, ou seja, os efeitos tóxicos que uma substância química é capaz de causar a um organismo quando este é exposto por longos períodos ou por uma fase considerável ou todo o ciclo de vida do organismo a concentrações que permitem sua sobrevivência, entretanto, são capazes de alterar funções como a reprodução, o crescimento, o comportamento, entre outros (Adams et al., 2002; Yu, 2004).

Nos testes de toxicidade crônica os resultados obtidos são expressos como CENO concentração de efeito não observado e CEO concentração de efeito observado (Adams et al., 2002; Aragão et al., 2008).

\subsubsection{Organismos teste}

A toxicidade é uma propriedade que reflete os efeitos adversos que uma substância pode causar a um organismo teste. A intensidade destes efeitos depende da concentração e propriedades químicas da substância, da sensibilidade do organismo teste e do tempo de exposição. Deste modo, é recomendável que o efeito tóxico de uma amostra seja avaliado com a 
realização de testes de toxicidade com organismos de espécies diferentes e preferencialmente de níveis tróficos diversos (FIG. 5) (Costa et al., 2008).

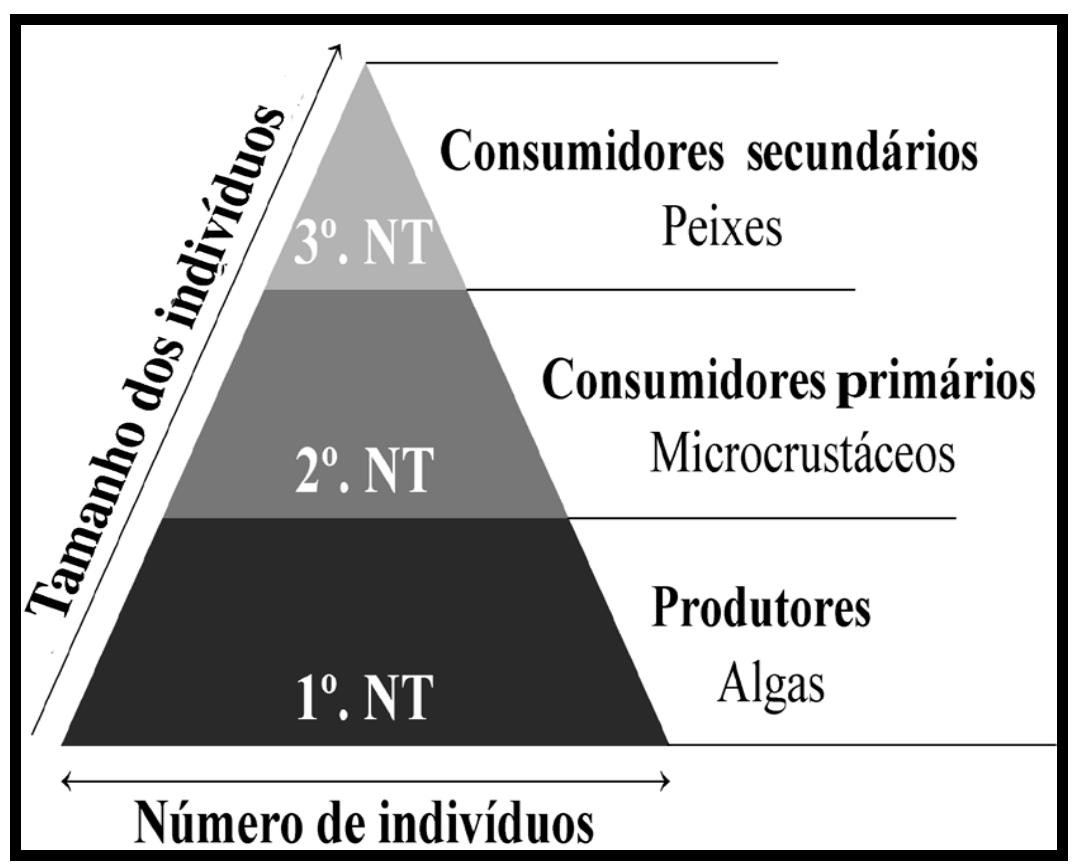

FIGURA 5 - Exemplo de uma cadeia alimentar de um ecossistema aquático constituído por três níveis tróficos (NT)

Fonte: Costa et al., 2008.

Das espécies de organismos que são utilizados em testes de toxicidade deve se conhecer previamente a fisiologia, genética e o comportamento destes organismos, a fim de facilitar e garantir a interpretação dos resultados. Para uma espécie poder ser utilizada como organismo teste é necessário que esta apresente uma seletividade constante aos contaminantes, seja uma espécie disponível em abundância, representativa em seu nível trófico e que possa ser facilmente cultivada e adaptada às condições de laboratório (Costa et al., 2008; Domingues et al., 2008).

As diferentes características biológicas entre as espécies de organismos teste refletem como estes organismos respondem a exposição de uma substância tóxica a uma dada concentração, isto é, as diferentes espécies têm sensibilidades diferentes (Posthuma et al., 2002) 
Atualmente, organismos teste como as bactérias, algas, microcrustáceos, minhocas e peixes, têm sido amplamente utilizados em testes de toxicidade padronizados no Brasil. Na TAB. 4 foram apresentadas as espécies e os tipos de ensaios, agudo ou crônico, utilizados para cada organismo (Costa et al., 2008).

TABELA 4 - Organismos teste, efeito e espécie utilizados em testes de toxicidade no Brasil

\begin{tabular}{lll}
\hline Organismo & Efeito & \multicolumn{1}{c}{ Espécie } \\
\hline Bactéria & Agudo & Vibrio fischeri, Spirillum volutans \\
Alga & Crônico & $\begin{array}{l}\text { Pseudokirchneriella subcapiata, } \\
\text { Chlorella vulgarris }\end{array}$ \\
Microcrustáceo & Agudo & D. similis, Daphnia magna \\
Microcrustáceo & Crônico & Ceriodaphnia dubia, Ceriodaphnia silvestri \\
Oligoquetas & Agudo & Eisenia andrei, Eisenia fetida
\end{tabular}

Fonte: adaptado de Costa et al., 2008.

Na TAB. 5 foi apresentada a indicação dos ensaios de toxicidade e organismos teste para alguns tipos de amostras.

TABELA 5 - Indicação de ensaios de toxicidade e organismos teste para diferentes tipos de amostras

\begin{tabular}{|c|c|c|}
\hline Tipo de amostra & Tipo de ensaio & Organismo teste \\
\hline Água continental & Aguda / crônica & $\begin{array}{c}\text { Bactérias, Daphnia, C. dubia e/ou } \\
\text { peixes }\end{array}$ \\
\hline Efluentes líquidos & Aguda / crônica & Algas, Ouriços, Daphnia elou C. dubia \\
\hline Solo & Aguda / crônica & Esenia fetida (minhoca) \\
\hline Lixiviado artificial de solo & Aguda / crônica & Testes exploratórios* \\
\hline Chorume & Aguda / crônica & Algas, Daphnia, peixes e/ou C. dubia \\
\hline $\begin{array}{l}\text { Lixiviado de resíduos } \\
\text { sólidos }\end{array}$ & Aguda / crônica & Testes exploratórios* \\
\hline
\end{tabular}


Para assegurar a viabilidade dos resultados obtidos nos ensaios realizados com organismos teste substâncias de referência são empregadas para estabelecer uma faixa de resultados aceitáveis para sensibilidade dos organismos (Zagatto et al., 2008). É recomendada, de acordo com Environment Canada (1990), a realização de um ensaio por mês com as substâncias de referências. Dentre as substâncias de referências que vêm sendo empregadas em testes de toxicidade com organismos aquáticos no Brasil estão o dicromato de potássio, sulfato de cobre, sulfato de zinco, cloreto de cádmio, nitrato de chumbo, cloreto de mercúrio, sulfato de níquel, cloreto de sódio, cloreto de amônio, cloreto de potássio e fenol (Zagatto et al., 2008).

Segundo Sobrero (2004) o sulfato de zinco é a substância de referência mais indicada para assegurar a variabilidade e a viabilidade dos lotes de sementes empregados em ensaios de germinação e desenvolvimento das radículas de $L$. sativa, devido ao seu potencial tóxico conhecido para estes organismos testes.

\subsubsection{Ensaio de germinação e desenvolvimento das radículas com Lactuca sativa}

Os ensaios de germinação e desenvolvimento das radículas com sementes de diversas plantas superiores, tais como, a L. sativa, popularmente conhecida como alface, vêm sendo cada vez mais aplicados para a avaliação da toxicidade de compostos solúveis em água pura e também em misturas complexas, tais como, efluentes industriais, águas residuais, lixiviados de solos, sedimentos, entre outras matrizes (Bowers et al., 1997). Estes ensaios quando utilizados para avaliar a toxicidade de lixiviados de solos podem ser representativos tanto para a água subterrânea quanto para a horticultura (Ferreira, 2007).

Ensaios de germinação e desenvolvimento da radícula de sementes são ensaios padronizados internacionalmente por órgãos como a US EPA (1996) e OECD (2003), no entanto, no Brasil estes ensaios ainda não são padronizados. Estes ensaios vêm sendo cada vez mais utilizados na avaliação 
de potenciais danos ambientais devido ao seu custo relativamente baixo, a curta duração dos ensaios e a sensibilidade que estes organismos teste apresentam a substâncias tóxicas (Sobrero et al., 2004).

Ensaios de germinação e desenvolvimento das radículas com sementes de plantas superiores apresentam vantagem em relação aos ensaios de toxicidade que utilizam como organismos teste algas e plantas aquáticas devido ao fato de não haver necessidade da amostra líquida ser filtrada previamente por causa da turbidez e material particulado em suspensão nas amostras (Sobrero et al., 2004). Sendo assim, a amostra líquida é preservada sem retenção de substâncias que poderiam apresentar toxicidade. Além disso, não são necessários ajustes de dureza e pH das amostras líquidas.

As sementes de L. sativa têm características ideais para a realização de bioensaios, visto que estas apresentam um ciclo de vida curto, tem grande importância para a agricultura e o seu cultivo é difundido em quase todo o mundo (Ferreira, 2007).

A avaliação do efeito tóxico é determinada por meio da germinação das sementes e do desenvolvimento das radículas. Na FIG.6 é representada uma semente germinada com sua radícula desenvolvida. (Sobrero et al., 2004).

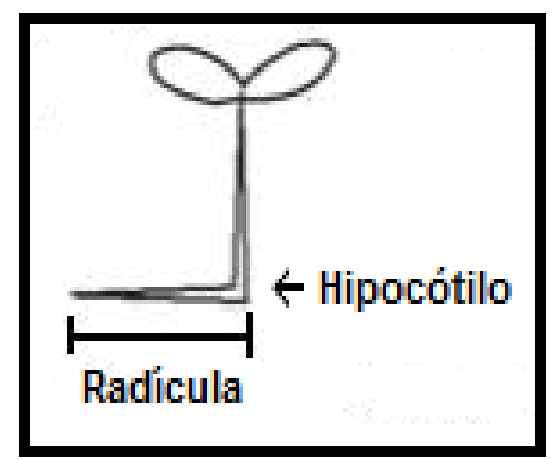

FIGURA 6 - Semente germinada de $L$. sativa com sua radícula desenvolvida Fonte: adaptado de Sobrero et al., 2004.

É importante destacar que os bioensaios de germinação com sementes de plantas são realizados durante os primeiros dias de seu 
desenvolvimento nos quais ocorrem uma série de processos fisiológicos importantes e a presença de uma substância tóxica pode causar efeitos adversos, resultando em uma série de anomalias e até mesmo interferir na sobrevivência desta planta (Sobrero et al., 2004; Environmental Canada, 2005).

Os ensaios de germinação e desenvolvimento das radículas de $L$. sativa são ensaios de toxicidade aguda, ou seja, uma avaliação dos efeitos letais. Entretanto, neste mesmo ensaio podem ser avaliados também os efeitos subletais por meio dos potenciais efeitos tóxicos sobre o desenvolvimento das radículas (Sobrero et al., 2004).

O efeito letal é avaliado por meio da determinação da concentração que causa inibição sobre a germinação de $50 \%$ dos organismos expostos e o efeito subletal por meio dos valores médios de CENO e CEO que estão relacionados com o desenvolvimento das radículas das sementes germinadas (Sobrero et al., 2004).

\subsubsection{Ensaio de toxicidade aguda com Daphnia similis}

Dentre os organismos de água doce passíveis de serem utilizados em testes de toxicidade aguda estão diversos cladóceros (microcrustáceos branquiópodes) do gênero Daphnia, dentre os quais encontram se espécies como a $D$. magna, $D$. pulex e $D$. similis. Esses cladóceros são popularmente conhecidos como pulgas d’água (FIG. 7) (Burton et al., 2002; Costa et al 2008).

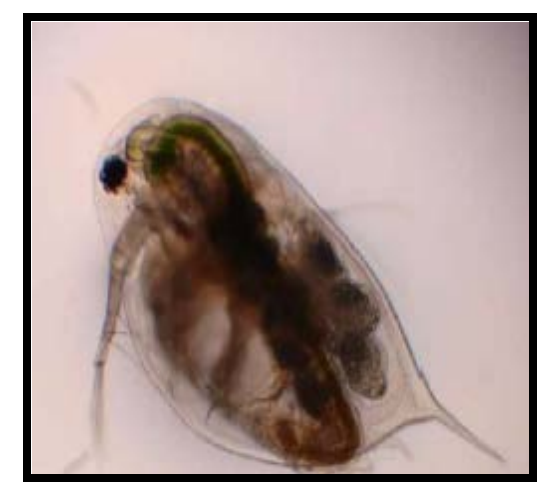

FIGURA 7 - Daphnia similis

Fonte: Lameira 2008. 
Os cladóceros têm sido tradicionalmente utilizados para a avaliação da toxicidade tanto de substâncias químicas puras como de amostras complexas, tais como águas residuais, águas superficiais, lixiviados entre outras, sendo a espécie $D$. similis a mais representativa em testes de toxicidade aguda no Brasil, uma vez que estes testes já são padronizados pela norma ABNT NBR 12713/2004 (Domingues et al., 2008). Segundo Valavanidis et al. (2010) o uso de tais organismos em testes de toxicidade para avaliar a contaminação de matrizes aquáticas por metais tóxicos tem sido reportado de forma satisfatória ao longo dos anos.

De forma geral, os microcrustáceos têm sido organismos muito utilizados para realização de testes de toxicidade, devido a grande abundância em corpos de água doce, ciclo de vida curto, fácil cultivo em laboratório, sensibilidade a diversos contaminantes e funções significativas na cadeia alimentar, uma vez que estes organismos são uma importante fonte de alimentação para peixes. Outra característica importante é a estabilidade genética que estes organismos apresentam, assegurando a obtenção de organismos teste com uma sensibilidade constante (Costa et al., 2008).

A espécie $D$. similis é utilizada em testes de toxicidade aguda nos quais diferentes organismos jovens são expostos a diferentes concentrações de uma substância tóxica ou a uma mistura complexa. Os efeitos tóxicos observados são a mortalidade e/ou a imobilidade dos organismos expostos. E com estes resultados por meio de métodos estatísticos se determina a concentração que causa efeito agudo de imobilidade e/ou mortalidade a 50\% dos organismos, CE50 48 h (Domingues et al., 2008).

\subsection{Estudos ecotoxicológicos para avaliação de elementos tóxicos}

Vários estudos ecotoxicológicos (Martens et al., 1976; Adriano et al., 1980; Wang, 1987; Printes et al., 2000; Cook et al., 2002; Seco et al., 2003; Meza et al., 2007; Guerra, 2009; Sukandar et al., 2009; Chapman et al., 2010; Wu et al., 2012) têm sido realizados para avaliar a toxicidade de amostras de águas superficiais, sedimento, lodo de esgoto e lixiviados de colunas de solos 
contaminados utilizando como organismos teste os microcrustáceos, sementes de hortaliças, bactéria, algas, anelídeos. Dentre estes estudos aqueles que buscam avaliar elementos tóxicos em amostras líquidas têm reportado cada vez mais a utilização de sementes de plantas como organismos teste.

Martens et al. (1976) e Adriano et al. (1980) avaliaram a toxicidade de solo com cinza de carvão e de lixiviados de cinza de carvão empregando como organismos teste sementes de Zea mays (milho) e Medicago sativa (alfafa) e sementes de Sorghum bicolor (capim), respectivamente. Foram observados efeitos tóxicos à germinação das sementes Z. mays e M. sativa, bem como, à germinação das sementes de $S$. bicolor expostas ao solo com cinza de carvão. No entanto, nos ensaios com lixiviados de cinza de carvão foi observada uma redução dos efeitos tóxicos para as sementes de Z. mays e $M$. sativa e para as sementes de S. bicolor.

Wang (1987) avaliou a toxicidade dos elementos tóxicos (Cd, Cr, Cu, Mn, Ni e Zn) e compostos orgânicos em amostras de águas de descarte empregando como organismos teste sementes de Cucumis sativus (pepino), Panicum milaceum (milho) e L. sativa (alface), por meio do desenvolvimento da radícula das sementes germinadas. Foi observado efeitos tóxicos nas amostras para as sementes de $C$. sativus, $P$. milaceum e $L$. sativa, e a $L$. sativa apresentou uma maior sensibilidade aos metais tóxicos quando comparada com as demais espécies.

Cook et al. (2002) avaliaram a toxicidade dos lixiviados de colunas de solos contaminados por resíduos de hidrocarbonetos e elementos tóxicos empregando como organismos teste anelídeos (Lumbricus terrestris), sementes (L. sativa e Panicum miliaceum), algas (Selenastrum capricornutum) e bactérias (Pseudomonas fluorescens). Foi observado que os lixiviados de solos contaminados não apresentaram toxicidade aos anelídeos $L$. terrestris. Por outro lado, estes lixiviados apresentaram efeitos tóxicos com os demais organismos (P. miliaceum, L. sativa, S. capricornutum, P. fluorescens). 
Seco et al. (2003) avaliaram a toxicidade dos lixiviados de resíduos de esgoto, escória e de cinzas por meio de testes de toxicidade aguda com $D$. magna, e observaram efeito tóxico dos lixiviados ao organismo teste .

Fuentes et al. (2006) avaliaram a toxicidade dos elementos $\mathrm{Cd}, \mathrm{Cu}$, $\mathrm{Cr}, \mathrm{Fe}, \mathrm{Ni}, \mathrm{Pb}$ e $\mathrm{Zn}$ em extratos de lodo de esgoto empregando como organismos teste sementes de Hordeum vulgare (cevada) e de Lepidium sativum (agrião). Foram avaliados a germinação das sementes e o desenvolvimento das radículas e não foram observados efeitos tóxicos dos extratos nos organismos $H$. vulgare e $L$. sativum.

Meza et al. (2007) avaliaram a toxicidade de efluentes industriais contaminados com elementos tóxicos por meio da germinação das sementes de $L$. sativa e a redução da mobilidade da $D$. pulex, sendo observados efeitos tóxicos para ambas espécies.

Sukandar et al. (2009) avaliaram a toxicidade de extrato de cinza de material hospitalar contituída por As, Ba, Cd, Co, Cr, Cu, Fe, Hg, Mn, Mo, Ni, $\mathrm{Pb}, \mathrm{Zn}$ e $\mathrm{Sn}$, utilizando ensaios de germinação e desenvolvimento das radículas de sementes de $L$. sativa, ensaios com a bactéria Vibrio fischeri e ensaios de toxicidade aguda com o microcrustáceo $D$. magna. Foram observados efeitos tóxicos para as três espécies.

Chapman et al. (2010) avaliaram a toxicidade de percolados de solos contaminados com elementos tóxicos (As, $\mathrm{Ba}, \mathrm{Cd}, \mathrm{Cr}, \mathrm{Co}, \mathrm{Cu}, \mathrm{Pb}, \mathrm{Hg}$, $\mathrm{Mo}, \mathrm{Ni}, \mathrm{Ag}$ e $\mathrm{Zn}$ ) por meio de ensaios de toxicidade utilizando como organismos teste os cladóceros $D$. magna, sementes de $L$. sativa e sementes de Tricum aestivum (trigo). Foram observados efeitos tóxicos a germinação das sementes e ao desenvolvimento das radículas dos organismos teste $L$. sativa, entretanto, não foram observados efeitos tóxicos a $D$. magna e $T$. aestivum.

Wu et al. (2012) avaliaram a toxicidade de solubilizado de nanopartículas de óxidos de metais $\left(\mathrm{CuO}, \mathrm{NiO}, \mathrm{TiO}_{2}, \mathrm{Fe}_{2} \mathrm{O}_{3}, \mathrm{CO}_{3} \mathrm{O}_{4}\right)$ utilizando como organismos teste sementes de Raphanus sativus (rabanete), $C$. sativus 
(pepino) e L. sativa (alface). Foram observados maiores efeitos tóxicos a sementes de $L$. sativa quando comparados com as demais sementes.

No Brasil estudos relacionados com a avaliação ecotoxicológica de amostras diversas, tais como, águas de chuva, chorume gerado do tratamento da água de produção de petróleo, águas superficiais e sedimentos (Printes et al., 2000; Guerra, 2009; Martins, 2009) têm sido publicados e poucos estudos relacionados com a toxicidade de amostras de cinza de carvão (Leffa, 2008). Os estudos brasileiros que envolvem o descarte inadequado de cinzas de carvão sobre o solo têm descrito a concentração de elementos tóxicos na atmosfera, águas superficiais, solos e sedimento (Cerutti et al 2000; Prochnow et al., 2000; Rohde et al., 2000; Schneider et al., 2000; Flues et al., 2008), mas não têm descrito sobre avaliação ecotoxicológica.

Printes et al. (2000) realizaram o monitoramento e controle ambiental de amostras de águas superficiais e sedimentos da região Carbonífera do Baixo Jacuí, no Rio Grande do Sul, utilizando ensaios de toxicidade aguda e crônica com os microcrustáceos $D$. similis e $C$. dubia, respectivamente. Foram observados efeitos tóxicos tanto nos ensaios de toxicidade aguda com $D$. similis como nos ensaios de toxicidade crônica com C. dubia para as amostras de água superficial. Para as amostras de sedimento foram observados efeitos tóxicos nos ensaios de toxicidade crônica com $C$. dubia.

Leffa (2008) avaliou a genotoxicidade do rejeito do carvão mineral utilizando testes de toxicidade aguda com o molusco Helix aspersa. Foi observado um efeito genotóxico ao molusco $H$. aspersa quando comparado ao grupo controle.

Guerra (2009) avaliou a toxicidade do extrato do lodo ou chorume gerado em um reator biológico pelo tratamento da água de produção do petróleo, empregando como organismos teste sementes de Cucumis sativus (pepino), Barbarea verna (agrião), Brassica oleracea (couve) e Eruca sativa (rúcula). Foi observado efeito tóxico nas amostras para todos os organismos e 
as espécies $C$. sativus e $B$. verna apresentaram uma maior sensibilidade a qual foi atribuída ao baixo potencial osmótico e toxicidade de íons presentes em alta concentração.

Martins (2009) avaliou a toxicidade de amostras de água de chuva coletadas na Região Metropolitana de São Paulo e nas cidades de Taiaçupeba e Mogi das Cruzes utilizando como organismos teste microcrustáceos Daphnia similis e Ceriodaphnia dubia, bactéria Vibrio fischeri e alga Pseudokirchneriella subcapitata. Foi observada toxicidade nas amostras de água de chuva coletadas na Região Metropolitana de São Paulo e Taiaçupeba aos organismos teste $D$. similis, $V$. fischeri e $C$. dubia e apenas para as amostras de água de chuva coletadas na Região Metropolitana de São Paulo também foi obsevada toxicidade crônica nos ensaios realizados com $P$. subcapitata.

Estudos como os realizados por Martens et al. (1976), Adriano et al. (1980) e Printes et al (2000) ressaltam a importância de se avaliar o potencial tóxico da cinza de carvão e os danos que este resíduo pode causar ao meio ambiente. Essa importância e os poucos trabalhos brasileiros publicados que relacionam a avaliação da toxicidade de amostras de cinza de carvão justificam o presente estudo. 


\section{MATERIAIS E MÉTODOS}

O presente trabalho faz parte de um projeto financiado pela Fundação de Amparo a Pesquisa do Estado de São Paulo (FAPESP), cujo nome é "Mobilidade e transporte de As, Cd, Mo, Pb e Zn em colunas de solos tropicais contaminadas com cinza de carvão da usina termoelétrica de Figueira, Paraná". Neste projeto foram realizados dois estudos para avaliar a mobilidade dos elementos tóxicos em colunas de solo com cinza de carvão e a contaminação dos solos (Lange, 2012; Silva, 2013).

No presente estudo a toxicidade dos percolados da coluna de cinza de carvão e das colunas de solo com cinza de carvão obtida nos estudos desenvolvidos por Lange (2012) e Silva (2013) foi avaliada por meio de ensaios de germinação e desenvolvimento das radículas e ensaios de toxicidade aguda empregando como organismos teste a dicotiledônea $L$. sativa e 0 microcrustáceo $D$. similis, respectivamente.

Os ensaios ecotoxicológicos foram realizados no laboratório de ecotoxicologia do Centro de Química e Meio Ambientes (CQMA) do Instituto de Pesquisas Energéticas e Nucleares (IPEN/CNEN-SP).

\subsection{Obtenção dos percolados das colunas de cinza de carvão e de solo com cinza de carvão}

Os percolados das colunas de cinza de carvão e de solo com cinza de carvão foram obtidos dos estudos desenvolvidos por Lange (2012) e Silva (2013) que fazem parte do mesmo grupo de trabalho do presente estudo.

Nos estudos de Lange (2012) e Silva (2013) foram preparadas colunas com dois solos de texturas diferentes, um franco arenoso e outro argiloso, respectivamente. Os solos foram coletados no estado de São Paulo, em 2009, em áreas de mata nativa ou de reflorestamento antigo, com pouca perturbação antropogênica. O solo de textura franco arenosa foi coletado entre os municípios de Araras e Conchal e o solo de textura argilosa no município de 
Piracicaba. Estes solos foram selecionados para coleta por serem latossolos (classe de solo mais representativa do Brasil e do Estado de São Paulo) e por apresentarem diferentes características químicas e físicas.

Estes solos (286 $\mathrm{g}$ do solo franco arenoso e $279 \mathrm{~g}$ do solo argiloso) foram compactados separadamente em colunas de acrílico com uma prensa manual com base na densidade e umidade dos solos para simular as características dos solos coletados em campo. A dimensão das colunas utilizadas foi de $5 \mathrm{~cm}$ de altura por $8 \mathrm{~cm}$ de diâmetro. No topo das colunas de solo foi adicionada $50 \mathrm{~g}$ cinza de carvão. Esta cinza de carvão foi proveniente da usina termelétrica de Figueira, Paraná. Uma coluna de cinza de carvão também foi preparada com a mesma quantidade de cinza adicionada no topo das colunas de solo e na mesma dimensão, contudo o solo foi substituído por areia inerte nesta coluna.

As colunas foram percoladas com uma solução aquosa de pH 4,5 composta por ácido nítrico e ácido sulfúrico para simular a água de chuva, por um período de 336 dias. O volume da solução adicionado nas colunas foi calculado com base na média do índice pluviométrico mensal dos últimos anos (1933 - 2008) da cidade de São Paulo. O volume da solução adicionado em cada coluna foi $6914 \mathrm{~mL}$, que corresponde a um ano de precipitação. Na FIG.8 foi apresentado o sistema de percolação das colunas. 

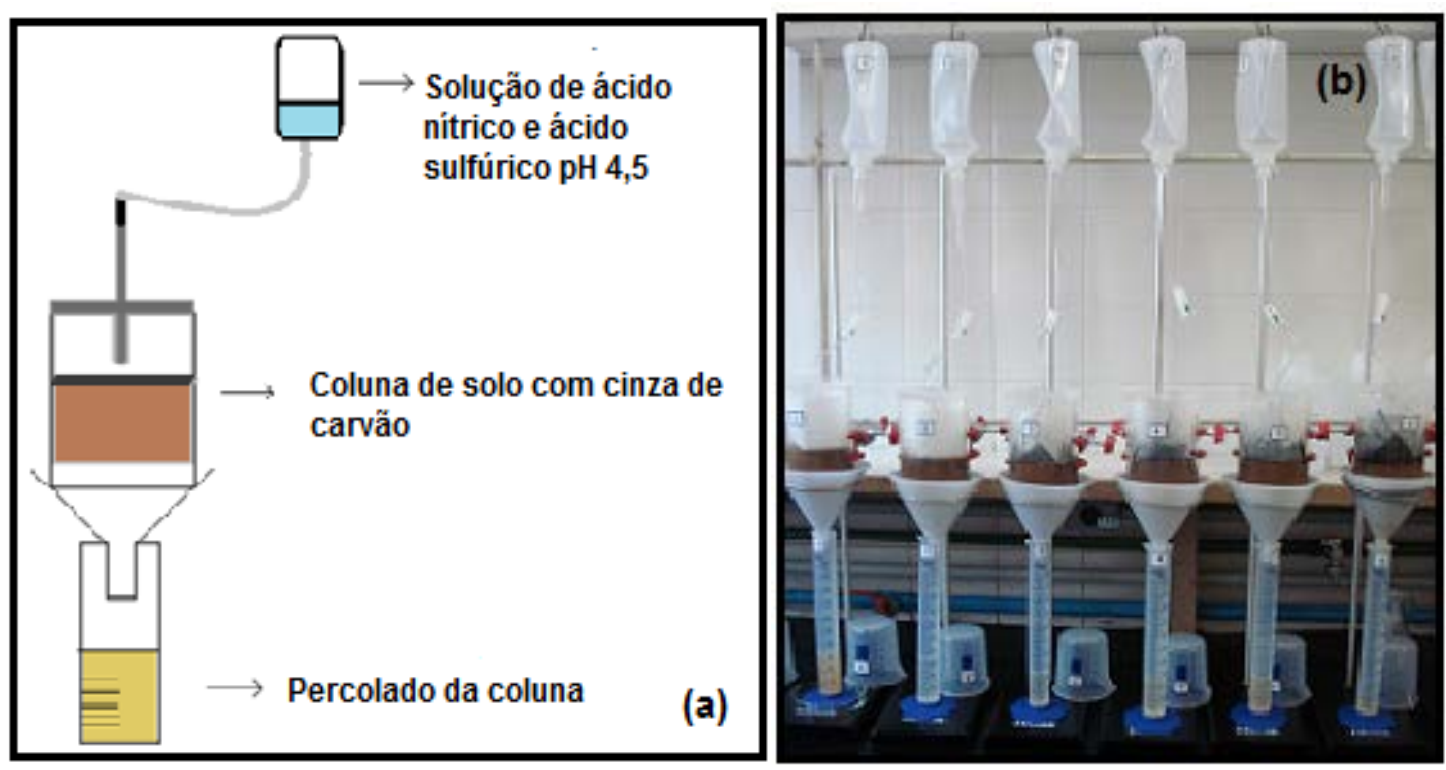

FIGURA 8 - (a) Esquema experimental do sistema de percolação da coluna de solo com cinza de carvão; (b) Foto do sistema de percolação das colunas de solo franco arenoso com cinza de carvão

Os percolados gerados de três colunas foram coletados a cada 28 dias em um período de 336 dias de percolação das colunas, gerando 12 amostras para cada coluna, portanto, um total de 36 amostras de percolado. Os percolados provenientes das três colunas foram denominados como C (percolado da coluna de cinza de carvão), SPC (percolado da coluna de solo de Piracicaba com cinza de carvão) e SCC (percolado da coluna de solo de Conchal/Araras com cinza de carvão). Na FIG.9 foram apresentados os percolados gerados das colunas ao longo de 336 dias de lixiviação. 


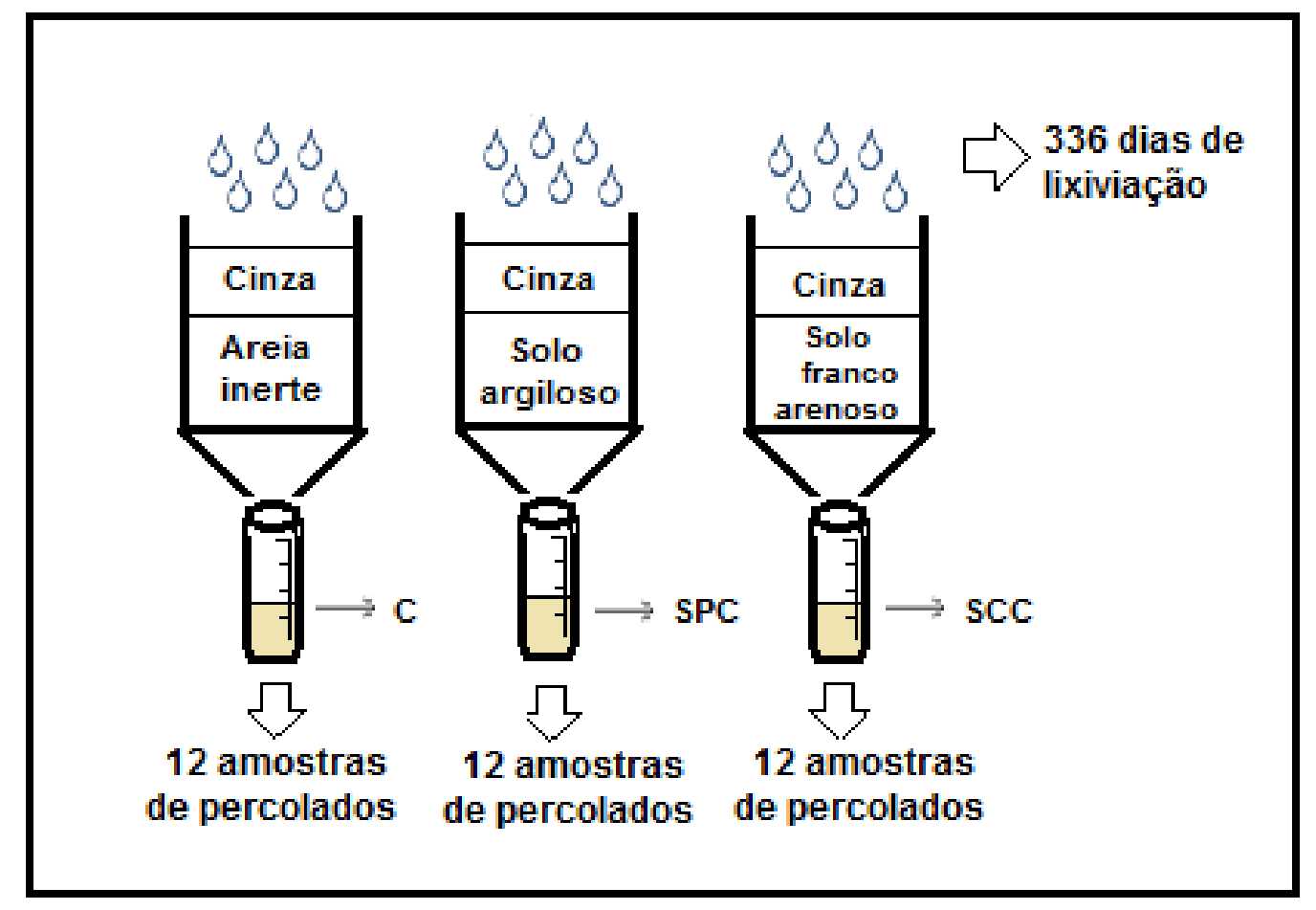

FIGURA 9 - Percolados C, SPC e SCC gerados ao longo de 336 dias

Os 12 percolados de cada coluna foram denominados conforme a sequência da coleta como 28, 56, 84, 112, 140, 168, 196, 224, 252, 280, 308, 336.

\subsection{Ensaio de germinação e desenvolvimento das radículas de Lactuca sativa}

Os percolados das colunas de cinza de carvão e das colunas de solos com cinza de carvão foram submetidos a ensaios de toxicidade aguda de germinação e desenvolvimento das radículas, para avaliar tanto os efeitos letais por meio da não germinação das sementes como os efeitos subletais por meio do desenvolvimento das radículas. Nestes ensaios foram empregadas como organismos teste sementes orgânicas de L. sativa (alface manteiga), da Isla Pak, lote 28556 (validade das sementes: maio de 2013). Na TAB.6 foi descrito um resumo das condições utilizadas para a realização do ensaio de toxicidade com L. sativa. 
TABELA 6 - Condições gerais utilizadas no ensaio de germinação e desenvolvimento da $L$. sativa e critérios de aceitabilidade

\begin{tabular}{|c|c|}
\hline Organismo teste & Lactuca sativa (Asterales, Lactuca) \\
\hline Tipo de ensaio & Estático \\
\hline Número de organismos teste por réplica & 20 sementes \\
\hline Número de réplicas & 4 \\
\hline Volume de amostra do percolado & $3 \mathrm{~mL}$ \\
\hline Água de diluição & Água deionizada \\
\hline Concentrações da amostra do percolado & $100 \% \rightarrow 50 ; 25 ; 12,5 ; 6,25$ e $3,125 \%$ \\
\hline Substrato & Papel de filtro qualitativo (porosidade $14 \mu \mathrm{m}$ ) \\
\hline Recipiente do teste & Placa de Petri (diâmetro 9,5cm) \\
\hline Temperatura & $25 \pm 2^{\circ} \mathrm{C}$ \\
\hline Fotoperíodo & 16 horas de luz / 8 horas de escuro \\
\hline Duração do ensaio & 120 horas \\
\hline Controle negativo & Água deionizada \\
\hline Controle positivo & Solução de $\mathrm{Zn}\left(\mathrm{SO}_{4}\right)_{2} 0,04 \mathrm{~g} \mathrm{~L}^{-1}$ \\
\hline Efeito avaliado & $\begin{array}{l}\text { Número de sementes germinadas e comprimento } \\
\text { das radículas }\end{array}$ \\
\hline Critérios de aceitabilidade & $\begin{array}{l}\text { Carta controle, germinação das sementes no } \\
\text { controle negativo > > } 0 \% \text {, comprimento das } \\
\text { radículas } \geq 5 \mathrm{~mm} \text {, variabilidade do comprimento } \\
\text { das radículas } \leq 30 \% \text { no controle negativo }\end{array}$ \\
\hline Resultado final & $\mathrm{CI}_{(120 h)}, \mathrm{IG}, \mathrm{CENO}$ e CEO \\
\hline Referências & $\begin{array}{l}\text { US EPA (1996); OECD (2003); } \\
\text { Sobrero et al.(2004) }\end{array}$ \\
\hline
\end{tabular}

Inicialmente foi realizado um ensaio preliminar para cada uma das 12 amostras de percolados das colunas de cinza de carvão e de solos com cinza de carvão a fim de avaliar previamente a toxicidade ou não destes percolados. Para isso ensaios de germinação e de desenvolvimento das radículas das amostras puras dos percolados (concentração 100\%) foram comparados a um controle negativo (água deionizada) seguindo as condições descritas na TAB.6. As amostras de percolados que apresentaram toxicidade no ensaio preliminar foram submetidas a um ensaio definitivo. Para a realização do ensaio definitivo foram preparadas as seguintes diluições $(50,25$, $12,5,6,25$ e 3,125\%) tomando-se como base a concentração $100 \%$ das amostras dos percolados. 
Para a realização do ensaio vinte sementes de $L$. sativa foram dispostas de forma equidistante na base de uma placa de Petri, na qual foi previamente coberta por um papel de filtro (porosidade $14 \mu \mathrm{m}$ ) umedecido com $3 \mathrm{~mL}$ da amostra a ser testada. Posteriormente, as placas de Petri foram vedadas com filme plástico e, então, acondicionadas em uma câmara de germinação com temperatura e fotoperíodo controlados por um período de 120 horas. Após esse período foi registrado tanto o número de sementes não germinadas e germinadas, como também o tamanho das radículas (USEPA, 1996; OECD, 2003). Na FIG.10 foram apresentadas fotos do ensaio de germinação e desenvolvimento das radículas de $L$. sativa.
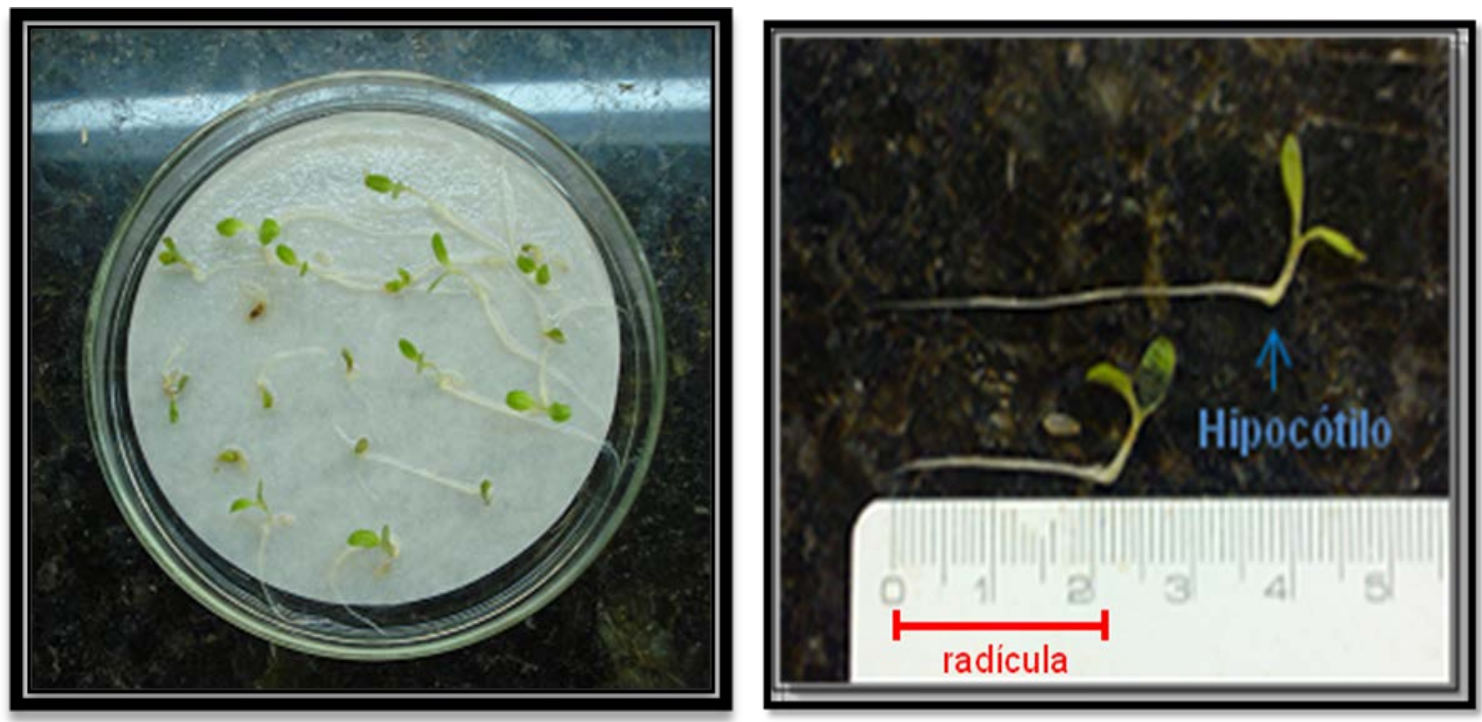

FIGURA 10 - Fotos do ensaio de germinação e desenvolvimento das radículas de $L$. sativa

A carta controle dos ensaios com sementes de L. sativa foi determinada por meio da média ( \pm dois desvios padrões) dos valores obtidos para $\mathrm{Cl50}_{(120 \mathrm{~h})}$ para os cinco primeiros ensaios, utilizando como substância de referência uma solução de sulfato de zinco $0,04 \mathrm{~g} \mathrm{~L}^{-1}$ (controle positivo) e como controle negativo a água deionizada. Tomando-se como base essa solução de sulfato de zinco $0,04 \mathrm{~g} \mathrm{~L}^{-1}$ foram realizadas as seguintes diluições $50,25,12,5$, 6,25 e 3,125\%. Estes ensaios que foram utilizados para determinação da carta controle foram realizados mensalmente, paralelamente aos ensaios preliminares e definitivos. 


\subsection{Ensaio de toxicidade aguda com Daphnia similis}

Os percolados das colunas de cinza de carvão e das colunas de solo com cinza de carvão foram submetidos a ensaios de toxicidade aguda, empregando-se como organismos teste neonatas (organismos jovens como menos de 24 horas de vida) do microcrustáceo $D$. similis. Na TAB.7 foram descritas as condições gerais dos ensaios de toxicidade aguda com $D$. similis.

TABELA 7 - Condições gerais do ensaio de toxicidade aguda com $D$. similis e critérios de aceitabilidade

\begin{tabular}{ll}
\hline Organismos teste & Daphnia similis (Cladocera, Crustacea) \\
Tipo de Ensaio & Estático \\
Número de organismos teste por réplica & 5 neonatas \\
Número de réplicas & 4 \\
Volume de amostra do percolado & $10 \mathrm{~mL}$ \\
Água de diluição & Água de cultivo para $D$. similis \\
Concentração das amostras de percolados & $100 \% \rightarrow 50,25,12,5,6,25$ e 3,125\% \\
Recipiente do ensaio & Tubos de ensaio \\
Temperatura & $20 \pm 2^{\circ} \mathrm{C}$ \\
Fotoperíodo & 12 horas de luz /12 horas de escuro \\
Duração do ensaio & 48 horas \\
Controle negativo & Água de cultivo para $D$. similis \\
Controle positivo & NaCl $10 \mathrm{~g} \mathrm{~L}^{-1}$ \\
Efeito avaliado & Mortalidade e/ou imobilidade \\
& \\
Critérios de aceitabilidade & Carta controle, mobilidade e/ou \\
& sobrevivência $\geq 80 \%$ no controle \\
Resultado final & negativo \\
Referência & CE50 $(48 \mathrm{~h})$ \\
\hline
\end{tabular}

Inicialmente foi realizado um ensaio preliminar para cada uma das 12 amostras de percolados das colunas de cinza de carvão e de solos com cinza de carvão a fim de avaliar previamente a toxicidade ou não destes percolados, assim como foi descrito para os ensaios de germinação e desenvolvimento das radículas de $L$. sativa no item 4.2. Para isso as amostras puras de percolados (concentração 100\%) foram comparadas com a água de 
cultivo para $D$. similis (controle negativo) seguindo as condições gerais descritas na TAB.7. As amostras de percolados que apresentaram toxicidade no ensaio preliminar foram submetidas a um ensaio definitivo no qual estas amostras de percolados foram utilizadas nas concentrações 100, 50, 25, 12,5, 6,25 e $3,125 \%$.

As amostras dos percolados foram previamente filtradas para a realização deste ensaio. Foram adicionados $10 \mathrm{~mL}$ das amostras em tubos de ensaios nos quais foram distribuídas cinco neonatas em cada réplica. Estes tubos de ensaios foram acondicionados em câmaras de germinação com temperatura e fotoperíodo controlados, durante um período de 48 horas. Após esse período foi registrado o número de organismos mortos e/ou imóveis. Em paralelo aos ensaios foram realizadas análises física e químicas $(\mathrm{pH}$, condutividade elétrica, dureza da água) da água de cultivo que foi ajustada conforme a norma da ABNT NBR 12713 / 2004 (APÊNDICE C). Na FIG.11 foram apresentadas fotos do ensaio de toxicidade aguda com $D$. similis.
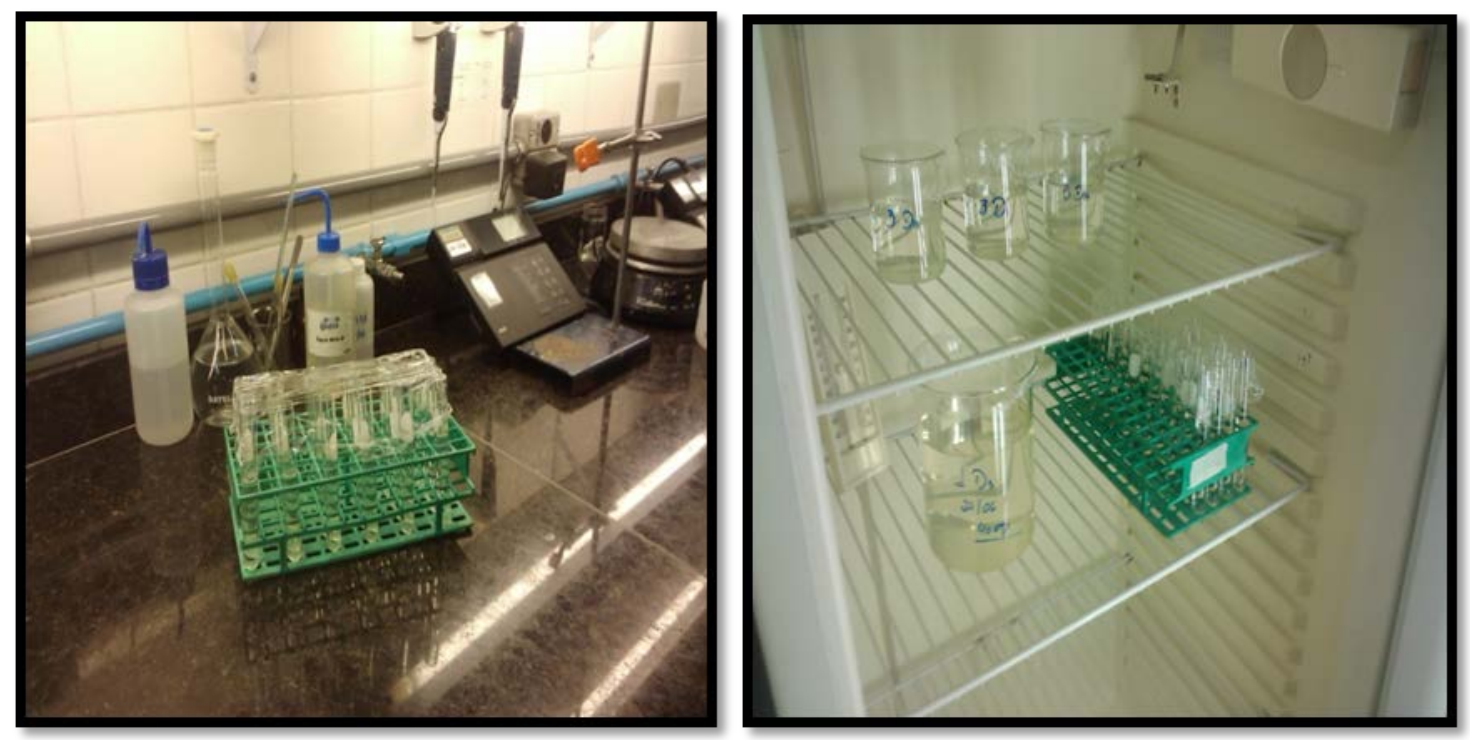

FIGURA 11 - Fotos do ensaio de toxicidade aguda com D. similis

A carta controle dos ensaios de toxicidade aguda para os organismos $D$. similis foi determinada por meio da média ( \pm dois desvios padrões) dos valores obtidos para $\mathrm{CE} 50_{(48 \mathrm{~h})}$ para os cinco primeiros ensaios. Para a realização destes ensaios foi utilizada como controle negativo a água de 
cultivo de $D$. similis e como substância de referência uma solução de cloreto de sódio $10 \mathrm{~g} \mathrm{~L}^{-1}$ (controle positivo). Tomando-se como base essa solução foram realizadas as seguintes diluições 8,0,4,0, 2,0, 1,0, 0,5 $\mathrm{mg} \mathrm{L}^{-1}$. Estes ensaios que foram utilizados para determinação da carta controle foram realizados mensalmente, paralelamente aos ensaios preliminares e definitivos.

\subsection{Tratamentos estatísticos}

Os tratamentos estatísticos dos dados obtidos nos ensaios preliminares e definitivos para ambos os organismos teste ( $L$. sativa e $D$. similis) foram descritos separadamente nos subitens a seguir.

\subsubsection{Ensaio preliminar}

As análises estatísticas dos dados obtidos por meio do ensaio preliminar de germinação e desenvolvimento das radículas de $L$. sativa e de toxicidade aguda com $D$. similis foram realizadas de acordo com o fluxograma adaptado da USEPA (2002) apresentado na FIG.12, utilizando o programa estatístico Toxstat 3.5 (Gulley et al., 1995). De acordo com esta metodologia os valores obtidos para o número de sementes germinadas e o número de neonatas de $D$. similis mortas e/ou imóveis nos percolados foram analisados estatisticamente para avaliar se os percolados foram significativamente diferentes ou não quando comparados com o controle negativo, indicando a toxicidade aguda da amostra. 


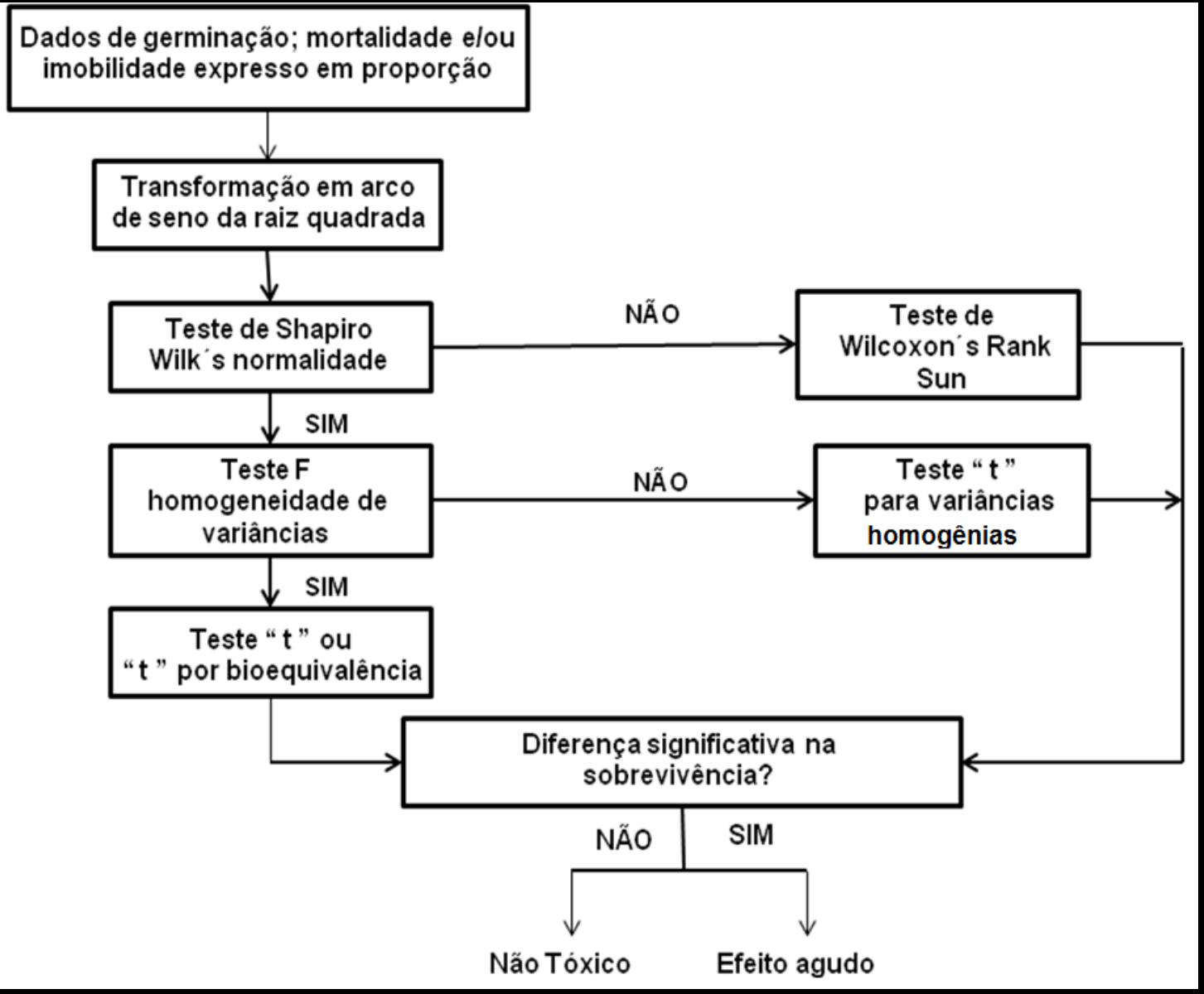

FIGURA 12 - Fluxograma para análise estatística dos dados do ensaio preliminar com uma única concentração e o controle negativo

Fonte: adaptado de US EPA, 1993

As amostras dos percolados das colunas que apresentaram toxicidade aguda no ensaio preliminar foram submetidas a ensaio definitivo.

No ensaio preliminar de germinação e desenvolvimento das radículas o valor médio do tamanho das radículas, o desvio padrão e o coeficiente de variação foram calculados. Para avaliar se o tamanho das radículas nos percolados das colunas de cinza de carvão e de solos com cinza de carvão foi significativamente diferente ou não quando comparado com o controle negativo tomou-se como base o fluxograma da FIG.13. 


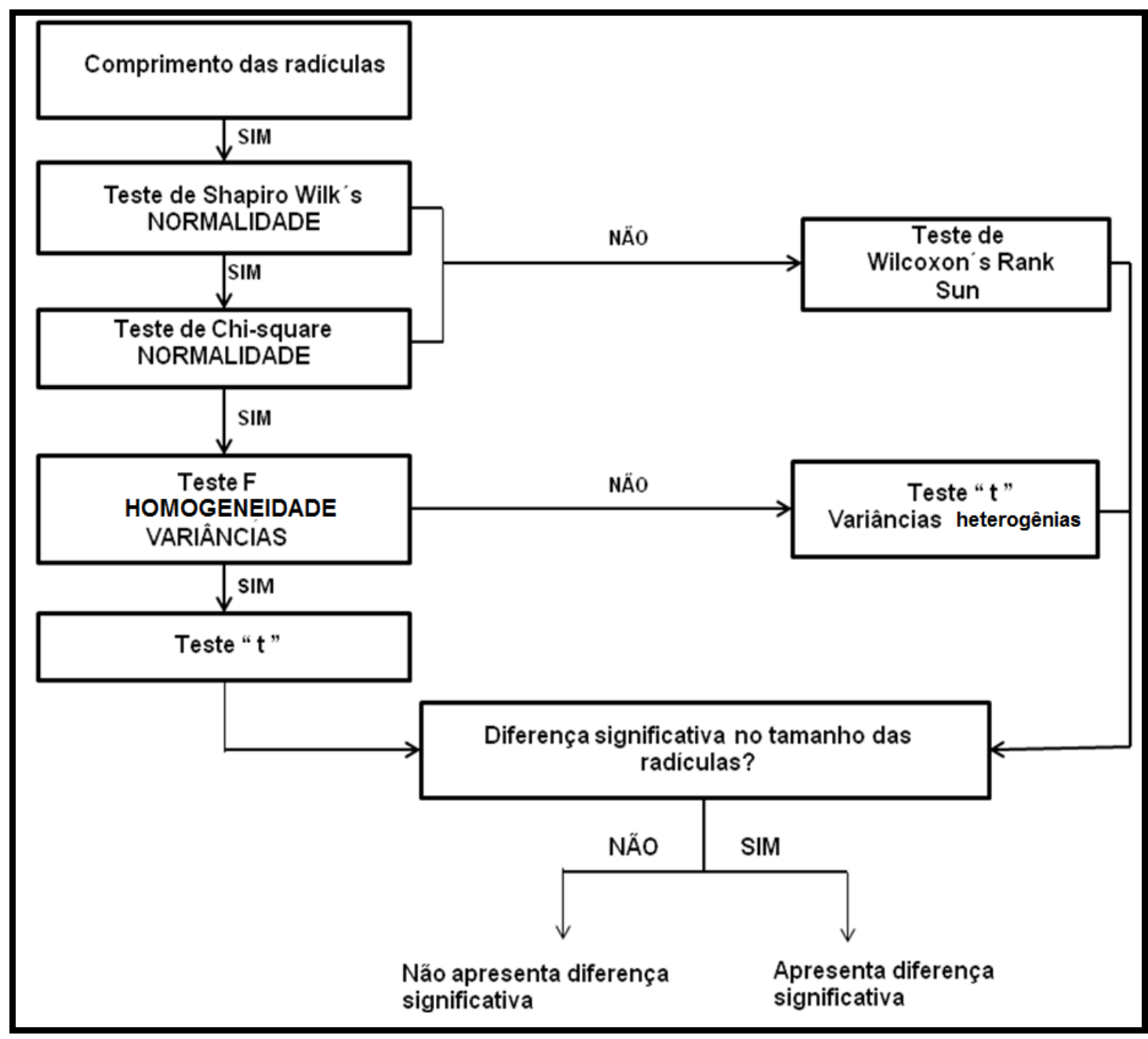

FIGURA 13 - Fluxograma para análise estatística dos dados do comprimento das radículas das amostras dos percolados e do controle negativo

\subsubsection{Ensaio definitivo}

As análises estatísticas dos dados obtidos por meio do ensaio definitivo de germinação e desenvolvimento das radículas de $L$. sativa (número de sementes germinadas em cada concentração) e do ensaio definitivo de toxicidade aguda com $D$. similis (número de neonatas mortas e/ou imóveis em cada concentração) foram realizadas por meio do programa estatístico Trimmed Spearman-Karber, versão 1.5 (Hamilton et al., 1999). De acordo com esta metodologia foram determinados os valores de $\mathrm{Cl}^{50_{(120 h)}}$ (concentração de inibição em 50\% dos organismos teste) para o ensaio definitivo de germinação e desenvolvimento das radículas de $L$. sativa e os valores de $C E 50_{(48 \mathrm{~h})}$ 
(concentração efetiva que causa mortalidade e/ou imobilidade a 50\% dos organismos teste) para o ensaio definitivo de toxicidade aguda com $D$. similis.

No ensaio definitivo de germinação e desenvolvimento das radículas de L. sativa os valores médios de CENO (concentração de efeito não observado) e CEO (concentração de efeito observado) foram determinados tomando como base os valores obtidos para o comprimento das radículas de acordo com o fluxograma descrito na FIG.14, os quais foram calculados por meio do programa estatístico Toxstat 3.5 (Gulley et al., 1995).

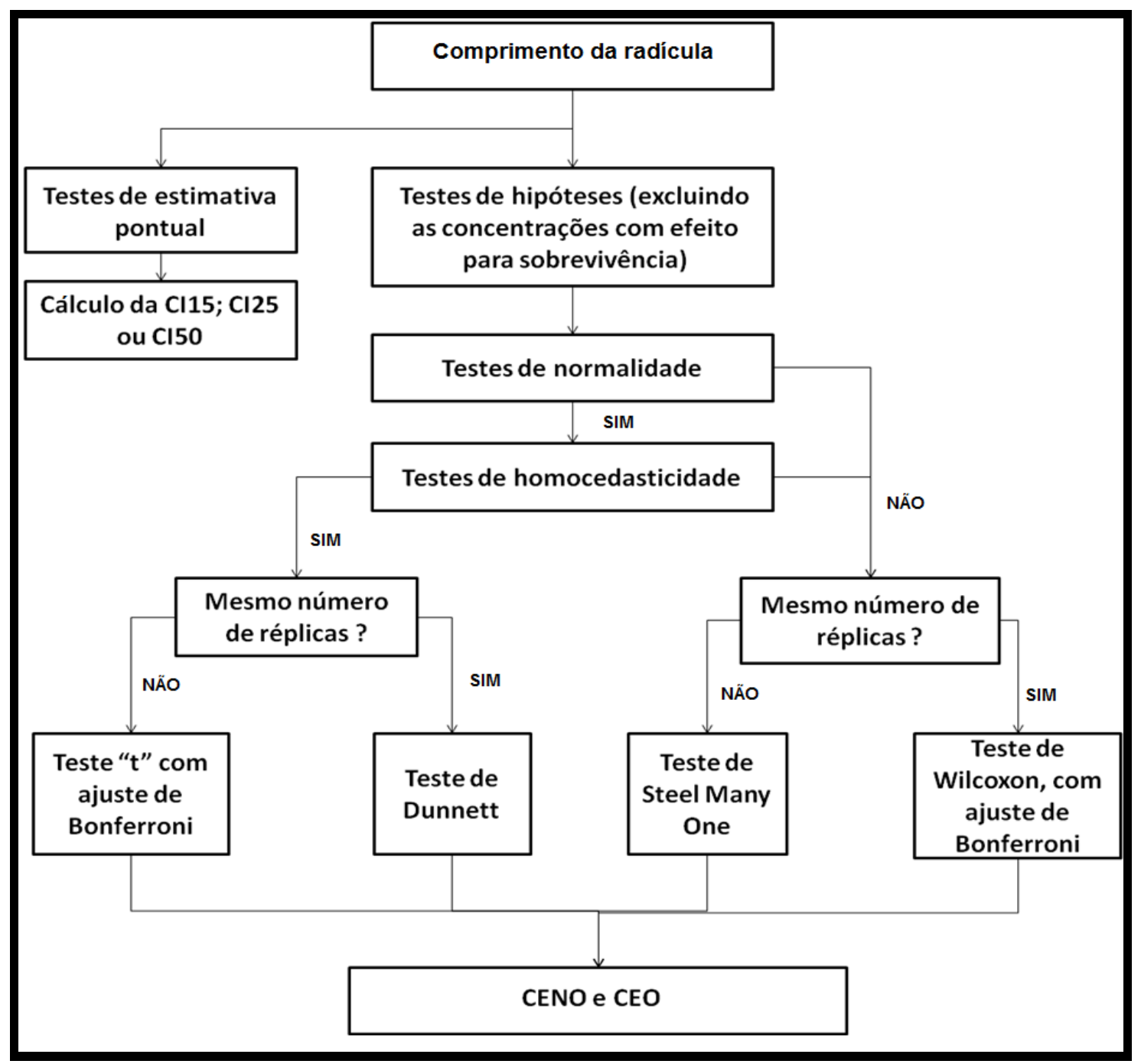

FIGURA 14 - Fluxograma para análise estatística dos dados dos efeitos subletais para o crescimento das radículas de $L$. sativa Fonte: adaptado de US EPA, 1993. 
No ensaio definitivo de germinação e desenvolvimento das radículas de L. sativa também foi calculado o IG (índice de germinação) das sementes dos percolados de acordo com a equação 1 (ASTM, 1994).

$\%$ Îndice de germinação $=\frac{\% \text { germinação das sementes } \times \% \text { crescimento das radículas }}{100}$

$\mathrm{Na}$ qual

$\%$ Germinação das sementes $=\frac{\% \text { germinação no percolado }}{\% \text { germinação no controle }} \times 100$

e

$\%$ Crescimento médio das radículas $=\frac{\text { média do comprimento das radículas no percolado }}{\text { média do comprimento das radículas no controle }}$ 


\section{RESULTADOS E DISCUSSÃO}

Os percolados das colunas de cinza de carvão e de solos com cinza de carvão foram avaliados quanto à toxicidade e as propriedades químicas e a concentração dos elementos destes percolados que foram descritas com base nos dados de Lange (2012) e Silva (2013).

\subsection{Ensaios ecotoxicológicos}

Foram realizados dois ensaios ecotoxicológicos: um de germinação e desenvolvimento da radícula de $L$. sativa e outro de toxicidade aguda com $D$. similis. Para a realização destes ensaios foi estabelecida uma carta controle para cada um com finalidade de determinar uma faixa de resultados aceitáveis para a sensibilidade dos organismos teste utilizados ao longo dos ensaios.

\subsubsection{Ensaios de germinação e desenvolvimento das radículas de $L$. sativa}

Os ensaios de germinação e desenvolvimento das radículas de $L$. sativa foram justificados no presente trabalho com base no texto descrito na revisão de literatura (itens 3.4 .3 e 3.5 ) por serem utilizados para avaliar a toxicidade de amostras de lixiviados de solo e de resíduos, padronizados por agências internacionais e por apresentarem vantagem na preservação da amostra líquida, sem necessidade de filtração, em relação aos organismos teste alga e plantas aquáticas.

Os ensaios de germinação e desenvolvimento das radículas com sementes de $L$. sativa foram realizados para os percolados da coluna de cinza de carvão (percolado C) e para os percolados das colunas de solos com cinza de carvão (percolado SPC e percolado SCC). 


\subsubsection{Ensaios preliminares}

Os ensaios preliminares foram realizados para determinar 0 potencial tóxico das amostras puras (concentração 100\%) dos percolados das colunas de cinza de carvão e de solos com cinza de carvão.

Inicialmente, as amostras puras dos percolados foram comparadas ao controle negativo (água deionizada) por meio do teste t de Student com nível de significância de 0,05, conforme descrito no item 4.4.1. Na TAB.8 foram apresentados os resultados de toxicidade dos percolados obtidos por meio dos ensaios de germinação e desenvolvimento das radículas de sementes de $L$. sativa.

TABELA 8 - Toxicidade dos percolados C, SCC e SPC (concentração 100\%) obtida nos ensaios preliminares, utilizando como organismos teste $L$. sativa

\begin{tabular}{ccccccccccccc}
\hline Percolado & 28 & 56 & 84 & 112 & 140 & 168 & 196 & 224 & 252 & 280 & 308 & 336 \\
\hline C & Tóxico & Tóxico & Tóxico & NT & NT & NT & NT & NT & NT & NT & NT & NT \\
SPC & NT & NT & NT & NT & NT & NT & NT & NT & NT & NT & NT & NT \\
SCC & NT & NT & NT & NT & NT & NT & NT & NT & NT & NT & NT & NT \\
\hline
\end{tabular}

Teste t de Student $\alpha<0,05$; Tóxico - Toxicidade aguda; NT - Não tóxico; C: percolado da coluna de cinza de carvão; SPC: percolado da coluna de solo de Piracicaba com cinza de carvão; SCC: percolado da coluna de solo de Conchal/Araras com cinza de carvão.

Apenas os percolados 28, 56 e 84 provenientes da coluna de cinza de carvão (percolado $\mathrm{C}$ ) apresentaram potencial para causar efeito tóxico à germinação das sementes de L. sativa (TAB.8). Isso indica que as substâncias tóxicas presentes na cinza de carvão foram mais lixiviadas pela coluna de cinza de carvão no período inicial de percolação.

Os percolados das colunas de solo com cinza de carvão SPC e SCC (TAB.8) não apresentaram efeito tóxico sobre a germinação de sementes de $L$. sativa ao longo de 336 dias de percolação, o que indica que possivelmente as 
substâncias tóxicas foram retidas nos solos das colunas, de modo que, os dois tipos de solos utilizados nas colunas agiram como um filtro. Entretanto, o fato dos percolados SPC e SCC não causarem toxicidade aguda nos organismos não indica necessariamente que a concentração das substâncias presentes nos percolados não possa causar toxicidade crônica a estes mesmos organismos teste, mas no presente trabalho a toxicidade crônica não foi avaliada nestes percolados.

Os resultados obtidos para os percolados SPC e SCC das colunas de solo (TAB.8) não foram coerentes aos resultados observados no estudo realizado por Chapman et al. (2010) no qual foram reportados efeitos tóxicos à germinação de sementes de $L$. sativa quando avaliada a toxicidade dos lixiviados de solos contaminados com elementos tóxicos. Do mesmo modo, os resultados apresentados na TAB.8 também não foram coerentes aos reportados no estudo realizado por Cook et al. (2002) no qual foi observado efeitos tóxicos ao desenvolvimento das radículas de $L$. sativa no primeiro lixiviado de solo contaminado com hidrocarbonetos e elementos tóxicos. Entretanto, nesse mesmo estudo não foi observado efeitos adversos aos demais lixiviados de solo contaminado, assim como no presente trabalho.

A diferença entre os resultados obtidos na literatura e no presente trabalho pode estar relacionada com a composição química, concentração dos compostos químicos e com os parâmetros físicos e químicos dos solos e lixiviados dos solos.

\subsubsection{Ensaios definitivos}

Os ensaios definitivos de germinação e desenvolvimento das radículas de $L$. sativa foram realizados com os percolados que apresentaram toxicidade aguda de acordo com os ensaios preliminares (percolados 28, 56 e 84 da coluna de cinza de carvão) descritos no item 5.1.1.1. Os resultados obtidos nos ensaios definitivos foram utilizados para calcular a concentração de inibição $\left(\mathrm{Cl}^{50} 0_{(120 h)}\right)$, a concentração de efeito não observado (CENO), concentração de efeito observado (CEO) e o índice de germinação (IG). 
A $\mathrm{Cl50}_{(120 \mathrm{~h})}$ foi calculada tomando-se como base as sementes germinadas nos ensaios de germinação e desenvolvimento das radículas de $\mathrm{L}$. sativa por meio do programa estatístico Trimmed Spearman-Karber, conforme descrito no capítulo de materiais e métodos no item 4.4.2. Na FIG.15 foram apresentados os valores obtidos para a $\mathrm{Cl}^{5} 0_{(120 \mathrm{~h})}$ para os percolados $28,56 \mathrm{e}$ 84 da coluna de cinza de carvão.

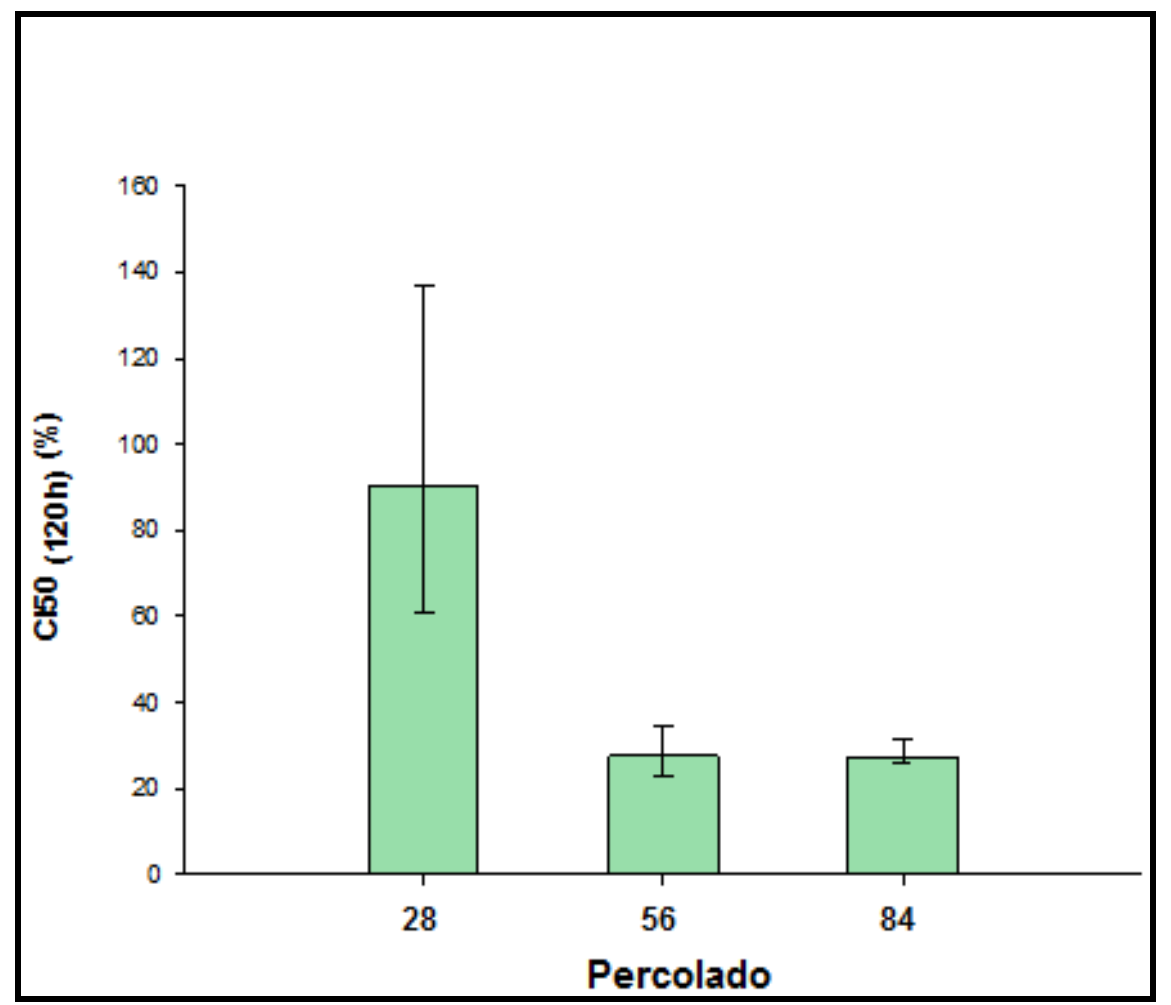

FIGURA 15 - $\mathrm{Cl}^{50_{(120 h)}}$ dos percolados da coluna de cinza de carvão empregando como organismo teste sementes de $L$. sativa $\mapsto$ : intervalo de confiança

Esses valores são aceitáveis uma vez que a carta controle estabelecida para os ensaios de germinação e desenvolvimento das radículas de L. sativa (Apêndice A) foi satisfatória, pois os valores de $\mathrm{Cl}_{(120 \mathrm{~h})}$ da carta apresentaram-se dentro de uma faixa considerada aceitável.

Para os percolados 28,56 e 84 da coluna de cinza de carvão foram observados valores médios de $\mathrm{Cl}_{(120 h)}$ de 90,6, 27,6 e 31,1\% (FIG.15), respectivamente. 
De acordo com os valores médios obtidos para $\mathrm{Cl}_{50} 0_{(120 h)}$ o percolado 28 da coluna de cinza de carvão apresentou o menor potencial para causar efeito tóxico à germinação das sementes de L. sativa, ao passo que os percolados 56 e 84 da mesma coluna de cinza de carvão apresentaram maior potencial tóxico à germinação das sementes.

Os valores médios de CENO e CEO para os percolados 28, 56 e 84 da coluna de cinza de carvão foram calculados tomando-se como base 0 comprimento das radículas da $L$. sativa por meio do programa Toxstat 3.5, conforme descrito em materiais e métodos, item 4.4.2. Os valores médios de CENO e CEO para estes percolados foram 12,5\% e 25\%, respectivamente. Isso indica que estes percolados com concentrações acima ou igual a $25 \%$ apresentam potencial para causar efeitos subletais sobre o desenvolvimento das radículas.

O índice de germinação (IG) foi calculado por meio da equação 1 descrita no capítulo de materiais e métodos no item 4.4.2., tomando-se como base tanto os dados de germinação das sementes quanto os de comprimento das radículas para os percolados 28, 56 e 84 da coluna de cinza de carvão. Nas FIG.16, FIG.17 e FIG.18 foram apresentados os valores obtidos para o índice de germinação (IG) dos percolados 28, 56 e 84, respectivamente. 


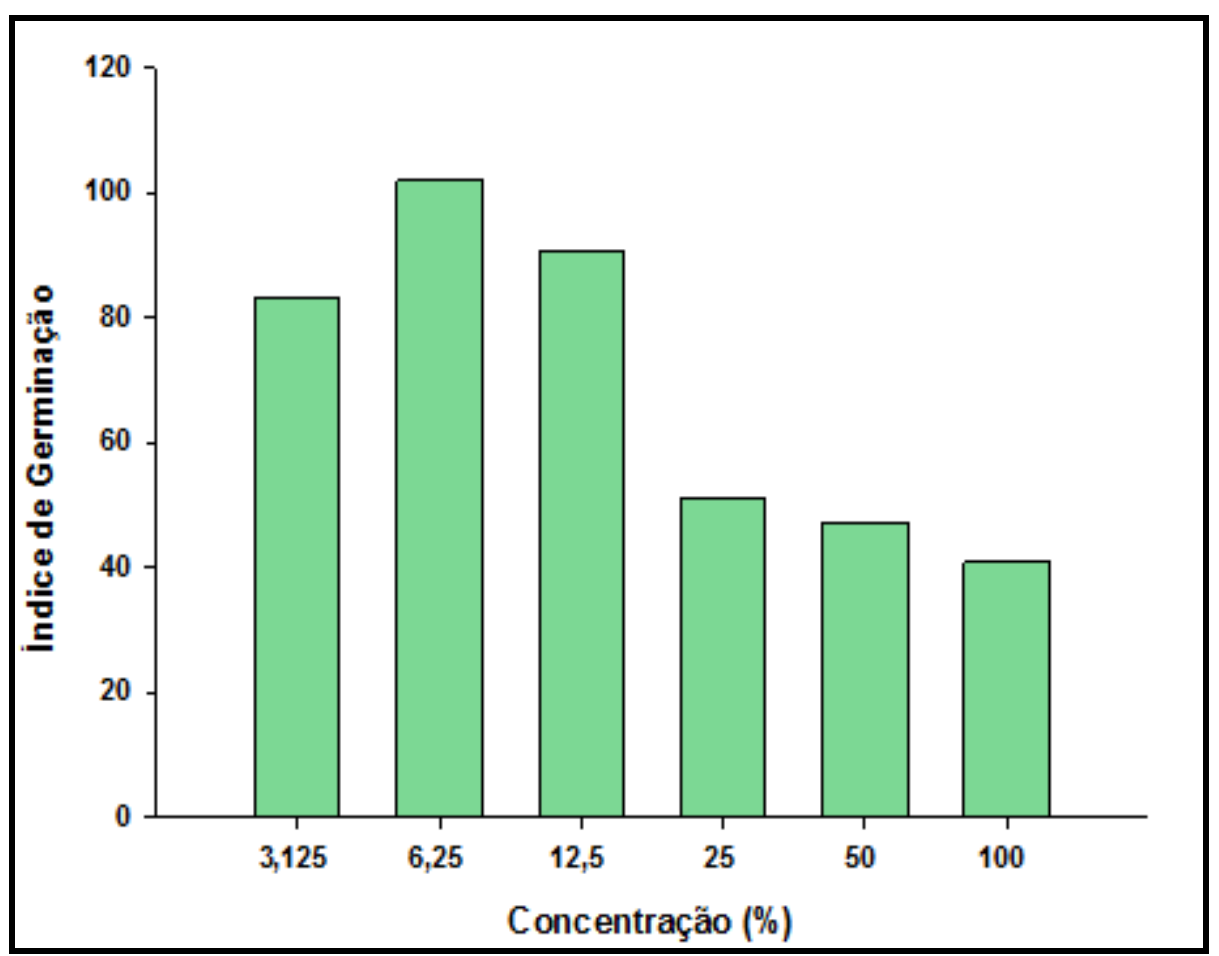

FIGURA 16 - Índice de geminação (IG) do percolado 28 da coluna de cinza de carvão

O percolado 28 da coluna de cinza de carvão (FIG.16) nas concentrações de 3,125, 6,25 e 12,5\% apresentou índices de germinação mais altos que variaram de 83,0 a 101,9. Por outro lado, nas concentrações de 25 a $100 \%$ do percolado foram observados os índices de germinação mais baixos, variando de 40,8 a 51,0 . 


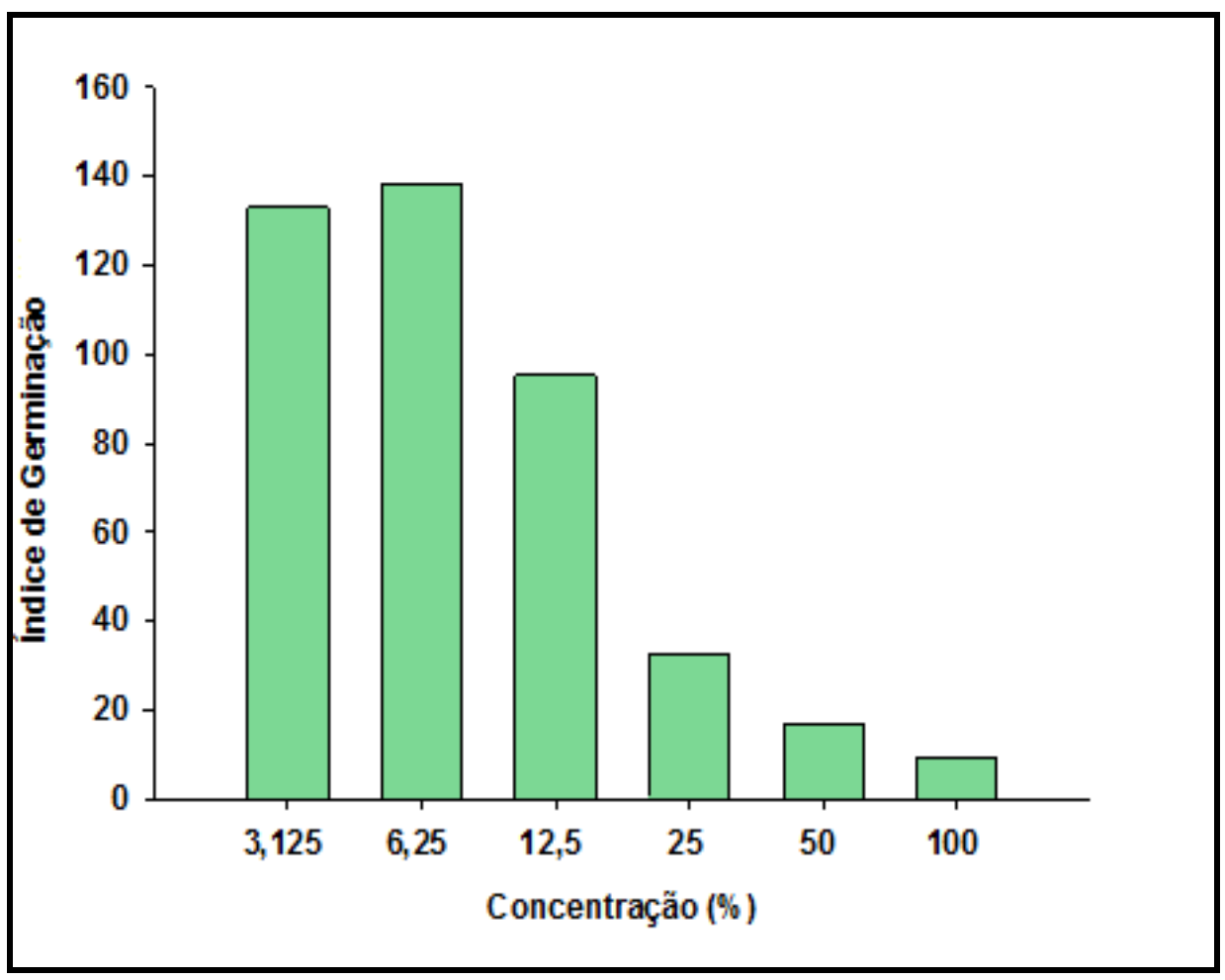

FIGURA 17 - Índice de geminação (IG) do percolado 56 da coluna de cinza de carvão

O percolado 56 da coluna de cinza de carvão (FIG.17) apresentou índices de germinação maiores nas concentrações de 3,125, 6,25 e 12,5\% que variaram de 95,3 a 137,9, ao passo que as concentrações de 25 a 100\% do mesmo percolado apresentaram índices de germinação mais baixos, os quais variaram entre 9,5 a 32,3 . 


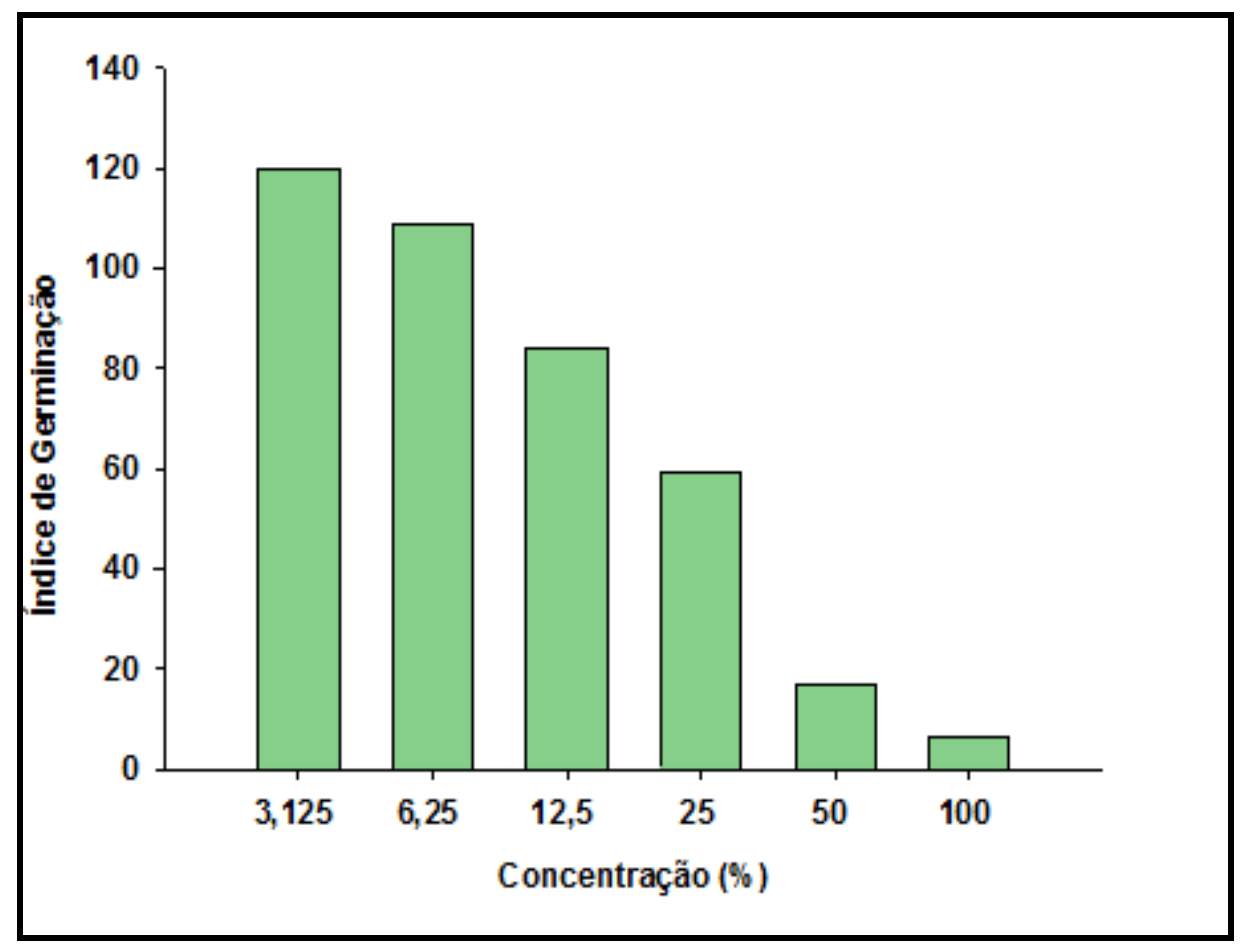

FIGURA 18 - Índice de geminação (IG) do percolado 84 da coluna de cinza de carvão

O percolado 84 da coluna de cinza de carvão (FIG.18) nas concentrações de $3,125,6,25$ e 12,5\% apresentou os maiores índices de germinação que variaram de 84,2 a 120,0 . Por outro lado, nas concentrações de 25, 50 e 100\% deste mesmo percolado foram observados os menores índices de germinação, os quais variaram de 6,7 a 59,0.

Os valores obtidos para o IG nos percolados 28 (FIG.16), 56 (FIG.17) e 84 (FIG.18) da coluna de cinza de carvão nas concentrações 3,125, 6,25 e $12,5 \%$ foram maiores que 80 . Isso mostra que tais percolados diluídos para as concentrações descritas anteriormente não apresentam potencial para causar danos sobre a germinação das sementes e desenvolvimento das radículas de $L$. sativa.

A diminuição do IG entre as concentrações 12,5\% e 25\% obsevada nos percolados 28 (FIG.16), 56 (FIG.17) e 84 (FIG.18) da coluna de cinza de carvão foi coerente com os valores de CENO $(12,5 \%)$ e CEO $(25 \%)$. 
Nas concentrações 50\% e $100 \%$ dos percolados da coluna de cinza de carvão os valores de IG foram 47,2 e 40,8 para o percolado 28 (FIG.16), 19,2 e 9,5 para o percolado 56 (FIG.17) e de 18,4 e 6,7 para o percolado 84 (FIG.18), respectivamente. Isso mostra que o percolado 28 apresentou os maiores valores de IG (47,2 e 40,8), ou seja, apresentou menor potencial para causar danos sobre a germinação do organismo teste $L$. sativa. Por outro lado, os percolados 56 e 84 que apresentaram os menores valores de IG (19,2 e 9,5 e 18,4 e 6,7) demonstraram um maior potencial para causar danos à germinação das sementes de L. sativa. Isso é coerente com os valores de $\mathrm{Cl}_{50}(120)$ para os percolados 28, 56 e 84 da coluna de cinza de carvão (FIG.15).

\subsubsection{Desenvolvimento das radículas de Lactuca sativa}

A média do comprimento das radículas das sementes germinadas nos percolados C, SPC e SCC e na água deionizada (controle negativo) foi determinada com os resultados obtidos nos ensaios preliminares e definitivos para avaliar o desenvolvimento das radículas. Na TAB.9 foram apresentadas as médias obtidas nos ensaios preliminares. 
TABELA 9 - Comprimento médio das radículas das sementes germinadas nos percolados C, SPC e SCC e na água deionizada obtida nos ensaios preliminares

\begin{tabular}{ccccccccc}
\hline & \multicolumn{7}{c}{ Comprimento das radículas (cm) } \\
\hline Percolado & \multicolumn{2}{c}{$\mathbf{C}$} & \multicolumn{2}{c}{$\mathbf{s P C}$} & $\mathbf{s C C}$ & \multicolumn{3}{c}{ Água deionizada } \\
\hline $\mathbf{2 8}$ & $\mathbf{m} \pm \mathbf{s}$ & $\mathbf{s r}(\%)$ & $\mathbf{m} \pm \mathbf{s}$ & $\mathbf{s r}(\%)$ & $\mathbf{m} \pm \mathbf{s}$ & $\mathbf{s r}(\%)$ & $\mathbf{m} \pm \mathbf{s}$ & $\mathbf{s r}(\%)$ \\
$\mathbf{5 6}$ & $1,5 \pm 0,4$ & 26,3 & $3,2 \pm 0,9$ & 29,1 & $2,5 \pm 0,7$ & 28,0 & $2,4 \pm 1,1$ & 44,7 \\
$\mathbf{8 4}$ & $1,2 \pm 0,3$ & 26,6 & $2,9 \pm 0,9$ & 31,7 & $2,3 \pm 0,6$ & 25,9 & $2,8 \pm 0,7$ & 23,2 \\
$\mathbf{1 1 2}$ & $1,0 \pm 0,6$ & 58,7 & $2,5 \pm 0,9$ & 36,3 & $2,3 \pm 1,4$ & 59,2 & $2,7 \pm 0,9$ & 32,2 \\
$\mathbf{1 4 0}$ & $1,5 \pm 0,4$ & 22,7 & $2,4 \pm 0,6$ & 29,9 & $2,6 \pm 0,5$ & 48,2 & $2,3 \pm 0,5$ & 22,3 \\
$\mathbf{1 6 8}$ & $1,8 \pm 0,4$ & 22,7 & $3,5 \pm 1,0$ & 20,9 & $3,0 \pm 1,4$ & 48,2 & $2,3 \pm 0,8$ & 32,3 \\
$\mathbf{1 9 6}$ & $1,8 \pm 0,4$ & 20,2 & $3,4 \pm 0,7$ & 22,4 & $2,6 \pm 0,5$ & 21,6 & $2,4 \pm 0,5$ & 19,2 \\
$\mathbf{2 2 4}$ & $1,6 \pm 0,3$ & 17,5 & $2,8 \pm 0,7$ & 29,8 & $2,7 \pm 0,5$ & 19,7 & $2,3 \pm 0,5$ & 22,2 \\
$\mathbf{2 5 2}$ & $1,8 \pm 0,4$ & 21,3 & $2,7 \pm 0,8$ & 29,2 & $2,4 \pm 0,8$ & 33,1 & $2,5 \pm 0,9$ & 37,4 \\
$\mathbf{2 8 0}$ & $1,3 \pm 0,4$ & 31,3 & $3,3 \pm 0,9$ & 26,3 & $3,5 \pm 0,6$ & 23,7 & $2,3 \pm 0,5$ & 22,2 \\
$\mathbf{3 0 8}$ & $1,5 \pm 0,6$ & 36,7 & $3,3 \pm 1,0$ & 29,5 & $2,9 \pm 0,8$ & 26,4 & $2,6 \pm 0,8$ & 29,7 \\
$\mathbf{3 3 6}$ & $1,3 \pm 0,4$ & 30,7 & $2,4 \pm 0,7$ & 27,2 & $2,7 \pm 0,7$ & 23,9 & $2,7 \pm 0,7$ & 25,5 \\
& $1,5 \pm 1,1$ & 72,3 & $3,4 \pm 0,5$ & 12,7 & $3,2 \pm 0,8$ & 25,6 & $2,8 \pm 0,7$ & 23,2 \\
\hline
\end{tabular}

ms: média \pm desvio padrão; sr: desvio padrão relativo

O valor médio obtido para o comprimento das radículas ao longo dos ensaios foi de $2,5 \mathrm{~cm}$ para a água deionizada e para os percolados C, SPC e SCC os valores médios obtidos foram de 1,5, 3,0 e 2,7cm, respectivamente. Esses valores indicam que houve uma diferença no desenvolvimento das radículas entre a água deionizada e os percolados. Para avaliar esta diferença foi realizado o teste t com um nível de significância de 0,05 . Os percolados $C$ e SPC apresentaram diferença significativa ao passo que o percolado SCC não, ou seja, somente os percolados C e SPC causaram uma alteração no comprimento das radículas das sementes de $L$. sativa.

A diferença significativa entre o percolado $\mathrm{C}$ e a água deionizada representa que este percolado apresentou potencial para causar efeitos adversos ao desenvolvimento das radículas das sementes de $L$. sativa, uma vez que a média do comprimento das radículas $(1,5 \mathrm{~cm})$ no percolado $C$ foi 
menor do que a média $(2,5 \mathrm{~cm})$ na água deionizada. Isto é coerente com os resultados de toxicidade do percolado $C$ obtidos para a germinação das sementes nos ensaios preliminares (TAB.8).

Por outro lado, também foi observada diferença significativa no comprimento das radículas entre os percolados da coluna de solo de Piracicaba com cinza de carvão (percolado SPC) e a água deionizada, mas a média do comprimento das radículas $(3,0 \mathrm{~cm})$ no percolado SPC foi maior do que a média $(2,5 \mathrm{~cm})$ na água deionizada.

Uma vez que os parâmetros químicos dos percolados podem estar relacionados com as alterações dos comprimentos das radículas das sementes de $L$. sativa os valores de concentração dos elementos (FIG.19 e FIG.20), ânions (FIG.21), carbono (FIG.22) e pH (FIG.23) dos percolados das colunas de solos SCC e SPC obtidos nos estudos de Lange (2012) e Silva (2013), respectivamente, foram apresentados. 


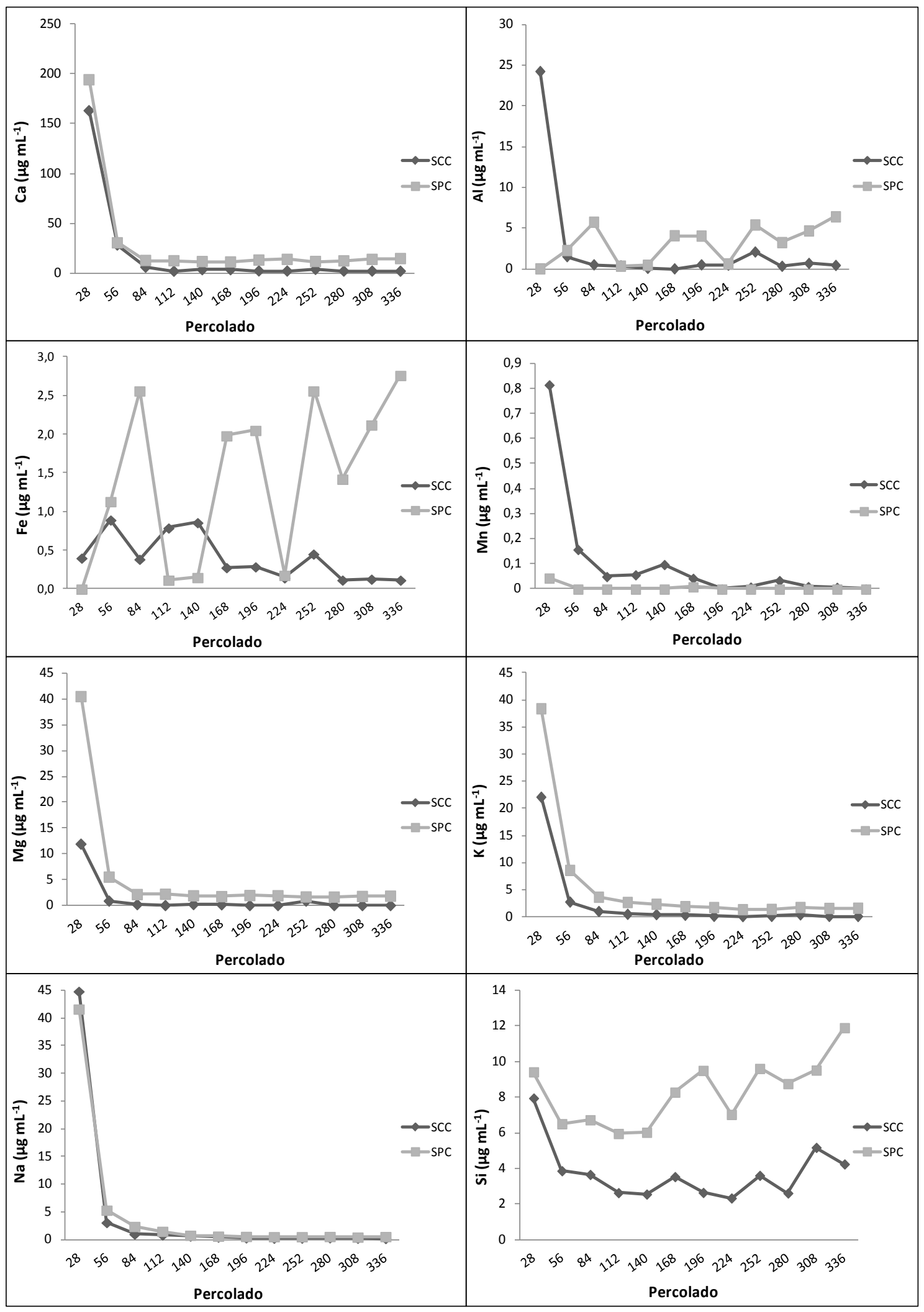

FIGURA 19 - Concentração dos elementos majoritários nos percolados SCC e SPC

Fonte: adaptada de Lange (2012) e Silva (2013) 
A concentração dos elementos $\mathrm{Ca}, \mathrm{K}$ e $\mathrm{Na}$ pouco variou entre os percolados das colunas SCC e SPC (FIG.19). A concentração do Mg no percolado 28 da coluna SPC foi maior que a da coluna SCC (FIG.19) e a do Mn foi maior nos percolados 28 e 56 da coluna SPC. Isso mostra que os elementos essenciais Ca, K, Mn e Mg para o desenvolvimento das plantas (Faquim, 1997) provavelmente não influenciaram no maior tamanho das radículas nos percolados SPC em relação aos percolados SCC.

A maior parte da concentração dos elementos Al e $\mathrm{Fe}$ nos percolados SPC (FIG.19) foi maior que a dos percolados SCC. A absosrção do Al é considerada benéfica para planta, entretanto existem evidências de que este elemento em dadas concentrações passa a ser tóxico (Furlani, 2004) e o Fe é essencial para o desenvolvimento da planta (Faquin, 1997). A concentração do Si nos percolados SPC foi maior que a nos percolados SCC (FIG.19) ao longo dos 336 dias de percolação das colunas. A absorção do Si é considerada benéfica para a planta, pois para esta absorção é atribuida uma maior resistência a estresses bióticos e abióticos, tais como, deficiência hidríca, doenças causadas por fungos e inibição da absorção de outros elementos potencialmente tóxicos a planta (EMBRAPA 2013). Sendo assim, os elementos $\mathrm{Al}$, Fe e Si poderiam ter contribuído para o maior tamanho das radículas nos percolados SPC em relação aos percolados SCC. 


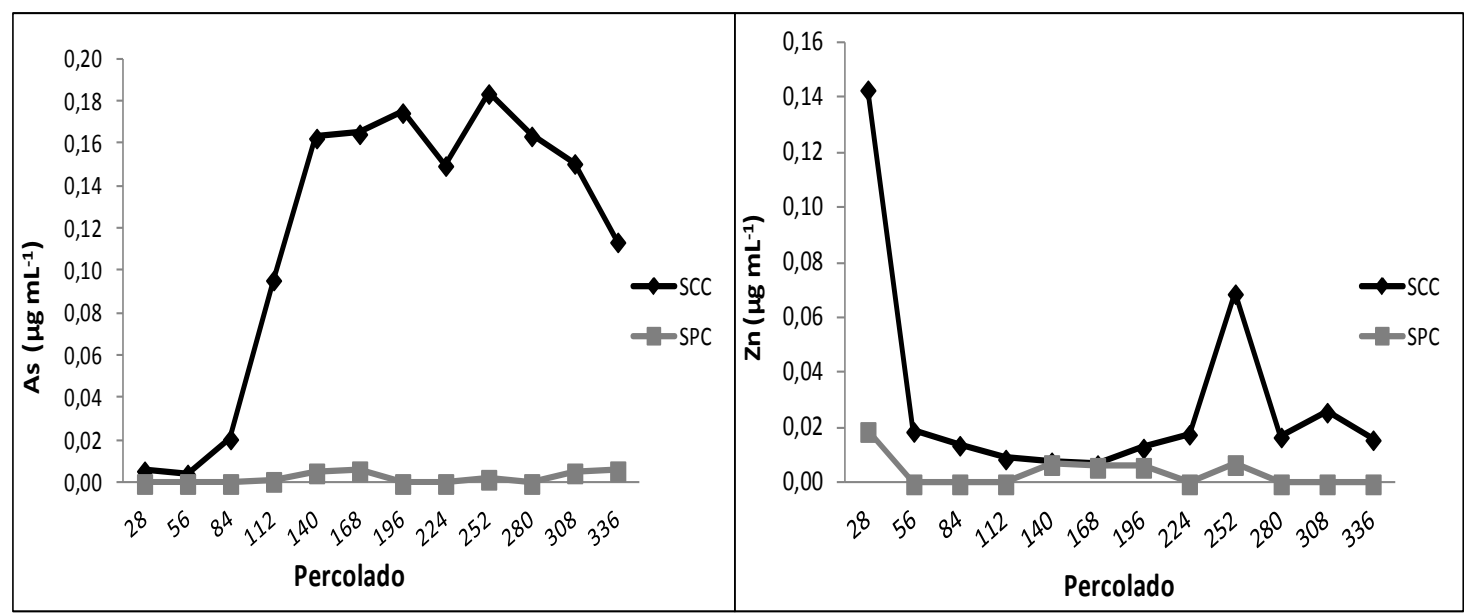

FIGURA 20 - Concentração dos elementos As e Zn nos percolados SCC e SPC

Fonte: adaptada de Lange (2012) e Silva (2013)

A concentração do As foi maior nos percolados SCC do que nos percolados SPC e a concentração de Zn foi maior nos percolados 28 e 252 da coluna SCC do que nos percolados SPC. De um modo geral o As é considerado um elemento tóxico para a planta (McBride, 1994) e o Zn essencial para o desenvolvimento da planta, mas pode ser tóxico dependendo de sua concentração (Faquin, 1997; Furlani, 2004). Como a concentração do As foi maior nos percolados SCC e a concentração de Zn foi baixa (FIG.20) e variou pouco nos percolados SCC e SPC ao longo de 336 dias de percolação das colunas, provavelmente estes elementos, As e Zn, não contribuíram para o maior tamanho das radículas nos percolados SPC. 


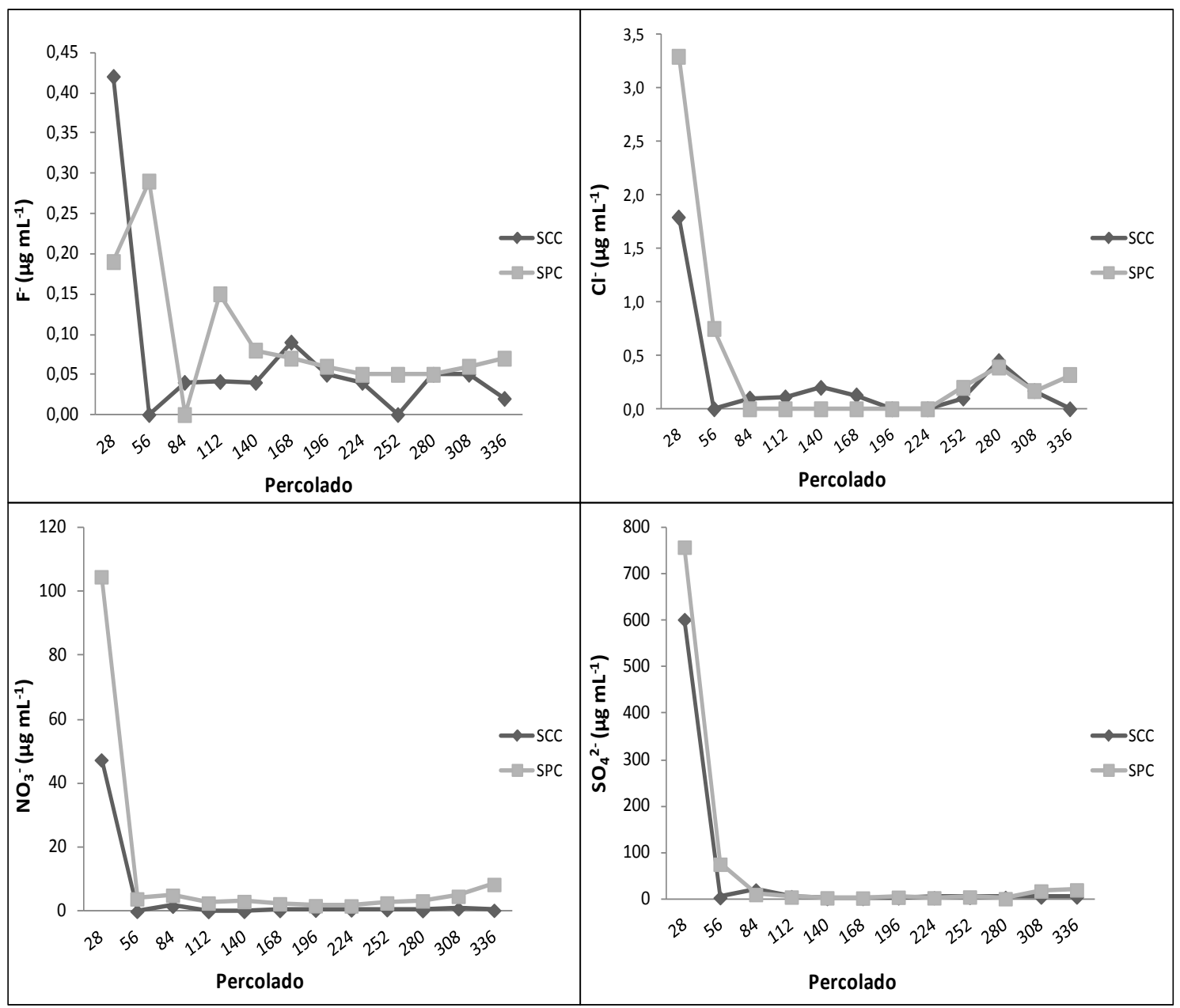

FIGURA 21 - Concentração dos ânions nos percolados SCC e SPC

Fonte: adaptada de Lange (2012) e Silva (2013)

De um modo geral, a concentração dos ânions fluoreto, cloreto, sulfato e nitrato variou pouco ao longo de 336 dias de percolação das colunas (FIG.21). Isso mostra que provavelmente esses ânions não contribuíram para o maior tamanho das radículas nos percolados SPC em relação aos percolados SCC. 


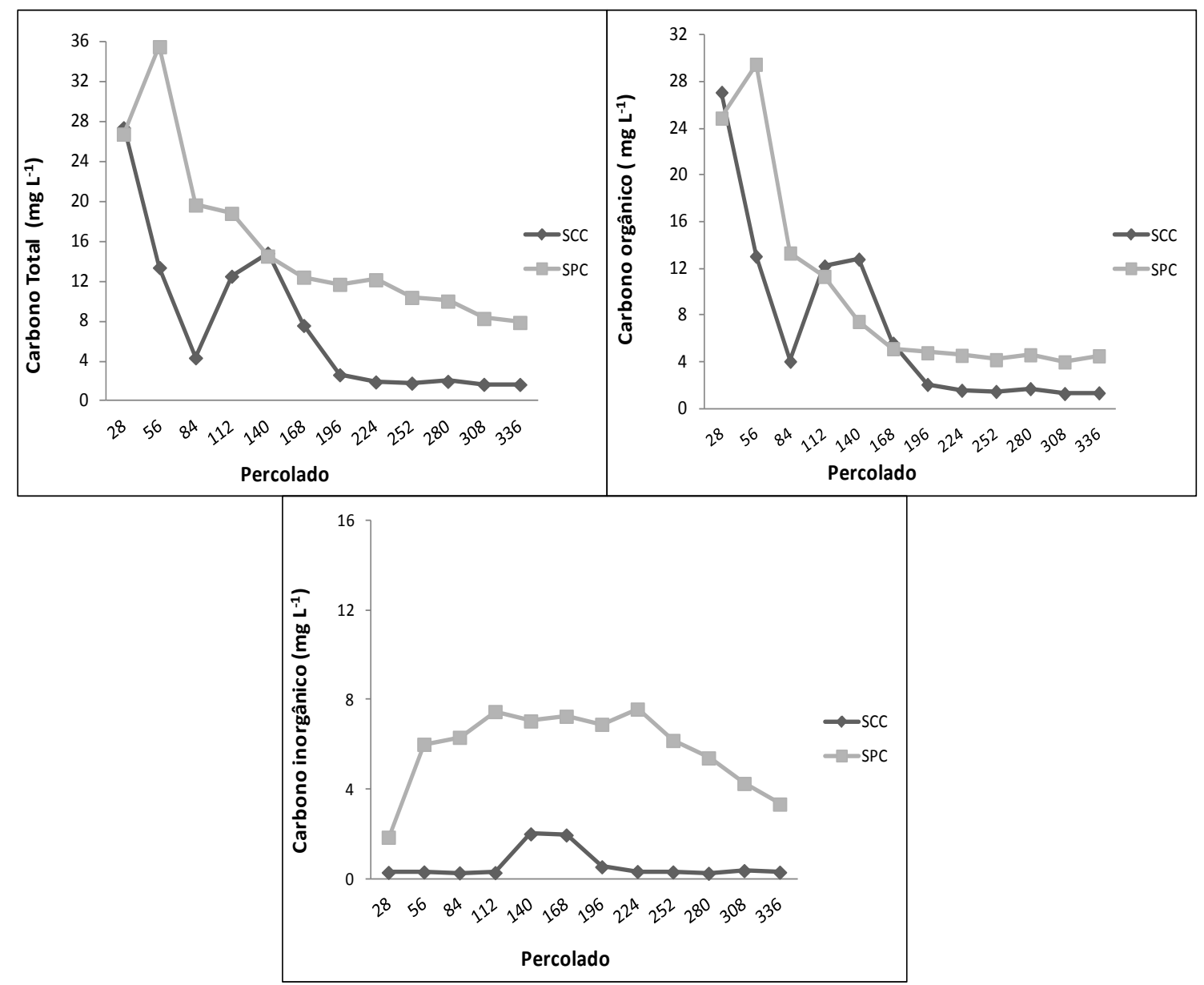

FIGURA 22 - Concentração de carbono orgânico, carbono inorgânico e carbono total nos percolados SCC e SPC

Fonte: adaptada de Lange (2012) e Silva (2013)

De acordo com a FIG.22 a concentração de carbono total e carbono inorgânico no percolado SPC foi maior ao longo dos 336 dias de percolação das colunas quando comparado com o percolado SCC. De um modo geral, a concentração do carbono orgânico também foi maior nos percolados SPC em relação aos percolados SCC, mas menos representativa que a concentração do carbono total inorgânico. De acordo com Ferreira (2007), a L. sativa é uma planta que em condições ideais requer solos ricos em matéria orgânica e nutrientes para seu desenvolvimento. 


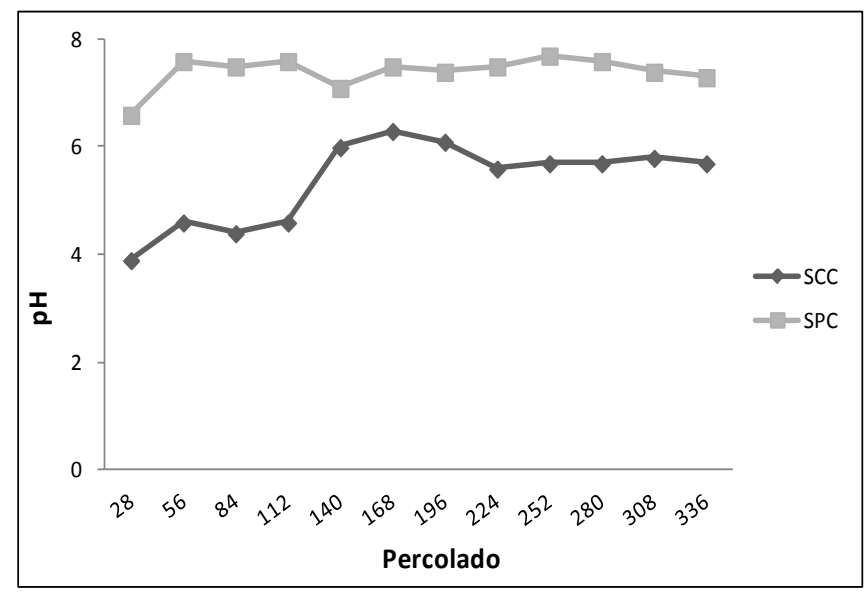

FIGURA 23 - pH dos percolados SPC e SCC

Fonte: adaptada de Lange (2012) e Silva (2013)

O valor do $\mathrm{pH}$ nos percolados SPC (de 6,6 a 7,7 ) foi maior que nos percolados SCC (de 3,9 a 6,3) (FIG.23). Segundo a Environmental Canada (2005), a faixa ideal de pH para a germinação de sementes $L$. sativa é de 6,0 a 8,0. Isso mostra que os valores de $\mathrm{pH}$ dos percolados SPC estão dentro da faixa ideal de pH para a germinação das sementes e isso poderia indicar que os percolados SPC favorecem o crescimento do tamanho das radículas.

O estímulo ao desenvolvimento das radículas de $L$. sativa observado no percolado SPC foi coerente com o observado no estudo realizado por Cook et al. (2002) no qual o crescimento de algas $S$. capricornutum foi estimulado nos lixiviados $(\mathrm{pH}$ entre 7,27 e 8,19$)$ de solo contaminado com elementos tóxicos e hidrocarbonetos.

O desvio padrão relativo observado para os comprimentos das radículas nos percolados $\mathrm{C}, \mathrm{SPC}, \mathrm{SCC}$ e na água deionizada (TAB.9) apresentou-se relativamente alto variando de 17,3 a $72,3 \%$ nos percolados $C$, 12,7 a $36,3 \%$ nos percolados SPC, 19,7 a 59,2\% nos percolados SCC e 19,2 a $44,7 \%$ na água deionizada demonstrando a não homogeneidade dos dados. Mas esta variabilidade foi semelhante entre os percolados e a água deionizada.

As médias do comprimento das radículas das sementes germinadas nos percolados 28,56 e 84 da coluna de cinza de carvão e na água deionizada 
(controle negativo) também foram determinadas nos ensaios definitivos para avaliar o desenvolvimento das radículas. Na TAB.10 foram apresentadas as médias do comprimento das radículas obtidas nos ensaios definitivos.

TABELA 10 - Comprimento médio das radículas das sementes germinadas nos percolados 28, 56 e 84 da coluna de cinza de carvão e na água deionizada obtida nos ensaios definitivos

\begin{tabular}{|c|c|c|c|c|c|c|c|}
\hline & \multicolumn{7}{|c|}{ Comprimento das radículas $(\mathrm{cm})$} \\
\hline & & $\mathbf{m} \pm \mathbf{s}$ & sr (\%) & $m \pm s$ & $\operatorname{sr}(\%)$ & $m \pm s$ & $\operatorname{sr}(\%)$ \\
\hline \multirow{8}{*}{ 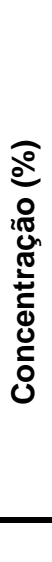 } & Percolado & \multicolumn{2}{|c|}{28} & \multicolumn{2}{|c|}{56} & \multicolumn{2}{|c|}{84} \\
\hline & 3,125 & $2,0 \pm 0,5$ & 25,06 & $3,1 \pm 0,9$ & 29,35 & $3,4 \pm 0,8$ & 22,38 \\
\hline & 6,25 & $2,4 \pm 0,6$ & 23,37 & $3,1 \pm 0,7$ & 22,61 & $3,0 \pm 0,9$ & 29,70 \\
\hline & 12,5 & $2,2 \pm 0,5$ & 22,31 & $2,5 \pm 0,7$ & 27,97 & $2,8 \pm 0,8$ & 27,82 \\
\hline & 25 & $1,7 \pm 0,4$ & 25,40 & $1,3 \pm 0,4$ & 27,48 & $2,0 \pm 0,6$ & 31,48 \\
\hline & 50 & $1,6 \pm 0,5$ & 30,32 & $1,2 \pm 0,4$ & 38,26 & $1,4 \pm 0,3$ & 23,71 \\
\hline & 100 & $1,9 \pm 0,6$ & 30,11 & $1,0 \pm 0,2$ & 19,08 & $1,1 \pm 0,2$ & 19,31 \\
\hline & Água deionizada & $2,3 \pm 0,5$ & 20,94 & $2,2 \pm 0,6$ & 27,52 & $2,8 \pm 0,7$ & 25,59 \\
\hline
\end{tabular}

$\mathrm{m} \pm \mathrm{s}$ : média \pm desvio padrão; sr: desvio padrão relativo

Os valores do comprimento das radículas dos percolados 28, 56 e 84 da coluna de cinza de carvão (TAB.10) foram comparados com os da água deionizada (controle negativo) por meio do teste t com um nível de significância de 0,05 . Foram observadas diferenças significativas entre os percolados 28, 56 e 84 nas concentrações iguais ou acima de 25\% e a água deionizada. Isso é coerente com o valor de CEO (25\%) descrito no item 5.1.1.2, ou seja, estes percolados nas concentrações iguais ou acima de 25\% apresentaram potencial para causar efeito sobre o desenvolvimento das radículas durante a exposição.

Para o percolado 56 da coluna de cinza de carvão nas concentrações $3,125 \%$ e $6,25 \%$ também foram observadas diferenças significativas quando comparado com a água deionizada, mostrando que as radículas nestes percolados cresceram mais que as na água deionizada. 


\subsubsection{Ensaios de toxicidade aguda com Daphnia similis}

Os ensaios de toxicidade aguda com $D$. similis foram justificados no presente trabalho com base no texto descrito na revisão de literatura (itens 3.4.2, 3.4.4 e 3.5) por serem recomendados como ensaios exploratórios para avaliar lixiviados de solos e lixiviados de resíduos, padronizados no Brasil desde 2004 de acordo com a norma da ABNT NBR 12713 e por estudos que empregam Daphnia para a avaliação de toxicidade aguda em lixiviados de solo.

Os ensaios de toxicidade aguda com $D$. similis foram realizados para os percolados C, SPC e SCC conforme descrito no item 4.3.

\subsubsection{Ensaios preliminares}

Os ensaios preliminares foram realizados para determinar a toxicidade potencial dos percolados puros (concentração 100\%) das colunas de cinza de carvão e de solos com cinza de carvão.

Para avaliar previamente a toxicidade ou não dos percolados C, SCC e SPC os percolados puros das colunas foram comparados à água para 0 cultivo de $D$. similis (controle negativo) por meio do teste t de Student com nível de significância 0,05, conforme descrito no item 4.4.1. Na TAB.11 foram apresentados os resultados obtidos nos ensaios preliminares de toxicidade aguda dos percolados C, SCC e SPC aos organismos teste D. similis. 
TABELA 11 - Toxicidade dos percolados C, SCC e SPC (concentração 100\%) obtida nos ensaios preliminares utilizando como organismos teste $D$. similis

\begin{tabular}{ccccccccccccc}
\hline Percolado & 28 & 56 & 84 & 112 & 140 & 168 & 196 & 224 & 252 & 280 & 308 & 336 \\
\hline C & Tóxico & Tóxico & Tóxico & Tóxico & NT & Tóxico & NT & NT & NT & NT & NT & NT \\
SPC & NT & NT & NT & NT & NT & NT & NT & NT & NT & NT & NT & NT \\
SCC & NT & NT & NT & NT & NT & NT & NT & NT & NT & NT & NT & NT
\end{tabular}

Teste t de Student $a<0,05$; Tóxico - Toxicidade aguda; NT - Não tóxico; C: percolado da coluna de cinza de carvão; SPC: percolado da coluna de solo de Piracicaba com cinza de carvão; SCC: percolado da coluna de solo de Conchal/Araras com cinza de carvão

Nos ensaios preliminares de toxicidade aguda foram observados efeitos tóxicos a mobilidade e/ou sobrevivência dos organismos teste expostos aos percolados 28, 56, 84, 112 e 168 da coluna de cinza de carvão (percolado C). Isso indica que as substâncias tóxicas presentes na cinza de carvão foram mais lixiviadas pela coluna de cinza de carvão na primeira metade do tempo de percolação.

Os percolados das colunas de solo com cinza de carvão SPC e SCC (TAB.11) não apresentaram potencial para causar efeitos tóxicos de imobilidade e/ou mortalidade dos organismos teste nos ensaios preliminares. Estes resultados indicam que as substâncias tóxicas lixiviadas da cinza de carvão foram retidas no solo das colunas. Assim como já foi descrito anteriormente no item 5.1.1.1, o fato dos percolados das colunas de solo com cinza de carvão não apresentarem potencial para causar toxicidade aguda a estes organismos não indica necessariamente que a concentração das substâncias presentes nestes percolados não possa causar toxicidade crônica a estes organismos, mas no presente trabalho a toxicidade crônica não foi avaliada para estes organismos.

Os resultados dos percolados das colunas de solo SPC e SCC obtidos no presente trabalho (TAB.11) foram coerentes aos observados no estudo realizado por Chapman et al. (2010) no qual os percolados de diferentes 
tipos de solos contaminados com elementos tóxicos não apresentaram efeitos adversos aos organismos teste $D$. magna quando expostos a estes percolados.

\subsubsection{Ensaios definitivos}

Os ensaios definitivos de toxicidade aguda com $D$. similis foram realizados com os percolados que apresentaram potencial para causar efeitos tóxicos aos organismos teste (percolados da coluna de cinza de carvão 28, 56, 84, 112 e 168) nos ensaios preliminares descrito no item 5.1.2.1.

A concentração efetiva, $\mathrm{CE} 50_{(48 \mathrm{~h})}$, foi calculada tomando-se como base os dados de imobilidade e/ou mortalidade dos organismos teste por meio do método estatístico Trimmed Spearman-Karber como descrito no capítulo de materiais e métodos, no item 4.4.2. Na FIG.24 foram apresentados os valores obtidos para CE50 $(48 \mathrm{~h})$ dos percolados $28,56,84,112$ e 168 da coluna de cinza de carvão.

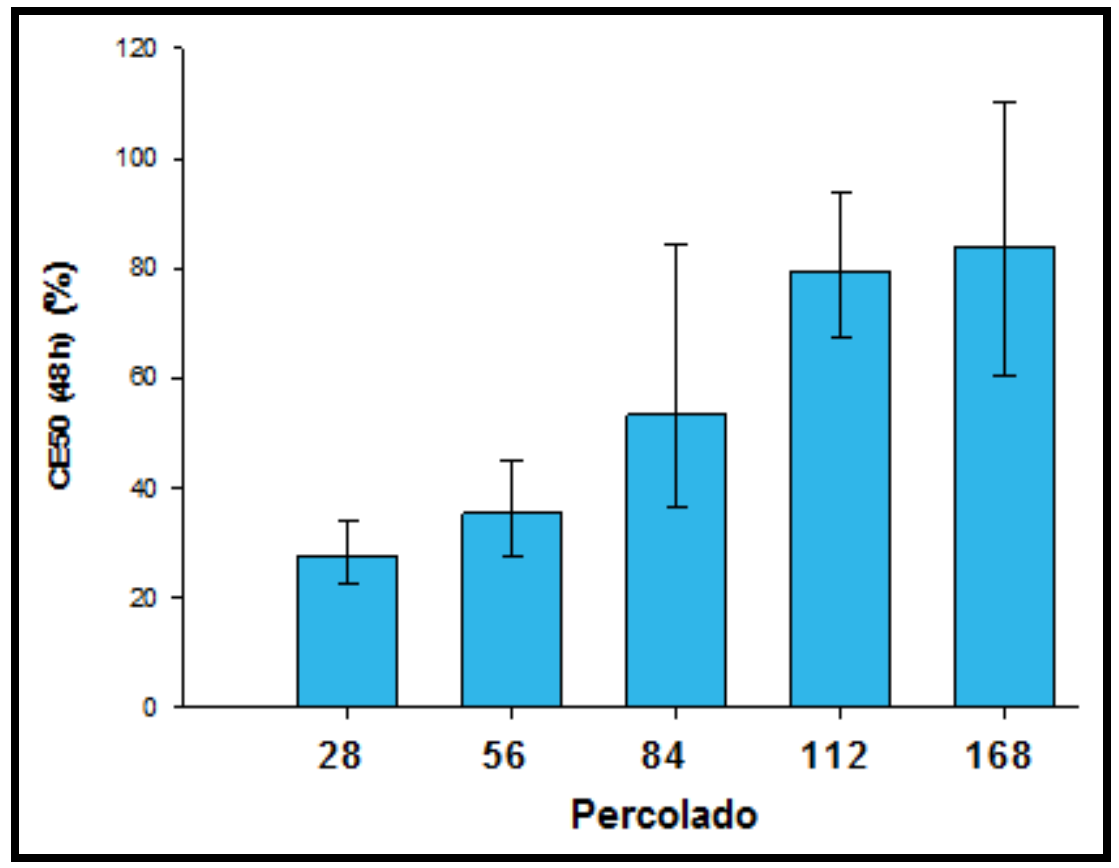

FIGURA 24 - CE50(48h) dos percolados da coluna de cinza de carvão utilizando como organismos teste $D$. similis $\mapsto$ : intervalo de confiança 
Esses valores são aceitáveis uma vez que a carta controle estabelecida nos ensaios de toxicidade aguda com $D$. similis (Apêndice $B$ ) foi satisfatória, pois os valores de $\mathrm{CE} 5 \mathrm{O}_{(48 \mathrm{~h})}$ da carta apresentaram-se dentro de uma faixa considerada aceitável.

Foram observados para os percolados 28 e 56 da coluna de cinza de carvão os menores valores de $\mathrm{CE50}_{(48 \mathrm{~h})}$, que foram 25,6 e 35,3\%, respectivamente (FIG.24) quando comparados com os dos percolados 84, 112 e 168 , que apresentaram valores de $55,3,79,4$ e $84,1 \%$, respectivamente. Os resultados indicam que os percolados 28 e 56 da coluna de cinza de carvão apresentaram maior potencial tóxico.

Na FIG.25 foram apresentados os valores de concentração dos elementos nos percolados da coluna de cinza de carvão (percolado C) obtidos no estudo de Lange (2012). 


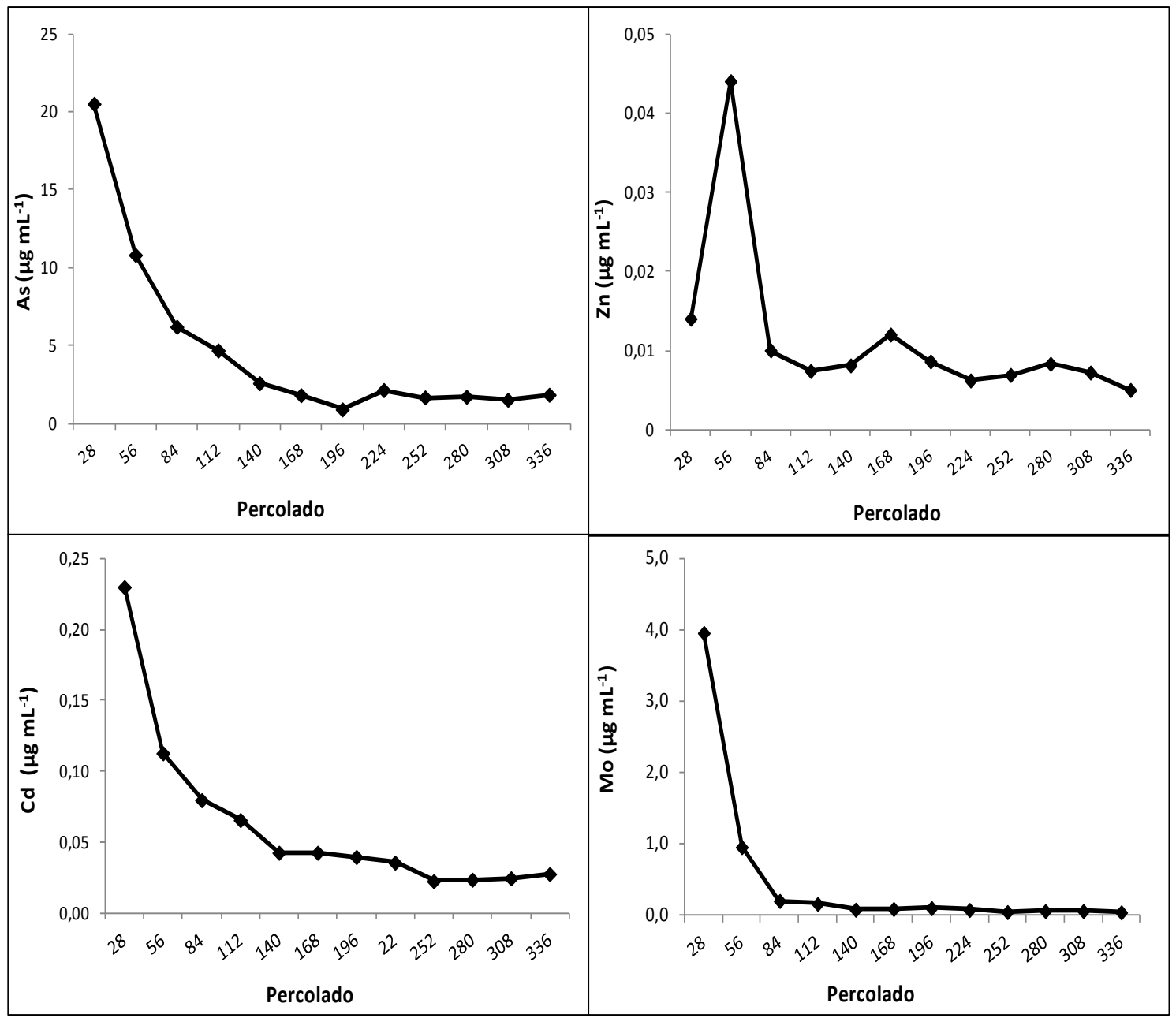

FIGURA 25 - Concentração dos elementos As, Zn, Cd e Mo no percolado C Fonte: adaptada de Lange (2012)

A concentração dos elementos As, Cd e Mo, que são elementos considerados tóxicos, foi maior nos percolados 28 e 56 da coluna de cinza de carvão. Esse resultado foi coerente com o menor CE50(48h) nos percolados $28 \mathrm{e}$ 56 , ou seja, foi coerente com o maior efeito tóxico.

\subsection{Coeficiente de correlação entre os valores obtidos para $\mathrm{Cl}^{50_{(120 h)}} \mathrm{e}$} CE50 (48h) e os parâmetros químicos dos percolados da coluna de cinza de carvão

Para avaliar a relação entre os valores obtidos para $\mathrm{Cl}^{5} 0_{(120 h)}$ (FIG.15) e CE50 (48h) $(F I G .24)$ com os parâmetros químicos (concentração dos elementos, ânions e carbono, pH e condutividade elétrica) dos percolados 28 , 
56 e 84 da coluna de cinza de carvão foi determinado o coeficiente de correlação de Pearson ( $r$ ), uma vez que os dados analisados apresentaram normalidade, com um nível de significância 0,05. Na TAB.12 foram apresentados os valores obtidos de $\mathrm{r}$.

TABELA 12 - Coeficiente de correlação (r) entre $\mathrm{Cl}_{50} 0_{(120 h)}$ e $\mathrm{CE} 50_{(48 \mathrm{~h})}$ e os parâmetros químicos dos percolados da coluna de cinza de carvão

\begin{tabular}{|c|c|c|}
\hline Parâmetro & $\mathrm{Cl} 0_{(12 \mathrm{Oh})}$ & CE50 $_{(48 \mathrm{~h})}$ \\
\hline Período de percolação (dias) & $-0,840$ & 0,948 \\
\hline As $\left(\mathrm{mg} \mathrm{L}^{-1}\right)$ & 0,932 & $-0,908$ \\
\hline $\mathrm{Cd}\left(\mathrm{mg} \mathrm{L}^{-1}\right)$ & 0,966 & $-0,864$ \\
\hline Mo $\left(\mathrm{mg} \mathrm{L}^{-1}\right)$ & 0,971 & $-0,780$ \\
\hline $\mathrm{Zn}\left(\mathrm{mg} \mathrm{L}^{-1}\right)$ & $-0,448$ & $-0,531$ \\
\hline $\mathrm{Na}\left(\mathrm{mg} \mathrm{L}^{-1}\right)$ & 0,993 & $-0,705$ \\
\hline$K\left(\mathrm{mg} \mathrm{L}^{-1}\right)$ & 0,992 & 0,714 \\
\hline $\mathrm{Ca}\left(\mathrm{mg} \mathrm{L}^{-1}\right)$ & 0,993 & $-0,711$ \\
\hline$M g\left(\mathrm{mg} \mathrm{L}^{-1}\right)$ & 0,995 & $-0,691$ \\
\hline Si $\left(\mathrm{mg} \mathrm{L}^{-1}\right)$ & 0,827 & $-0,354$ \\
\hline Sulfato $\left(\mathrm{mg} \mathrm{L}^{-1}\right)$ & 0,997 & $-0,684$ \\
\hline Nitrato $\left(\mathrm{mg} \mathrm{L}^{-1}\right)$ & 0,685 & $-0,469$ \\
\hline Fluoreto (mg L ${ }^{-1}$ ) & 0,004 & $-0,917$ \\
\hline Cloreto $\left(\mathrm{mg} \mathrm{L}^{-1}\right)$ & 0,902 & $-0,666$ \\
\hline $\mathrm{pH}$ & $-0,997$ & $-0,028$ \\
\hline Condutividade elétrica $\left(\mu \mathrm{S} \mathrm{cm}^{-1}\right)$ & 0,992 & $-0,723$ \\
\hline Carbono total ( $\left.\mathrm{mg} \mathrm{L}^{-1}\right)$ & 0,659 & $-0,903$ \\
\hline Carbono orgânico dissolvido $\left(\mathrm{mg} \mathrm{L}^{-1}\right)$ & 0,772 & $-0,866$ \\
\hline Carbono inorgânico dissolvido (mg L $\left.{ }^{-1}\right)$ & $-0,324$ & $-0,788$ \\
\hline
\end{tabular}

Os números em azul e vermelho são correlações significativas positivas e negativas, respectivamente.

Os valores de coeficiente de correlação ( $r$ ) foram considerados significativos quando foram acima do valor crítico $(0,95)$ para $n=3$ e $(0,87)$ para $n=5$ para um nível de significância 0,05, de acordo com Larson et al. (2011).

Foram observados coeficientes de correlação positiva entre os valores obtidos para $\mathrm{Cl}^{50} 0_{(120 h)}$ e as concentrações dos elementos $\mathrm{Na}(0,993), \mathrm{K}$ 
$(0,992)$, Ca $(0,993), M g(0,995), M o(0,971)$, indicando que essas variáveis são diretamente proporcionais, ou seja, nas condições de estudo quanto maior foi o valor de $\mathrm{Cl} \mathrm{0}_{(120 \mathrm{~h})}$ nos percolados 28,56 e 84 da coluna de cinza de carvão (FIG.15) maior foi a concentração destes elementos (FIG.25 e FIG.26). Isso mostra que os macronutrientes $\mathrm{K}, \mathrm{Ca}$ e $\mathrm{Mg}$, o micronutriente Mo e o elemento benéfico $\mathrm{Na}$ são essenciais para a germinação e desenvolvimento das sementes de $L$. sativa.

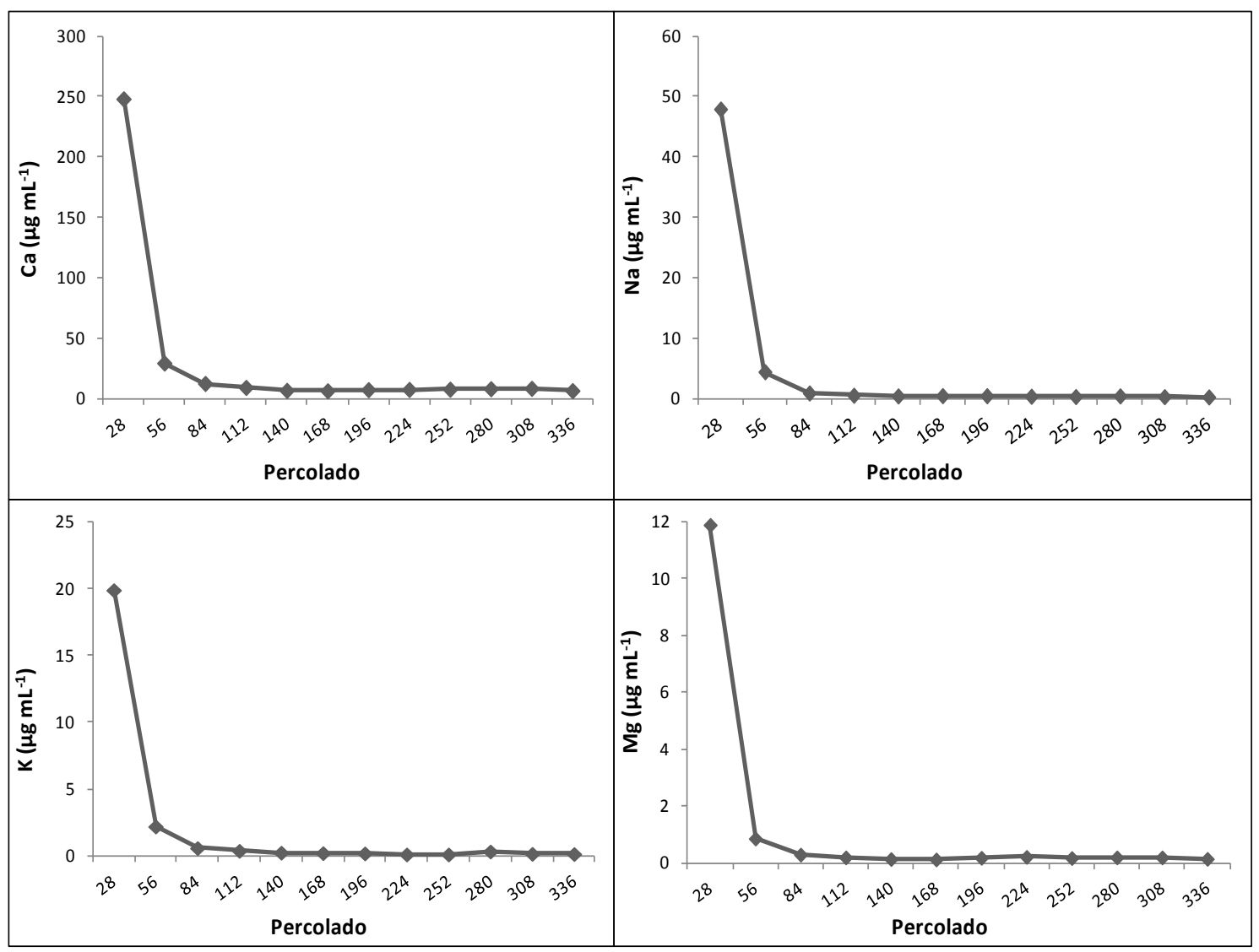

FIGURA 26 - Concentração dos elementos $\mathrm{Na}, \mathrm{Ca}, \mathrm{K}$ e Mg no percolado C Fonte: adaptada de Lange (2012)

O Cd que é considerado um elemento tóxico para as plantas também apresentou uma correlação positiva $(0,966)$ com os valores de $\mathrm{Cl} 0_{(120 h)}$. No percolado 28 o valor de $\mathrm{Cl}_{(120 h)}$ (FIG.15) e a concentração dos elementos essenciais (FIG.26) foram maiores que nos percolados 56 e 84, e os elementos essenciais poderiam prevalecer na absorção da planta por estarem em maior concentração no percolado quando comparado com o $\mathrm{Cd}$. Por outro 
lado, nos percolados 56 e 84 a concentração dos elementos essenciais, $\mathrm{Na}, \mathrm{K}$, Ca e Mg, diminuíram podendo favorecer a absorção do Cd e assim aumentar o efeito tóxico na planta.

Foram observados também coeficientes de correlação positiva entre os valores obtidos para $\mathrm{Cl}^{50_{(120 h)}}$ e a concentração do ânion sulfato $(0,997)$, o que mostra que quanto maior o valor de $\mathrm{Cl}_{50}(120 \mathrm{~h})$ nos percolados 28,56 e 84 da coluna de cinza de carvão (FIG.15) maior o valor de concentração de sulfato (FIG.27). Isso sugere que o sulfato foi um íon importante na germinação e desenvolvimento das sementes de $L$. sativa.

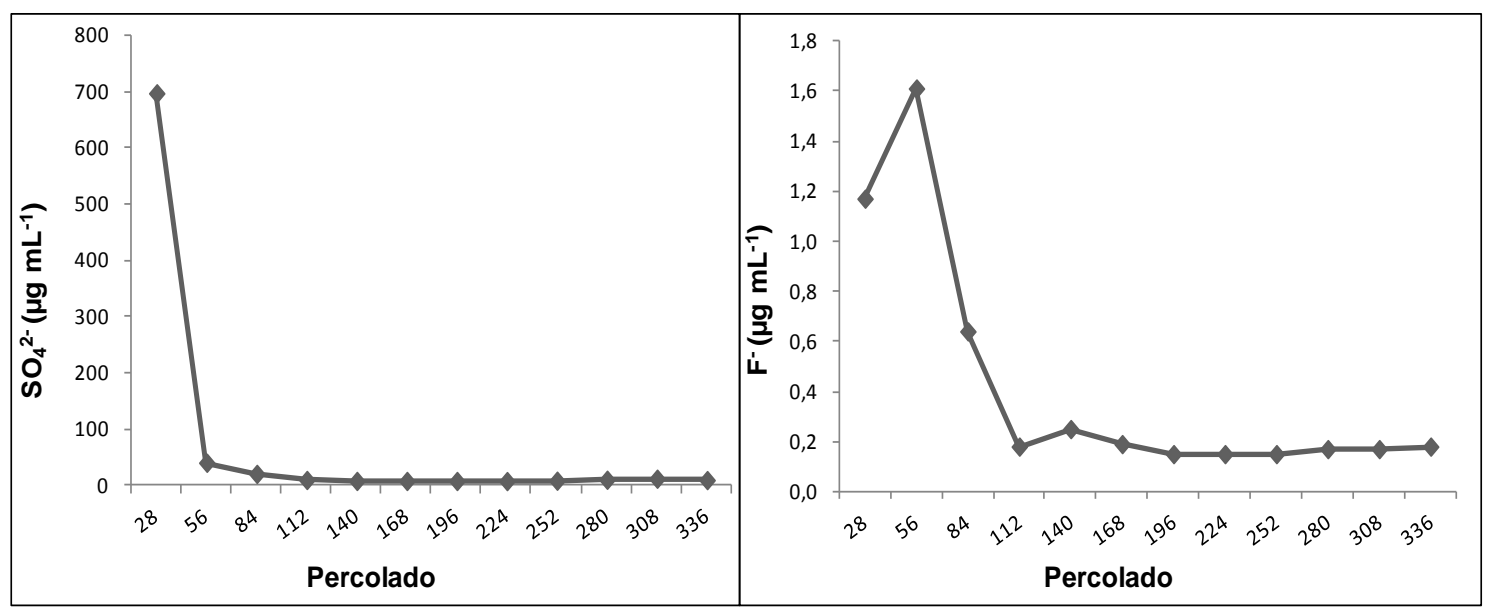

FIGURA 27 - Concentração dos ânions no percolado C Fonte: adaptada de Lange (2012)

A condutividade elétrica também apresentou um coeficiente de correlação positiva $(0,992)$ com os valores de $\mathrm{Cl}^{5} 0_{(120 h)}$. Essa correlação é coerente com as dos elementos essenciais $\mathrm{Na}, \mathrm{K}, \mathrm{Ca}, \mathrm{Mg}$ e $\mathrm{Mo}$ e do $\mathrm{SO}_{4}{ }^{2-}$ uma vez que a condutividade elétrica indica a quantidade de íons presentes nos percolados.

Foi observado coeficiente de correlação negativa apenas entre os valores obtidos para $\mathrm{Cl}_{50} \mathrm{O}_{(120 \mathrm{~h})}$ e $\mathrm{pH}$ dos percolados $(-0,997)$, indicando que essas variáveis são inversamente proporcionais, ou seja, nas condições de estudo quanto maior foi o valor de $\mathrm{Cl}_{50}(120 \mathrm{~h})$ nos percolados 28,56 e 84 da coluna de cinza de carvão (FIG.15) menor foi o valor obtido para o pH (FIG.28). 
Embora o pH dos percolados tenha apresentado uma correlação com a $\mathrm{Cl} 5_{(120 h)}$, provavelmente o $\mathrm{pH}$ não influenciou nos efeitos tóxicos observados para a germinação das radículas de $L$. sativa, pois, segundo a Environmental Canada (2005), a faixa ideal de pH para a germinação de sementes $L$. sativa é de 6,0 a 8,0, e o pH dos percolados estão dentro desta faixa variando entre 7,0 e 7,4 (FIG.28).

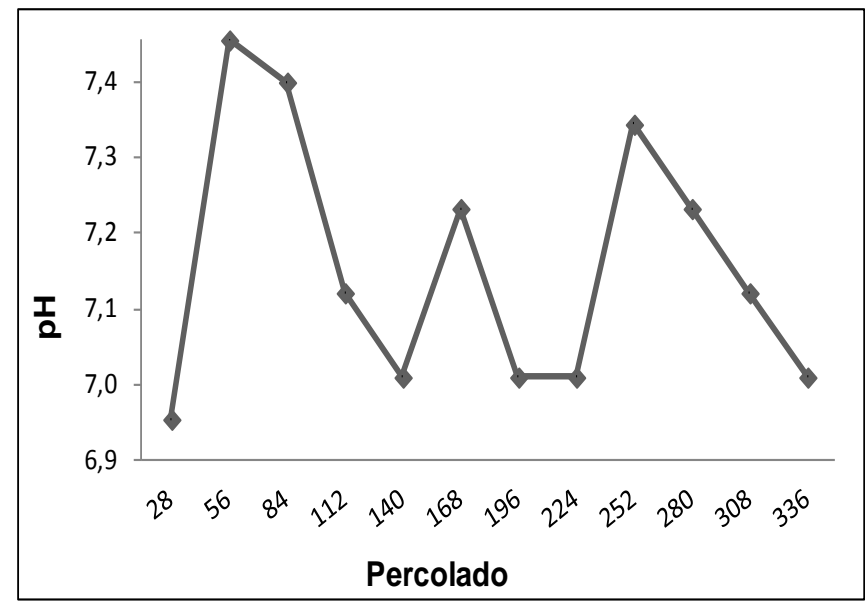

FIGURA 28 - pH do percolado C

Fonte: adaptado de Lange (2012)

Foi observado coeficiente de correlação positiva entre os valores de CE50 (48h) e o tempo de percolação $(0,948)$, o que sugere que quanto maior o valor de CE50(48h) nos percolados 28, 56, 84, 112 e 168 da coluna de cinza de carvão (FIG.24) maior foi o período de percolação. Isso indica que o percolado torna-se menos tóxico ao longo do período de percolação.

Foi observado coeficiente de correlação negativa apenas entre os valores obtidos para CE50 $(48 \mathrm{~h})$ e a concentração dos elementos As $(-0,908)$ e $\mathrm{Cd}(-0,864)$, indicando que nas condições de estudo quanto maiores foram os valores de CE50 (48h) nos percolados 28, 56, 84, 112 e 168 da coluna de cinza de carvão (FIG.24) menores foram os valores obtidos para concentração de As e Cd nestes percolados (FIG.25). Isso indica que a toxicidade observada nos percolados 28, 56, 84, 112 e 168 da coluna de cinza de carvão são decorrentes 
da concentração de As e Cd nestes percolados, uma vez que estes elementos são considerados tóxicos e podem causar danos ambientais.

Foi observado também coeficiente de correlação negativa entre os valores obtidos para $\mathrm{CE5} 0_{(48 \mathrm{~h})}$ e a concentração do ânion fluoreto $(-0,917)$, carbono total $(-0,903)$ e carbono orgânico dissolvido $(-0,866)$, indicando que nas condições de estudo quanto maiores foram os valores de CE50(48h) nos percolados 28, 56, 84, 112 e 168 da coluna de cinza de carvão (FIG.24) menores foram os valores obtidos para a concentração do fluoreto (FIG.27), carbono total e carbono orgânico dissolvido nestes percolados (FIG.29). Isso sugere que a maior toxicidade, isto é, menor valor de $\mathrm{CE}_{50}(48 \mathrm{~h})$ (FIG.24) observada esta associada a maior concentração de fluoreto (FIG.27), carbono total e carbono orgânico dissolvido nestes percolados da coluna de cinza de carvão (FIG.29). O fluoreto é um parâmetro inorgânico considerado para avaliação do padrão de qualidade de água para consumo (limite de concentração: $1,4 \mathrm{mg} \mathrm{L}^{-1}$ ) e do lançamento de efluentes (limite de concentração: $10 \mathrm{mg} \mathrm{L}^{-1}$ ) (CONAMA, 2005). 


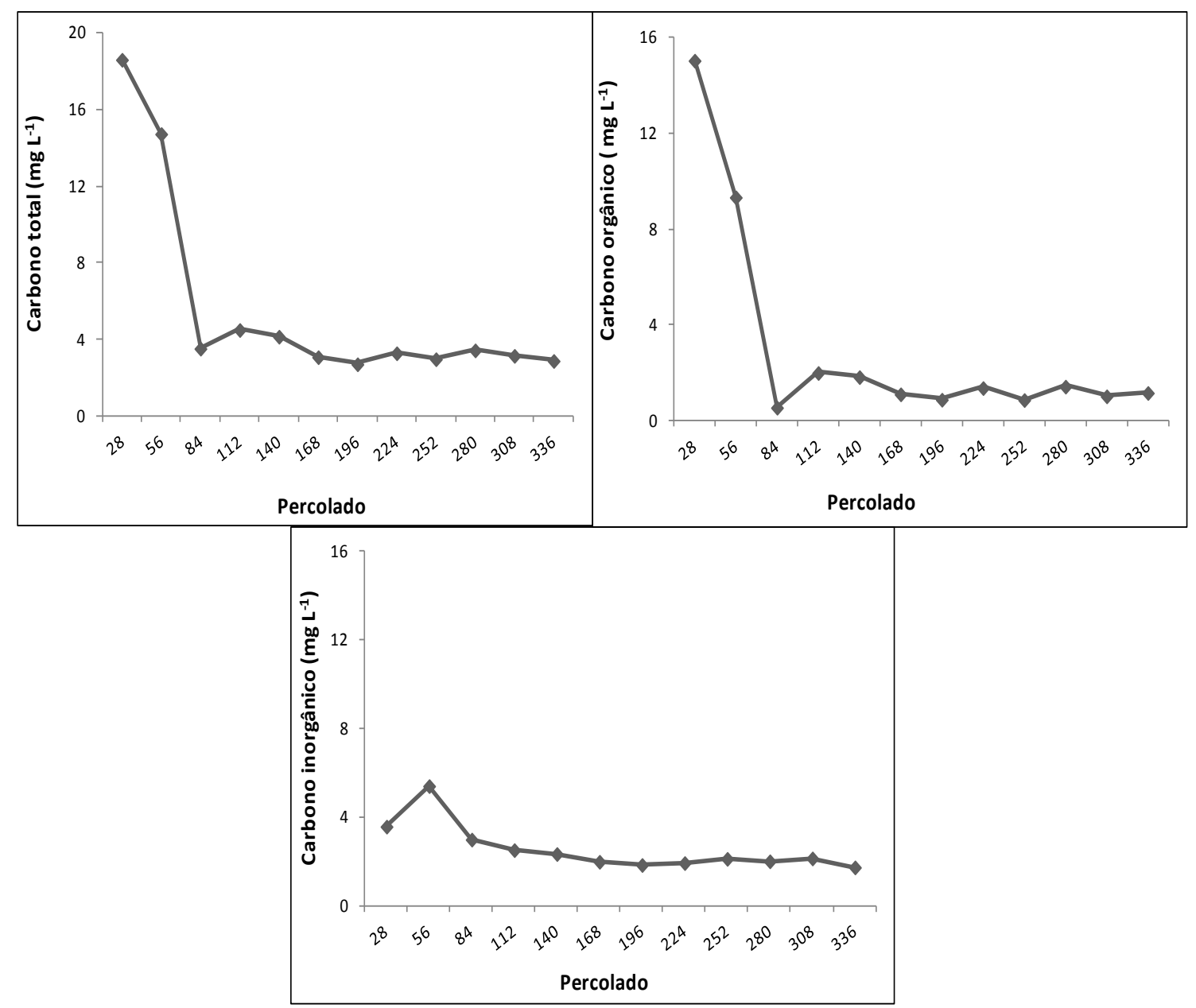

FIGURA 29 - Concentração de carbono orgânico, carbono inorgânico e carbono total no percolado $\mathrm{C}$

Fonte: adaptada de Lange (2012)

As diferentes correlações observadas entre os parâmetros químicos e os valores de $\mathrm{CI}_{50}(120 \mathrm{~h})$ e $\mathrm{CE} 50_{(48 \mathrm{~h})}$ nos percolados da coluna de cinza de carvão podem indicar diferentes sensibilidades que cada uma das espécies empregadas como organismos teste apresenta às substâncias que compõe os percolados analisados. 


\section{CONCLUSÕES}

- Os percolados 28,56 e 84 da coluna de cinza de carvão apresentaram potencial tóxico para causar inibição da germinação das sementes de $L$. sativa.

- Os percolados $28,56,84,112$ e 168 da coluna de cinza de carvão apresentaram toxicidade aguda dos organismos teste $D$. similis. A concentração de As, Cd e fluoreto contribuíram para a toxicidade destes percolados.

- O resultado do coeficiente de correlação positiva entre os valores de $\mathrm{Cl} 50_{(120 h)}$ e as concentrações dos elementos $\mathrm{Mo}, \mathrm{Na}, \mathrm{K}, \mathrm{Ca}, \mathrm{Mg}$ e do ânion sulfato indicaram que estes elementos e o ânion foram essenciais para a geminação das sementes de $L$. sativa.

- $\mathrm{O}$ pH apresentou coeficiente de correlação negativa com os valores de $\mathrm{Cl}_{50}(120 \mathrm{~h})$ nos percolados da coluna de cinza de carvão, mas provavelmente não influenciou na toxicidade dos percolados, pois o $\mathrm{pH}$ dos percolados estavam dentro da faixa ideal para a germinação das radículas de L. sativa.

- O resultado do coeficiente de correlação positiva entre os valores de $\mathrm{CE}_{50(48 \mathrm{~h})}$ e o tempo de percolação da coluna de cinza de carvão indicou que o percolado torna-se menos tóxico ao longo do período de percolação.

- O resultado do coeficiente de correlação negativa entre os valores de CE50(48h) e a concentração do carbono total e carbono orgânico dissolvido indicaram que o carbono contribuiu para a toxicidade dos percolados da coluna de cinza quando utilizado a $D$. similis como organismo teste.

- Os percolados das colunas de solo com cinza de carvão (percolados SPC e SCC) não apresentaram potencial para causar efeitos adversos tanto à germinação das sementes e ao desenvolvimento das 
radículas de $L$. sativa, bem como a mobilidade e/ou sobrevivência dos organismos teste $D$. similis. Isso indica que possivelmente as substâncias tóxicas lixiviadas da cinza de carvão foram retidas nos solos. 


\section{APÊNDICES}

APÊNDICE A - Carta controle de sensibilidade para Lactuca sativa

Organismos teste: Lactuca sativa

Método empregado: US EPA (1996), OECD (2003) e Sobrero et al. (2004)

Substância de referência: Sulfato de zinco $\left(\mathrm{ZnSO}_{4}\right)$

\begin{tabular}{|l|c|c|c|c|c|c|}
\hline Data & $1 / 12 / 10$ & $14 / 01 / 11$ & $10 / 02 / 11$ & $25 / 03 / 11$ & $27 / 04 / 11$ & $08 / 06 / 11$ \\
\hline $\begin{array}{l}\mathrm{Cl}_{(120 \mathrm{~h})} \\
(\%)\end{array}$ & 45,72 & 33,41 & 64,11 & 36,24 & 36,91 & 35,64 \\
\hline Data & $08 / 08 / 11$ & $26 / 10 / 11$ & $08 / 12 / 11$ & $31 / 01 / 12$ & $29 / 02 / 12$ & $27 / 03 / 12$ \\
\hline $\begin{array}{l}\mathrm{Cl}_{(120 \mathrm{~h})} \\
(\%)\end{array}$ & 43,98 & 46,16 & 43,97 & 35,58 & 37,86 & 33,59 \\
\hline
\end{tabular}

\begin{tabular}{|c|c|c|c|c|}
\hline \multicolumn{5}{|c|}{ Dados estatísticos obtidos na carta controle (\%) } \\
\hline Média & Desvio Padrão & Limite inferior & Limite superior & Coeficiente de Variação \\
\hline 43,28 & 12,52 & 18,24 & 68,23 & 26,70 \\
\hline
\end{tabular}

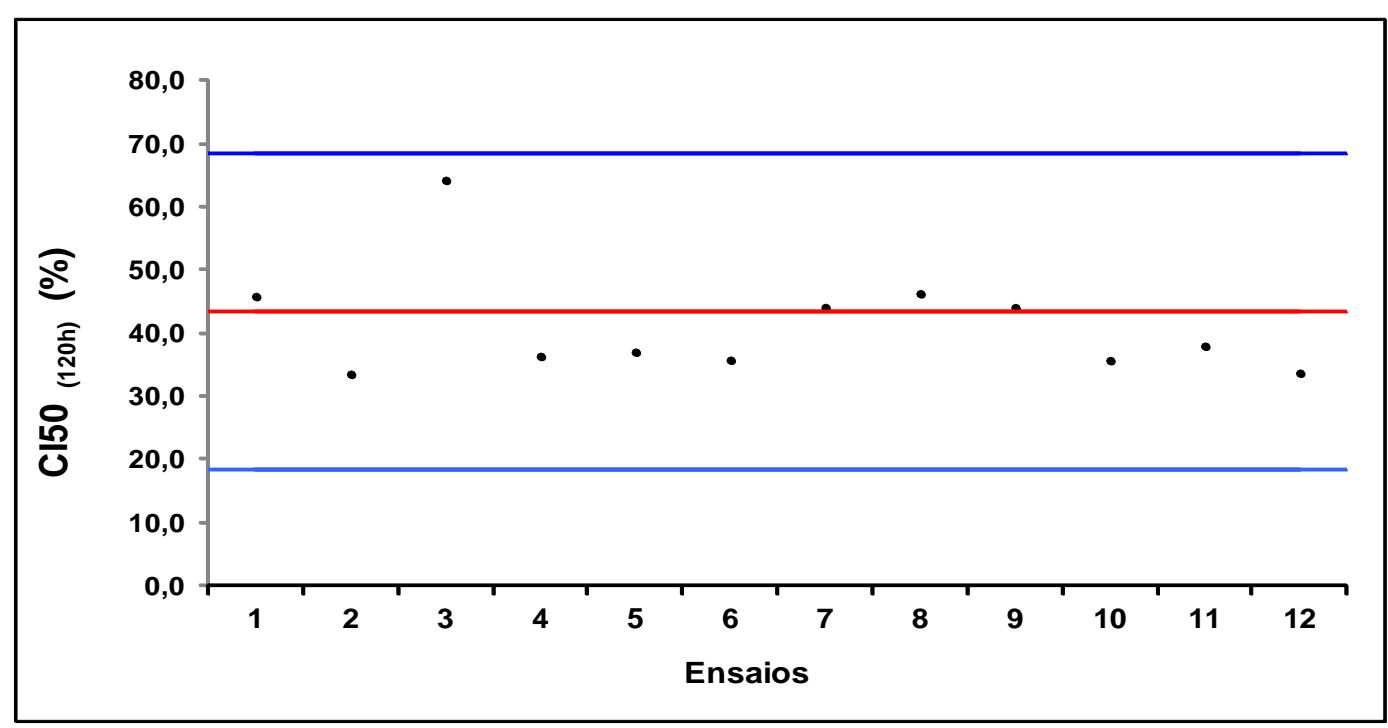




\section{APÊNDICE B - Carta controle de sensibilidade para Daphnia similis}

Organismos teste: Daphnia similis

Método empregado: ABNT NBR 12 713/ 2004

Substância de referência: Cloreto de sódio ( $\mathrm{NaCl})$

\begin{tabular}{|l|c|c|c|c|c|c|c|c|c|c|}
\hline Data & $23 / 10 / 10$ & $01 / 09 / 10$ & $15 / 09 / 10$ & $22 / 10 / 10$ & $19 / 11 / 10$ & $09 / 12 / 10$ & $04 / 02 / 11$ & $18 / 03 / 11$ & $28 / 04 / 11$ & $19 / 05 / 11$ \\
\hline $\begin{array}{l}\text { CE50 }_{(48 h)} \\
(\%)\end{array}$ & 3,25 & 2,30 & 3,10 & 3,01 & 2,11 & 2,36 & 2,93 & 2,83 & 2,14 & 1,83 \\
\hline Data & $09 / 06 / 11$ & $14 / 07 / 11$ & $11 / 08 / 11$ & $08 / 09 / 11$ & $10 / 11 / 11$ & $16 / 12 / 11$ & $13 / 01 / 12$ & $29 / 02 / 12$ & $08 / 03 / 12$ & $05 / 04 / 12$ \\
\hline $\begin{array}{l}\text { CE50 } \\
(\%)\end{array}$ & 2,30 & 3,61 & 2,70 & 2,46 & 2,73 & 2,83 & 2,00 & 3,35 & 2,70 & 2,93 \\
\hline
\end{tabular}

\begin{tabular}{|c|c|c|c|c|}
\hline \multicolumn{5}{|c|}{ Dados estatísticos obtidos na carta controle (\%) } \\
\hline Média & Desvio Padrão & Limite inferior & Limite superior & Coeficiente de Variação \\
\hline 2,75 & 0,47 & 1,72 & 3,78 & 45,66 \\
\hline
\end{tabular}

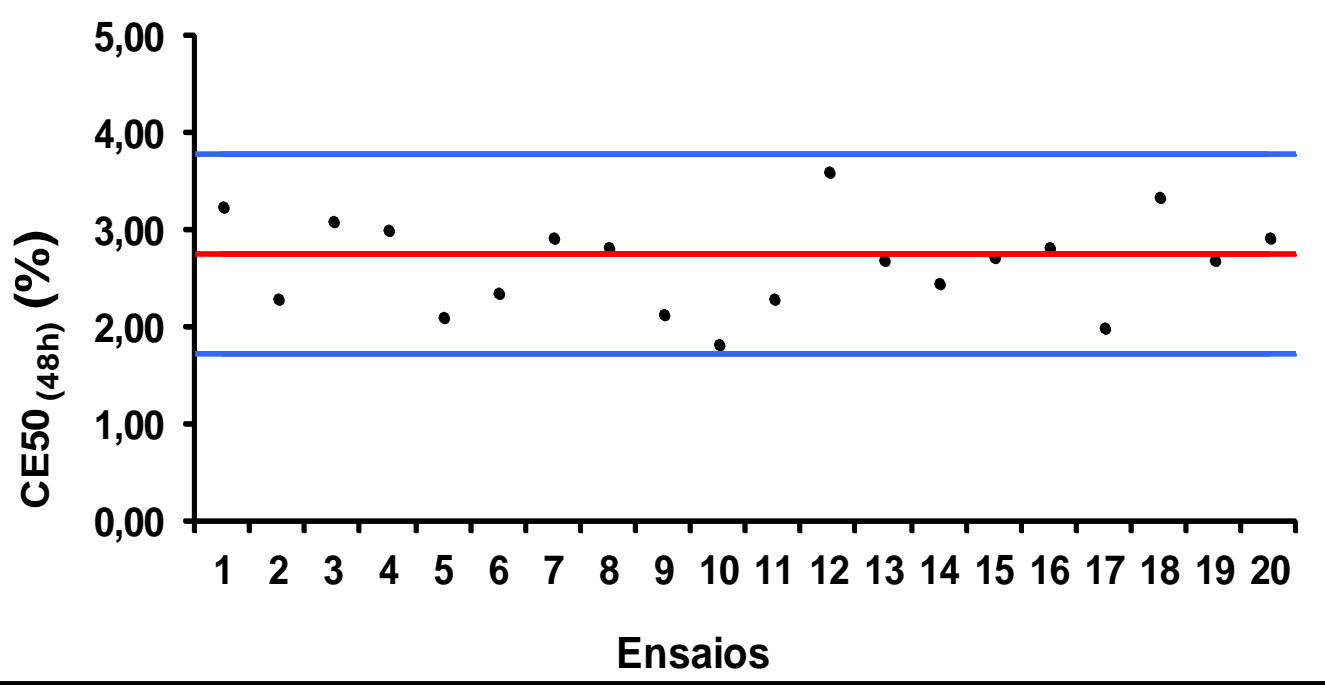


APÊNDICE C - Paramêtros iniciais da água de cultivo utilizada nos ensaios com $D$. similis

Local da coleta: Salto, São Paulo

\begin{tabular}{lccccc}
\hline \multicolumn{7}{c}{ Parâmetros da água de cultivo } \\
\hline \multicolumn{1}{c}{ Data } & Lote & pH & $\begin{array}{c}\text { OD } \\
\left(\mathbf{m g ~ L}^{-1}\right)\end{array}$ & $\begin{array}{c}\text { Dureza } \\
\text { (mg L CaCo3) }\end{array}$ & $\begin{array}{c}\text { Condutividade } \\
\left(\boldsymbol{\mu S}_{\mathbf{2 5}} \mathbf{c m}\right)\end{array}$ \\
\hline Outubro /2010 & 69 & 6,06 & 7,74 & 25 & 85,20 \\
Novembro/2010 & 70 & 6,30 & 7,74 & 22 & 134,30 \\
Dezembro/2010 & 71 & 6,30 & 7,93 & 20 & 97,60 \\
Fevereiro/2011 & 73 & nd & 14,52 & 20 & 114,10 \\
Março/2011 & 74 & nd & 6,78 & 18 & 61,10 \\
Abril/2011 & 75 & nd & 7,38 & 18 & 76,40 \\
Junho/2011 & 76 & nd & 8,10 & 20 & 92,60 \\
Julho/2011 & 77 & nd & 8,00 & 20 & 76,50 \\
Agosto/2011 & 78 & nd & 5,27 & 26 & 82,90 \\
Setembro/2011 & 79 & 5,00 & 8,70 & 17 & 82,30 \\
Outubro/2011 & 80 & 6,85 & 8,28 & 23 & 89,80 \\
Novembro/2011 & 81 & 6,69 & 8,19 & 20 & 104,50 \\
Dezembro/2011 & 82 & 6,86 & 8,04 & 20 & 153,80 \\
Janeiro /2012 & 83 & 7,50 & nd & 20 & 137,10 \\
Março/2012 & 84 & 6,82 & nd & 20 & 79,20 \\
Abril/2012 & 85 & 7,50 & nd & 20 & 139,20 \\
Maio/2012 & 86 & 7,43 & nd & 20 & 147,80 \\
\hline nd-não determinado & & & & &
\end{tabular}




\section{APÊNDICE D - Dados estatísticos para calcular os valores de $\mathrm{Cl}^{50} 0_{(120 \mathrm{~h})}$ dos percolados 28, 56 e 84 da coluna de cinza de carvão nos ensaios definitivos com sementes de $L$. sativa}

\section{Percolado 28}

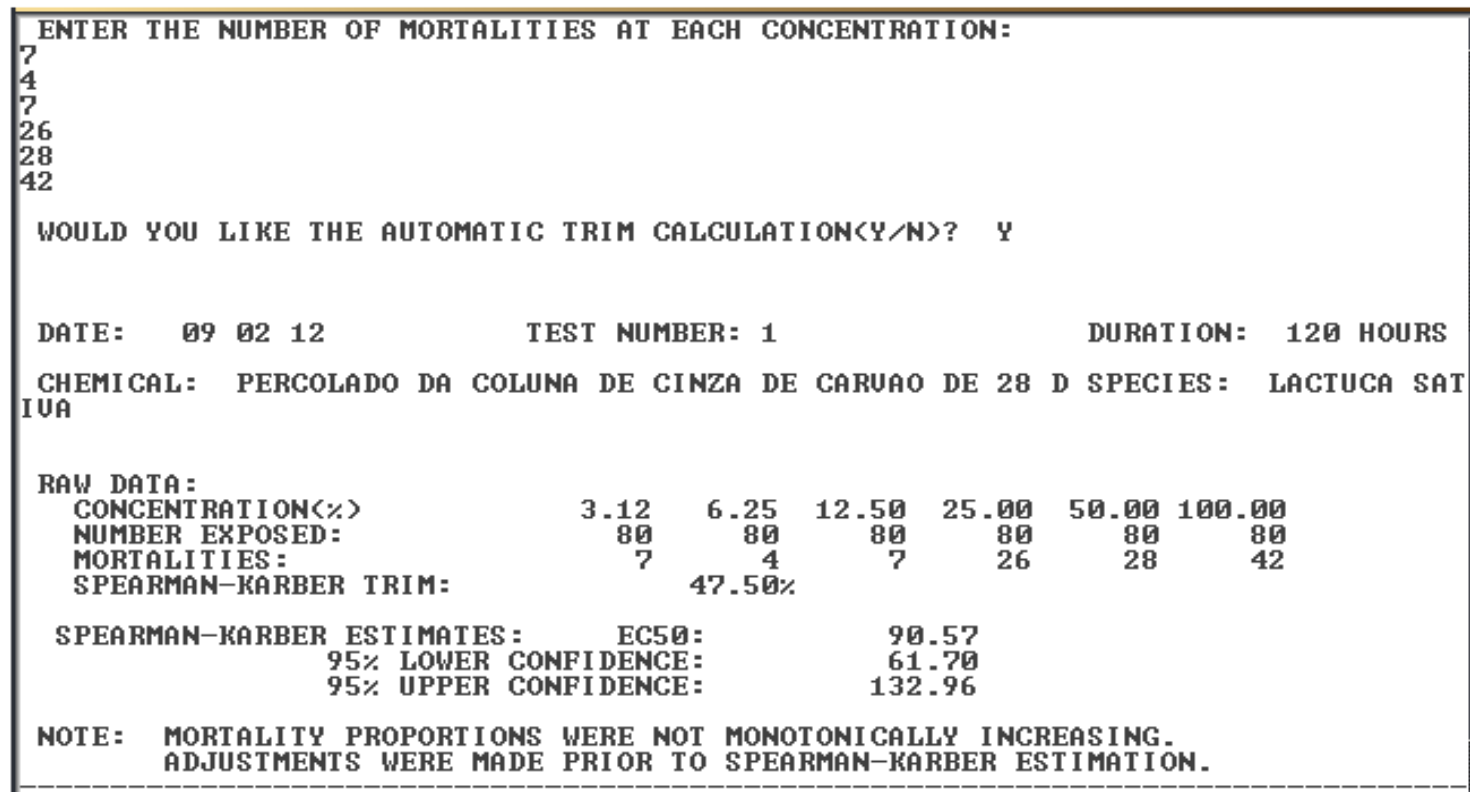

\section{Percolado 56}

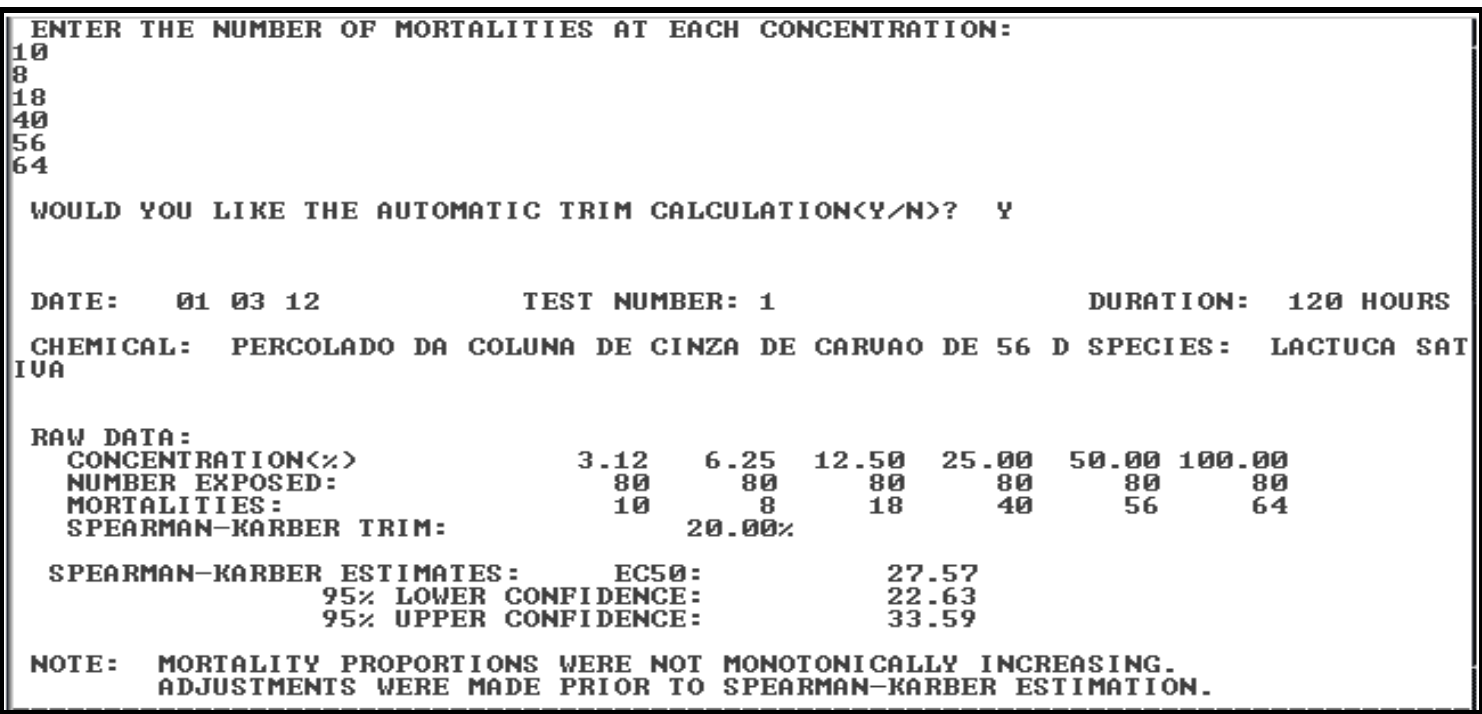


APÊNDICE D (continuação)

\section{Percolado 84}

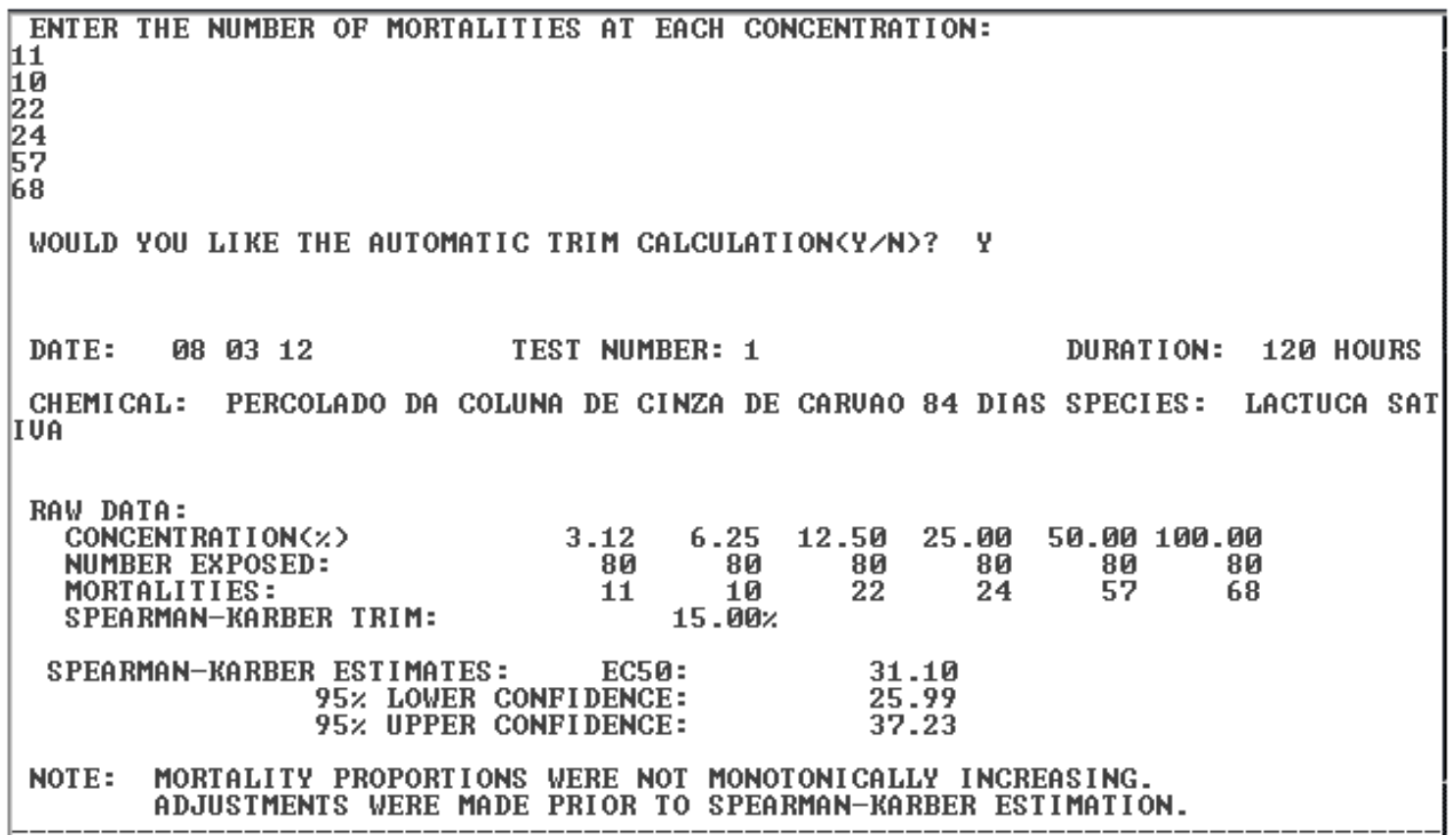


APÊNDICE E - Dados do Teste $\mathrm{t}$ para o desenvolvimento das radículas nos percolados C, SCC e SPC nos ensaios preliminares e definitivos com L. sativa

\section{Ensaios preliminares}

\section{Percolado SPC}

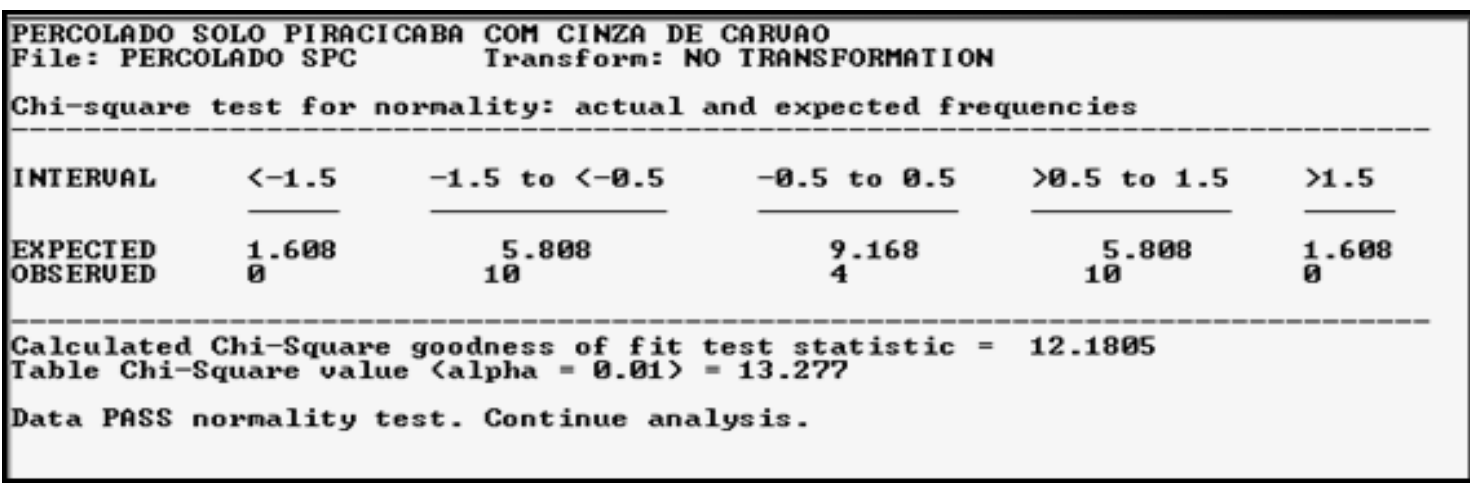

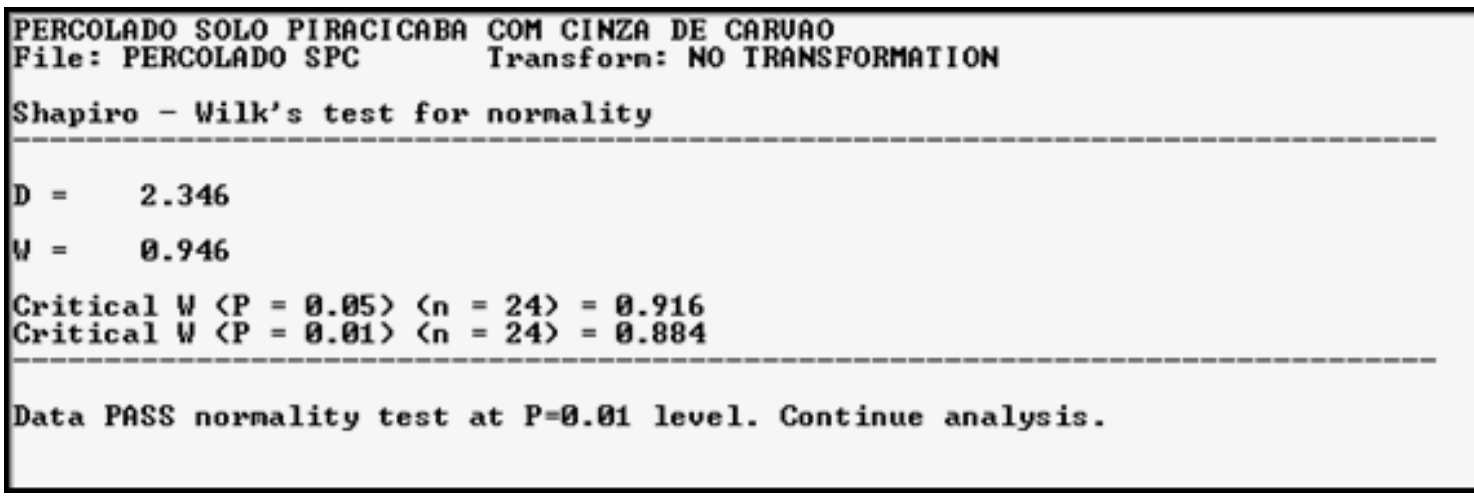

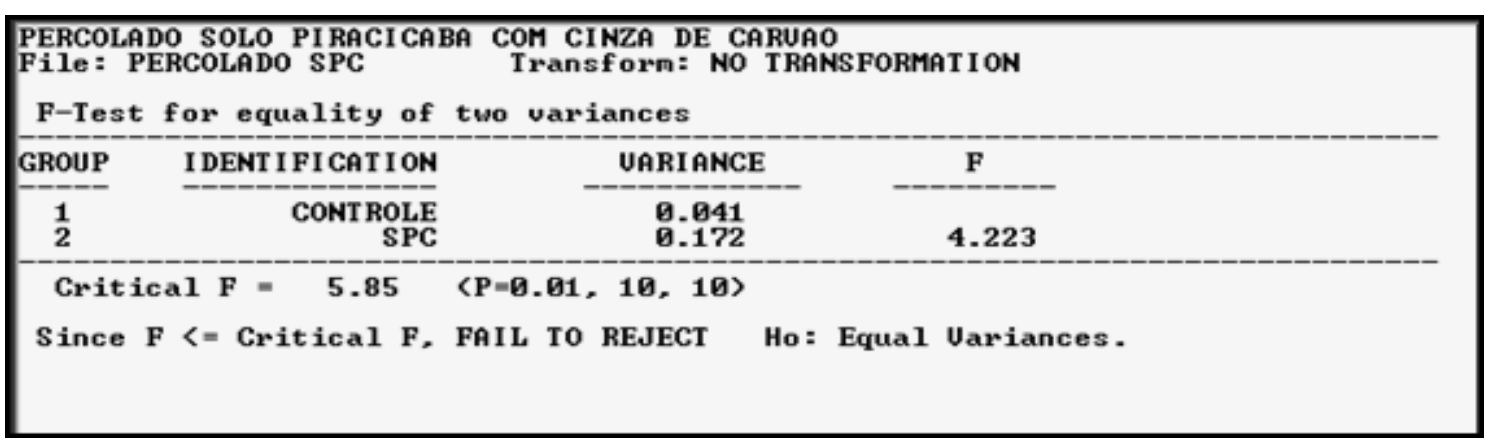

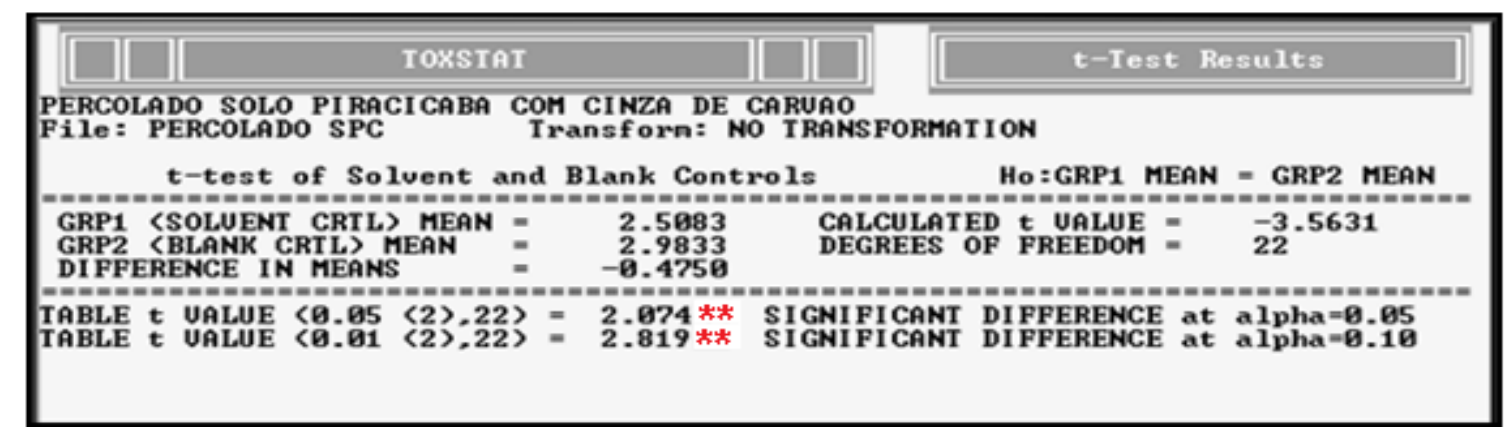


APÊNDICE E (continuação)

\section{Ensaios preliminares}

\section{Percolado SCC}

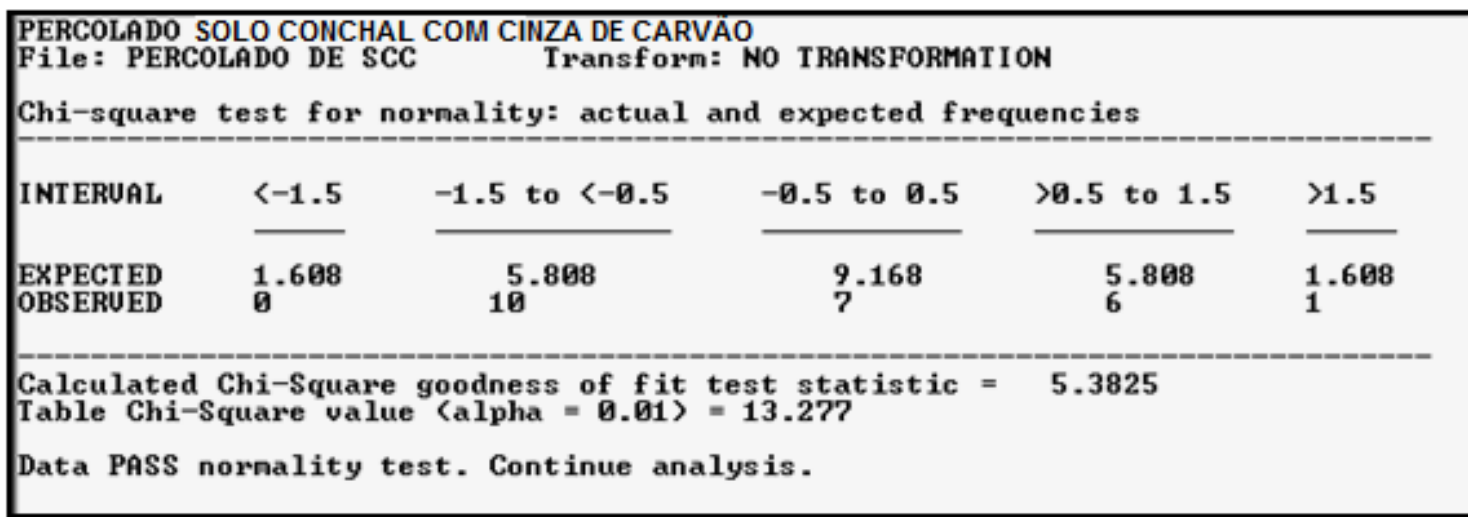

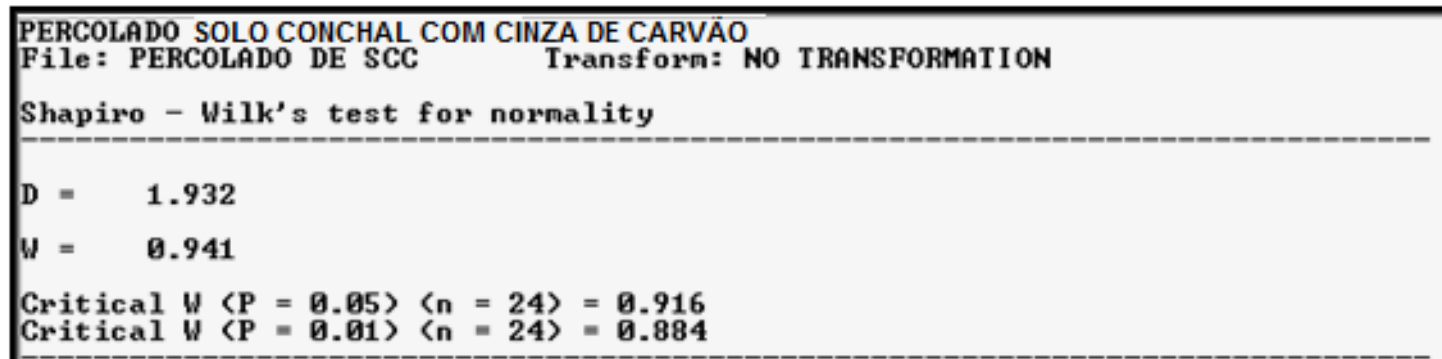

Data PASS normality test at $\mathrm{P}=0.01$ level. Continue analysis.

\begin{tabular}{|c|c|c|c|}
\hline \multicolumn{4}{|c|}{$\begin{array}{l}\text { PERCOLADO SOLO CONCHAL COM CINZA DE CARVA } \\
\text { File: PERCOLADO DE SCC Transforn } \\
\text { F-Test for equality of two variances }\end{array}$} \\
\hline GROUP & I DENT I FI CAT I ON & UARI ANCE & $\mathbf{F}$ \\
\hline$\frac{1}{2}$ & $\begin{array}{r}\text { CONT ROLE } \\
\text { SCC }\end{array}$ & $\begin{array}{l}0.641 \\
0.135\end{array}$ & 3.301 \\
\hline \multicolumn{4}{|c|}{$\begin{array}{l}\text { Critical } F=5.85 \quad\langle P=0.61,10,10\rangle \\
\text { Since } F<=\text { Critical } F \text {, FAIL To REJECT Ho: Equal Uariances . }\end{array}$} \\
\hline
\end{tabular}

\section{TOXSTAT}

PERCOLADO SOLO CONCHAL COM CINZA DE CARVÄO
File: PERCOLADO DE SCC
Transf orm: NO TRANSFORMATION
t-test of Solvent and Blank Controls
Ho:GRP1 MEAN = GRP2 MEAN
(1)
GRP1 (SOLUENT CRTL) MEAN $=\quad 2.5083 \quad$ CALCULATED $t$ UALUE $=1.7911$
$\begin{array}{llr}\text { GRP2 (BLANK CRTL) MEAN } & =2.7250 \\ \text { DIFFERENCE IN MEANS } & =-0.2167\end{array}$

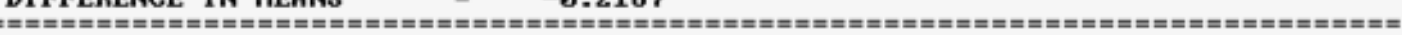
TABLE $t$ UALUE $(0.65(2) .22\rangle=2.674$ NO significant difference at alpha=0.05
TABLE $t$ UALUE $\langle 0.01\langle 2\rangle, 22\rangle=2.819$ NO significant difference at alpha=0.01 
APÊNDICE E (continuação)

\section{Ensaios preliminares}

\section{Percolado SCC}

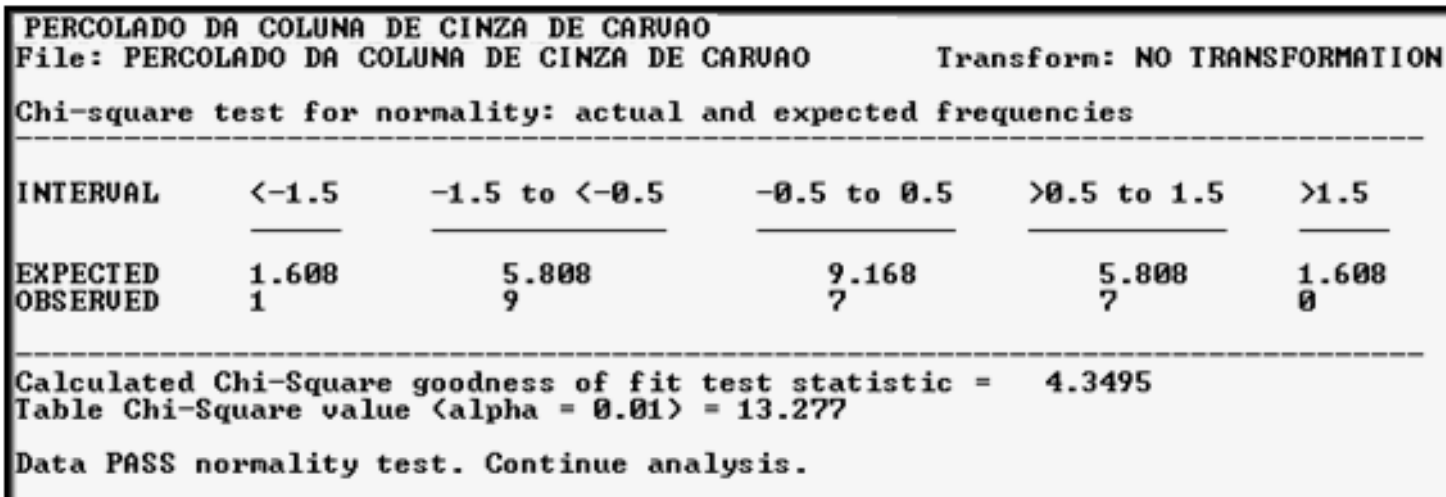

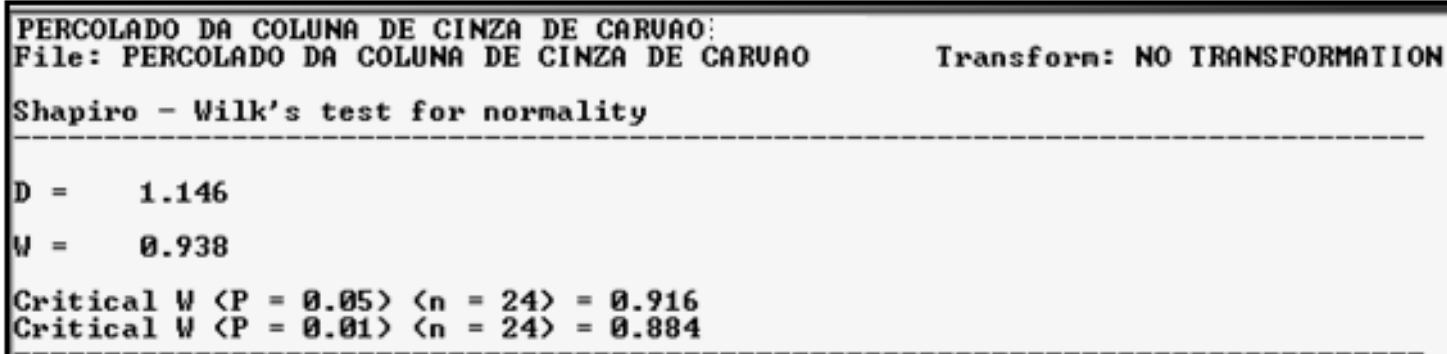

Data PASS normality test at $P=0.01$ level. Continue analysis.

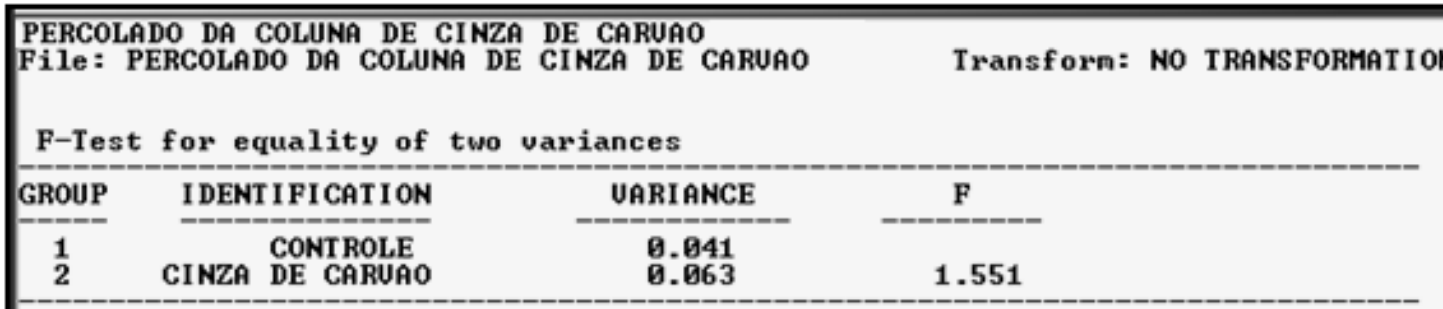

Critical $F=5.85\langle P=0.01,10,10\rangle$

Since $F<=$ Critical F, FAIL TO REJECT Ho: Equal Variances.

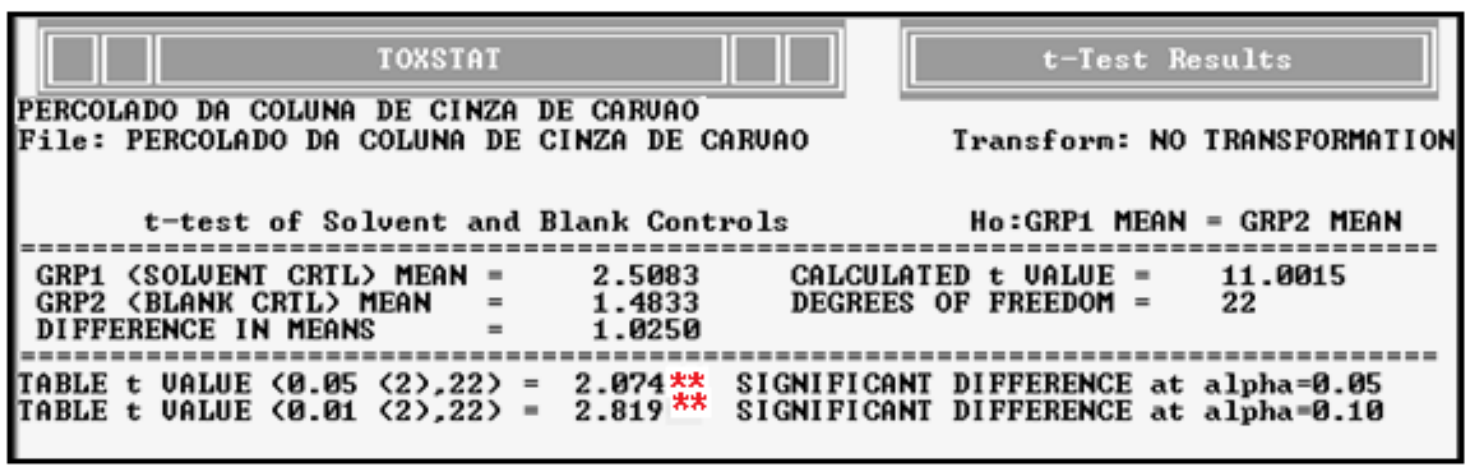


APÊNDICE E (continuação)

Ensaios definitivos

Percolado C 28

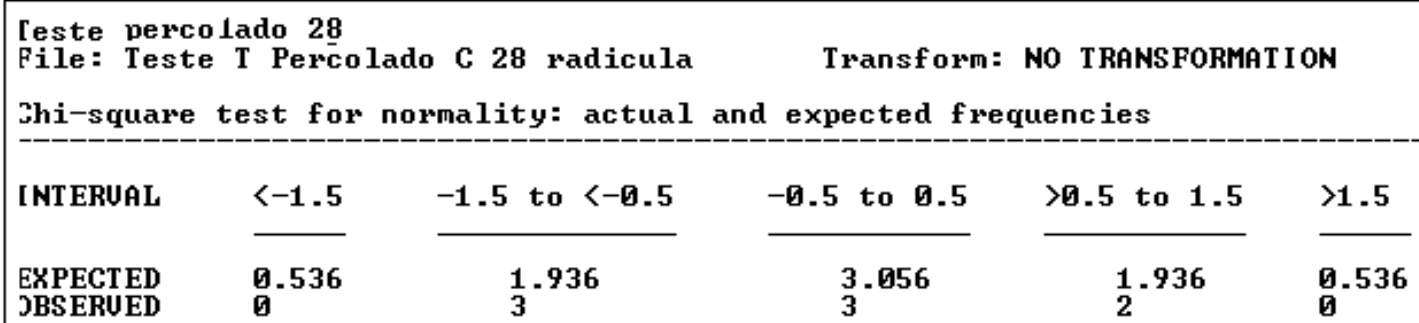

Salculated Chi-Square goodness of fit test statistic = 1.6599

[able Chi-Square value (alpha $=0.01$ ) $=13.277$

Teste percolado 28

File: Teste $T$ Percolado C 28 radicula

Transform: NO TRANSFORMAT I ON

Shapiro - Wilk's test for normality

$\mathrm{D}=0.204$

$W=0.968$

Critical W $(P=0.05\rangle\langle(\mathbf{P}=8\rangle=0.818$

Critical W $(P=0.01\rangle\langle n=8\rangle=0.749$

Data PASS normality test at $P=0.01$ level. Continue analysis.

\begin{tabular}{|c|c|c|}
\hline $\begin{array}{l}\text { Teste percolado } 28 \\
\text { File: leste I Percolado } \\
\text { F-Test for equality of }\end{array}$ & $\begin{array}{l}\text { C } 28 \text { radicula } \\
\text { two variances }\end{array}$ & Transform: NO TRANSFORMAT I ON \\
\hline I DENT I FI CAT I ON & UARIANCE & $\mathbf{F}$ \\
\hline $\begin{array}{r}\text { Controle } \\
100 \%\end{array}$ & $\begin{array}{l}0.024 \\
0.044\end{array}$ & 1.859 \\
\hline $\begin{array}{l}\text { Critical } F=47.50 \\
\text { Since } F<=\text { Critical F, }\end{array}$ & $\begin{array}{l}\langle P=0.01,3,3\rangle \\
\text { FAIL TO REJECT }\end{array}$ & Equal Uariances. \\
\hline
\end{tabular}

Teste percolado_ 28

File: Teste T Pércolado c 28 radicula Transform: No TRANSFORMATION t-test of Solvent and Blank Controls Ho:GRP1 MEAN = GRP2 MEAN

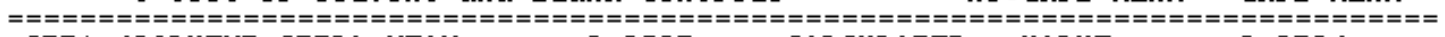
GRP1 (SOLUENT CRTL) MEAN $=$ 2.3025 CALCULATED t UALUE $=3.3524$ GRP2 (BLANK CRTL) MEAN = 1.8650 DEGREES OF FREEDOM = 6 DIFFERENCE IN MEANS $=0.4375$

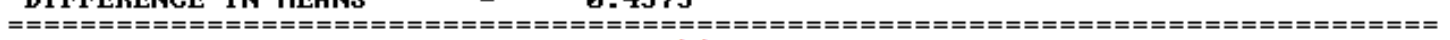
TABLE $t$ UALUE (0.05 (2), 6) $=2.447 *$ SIGNIFICANT DIFFERENCE at alpha=0.05 TABLE $t$ UALUE (0.01 (2), 6$\rangle=3.707$ NO significant difference at alpha=0.01 
APÊNDICE E (continuação)

Ensaios definitivos

Percolado C 56

\begin{tabular}{|c|c|c|c|c|c|}
\hline \multicolumn{6}{|c|}{$\begin{array}{l}\text { Teste percolado } 56 \\
\text { File: Teste T Percolado C } 56 \\
\text { Chi-square test for normality: }\end{array}$} \\
\hline I NT ERUAL & $<-1.5$ & -1.5 to $<-0.5$ & -0.5 to 0.5 & $>0.5$ to 1.5 & $>1.5$ \\
\hline $\begin{array}{l}\text { EXPECTED } \\
\text { OBSERUED }\end{array}$ & 0.536 & $\frac{1}{3} .936$ & 3.056 & $\frac{1}{3} .936$ & 0.536 \\
\hline \multicolumn{6}{|c|}{$\begin{array}{l}\text { Calculated Chi-Square goodness of fit test statistic = } 2.6064 \\
\text { Table Chi-Square value (alpha = } 0.01 \text { ) } 13.277\end{array}$} \\
\hline
\end{tabular}

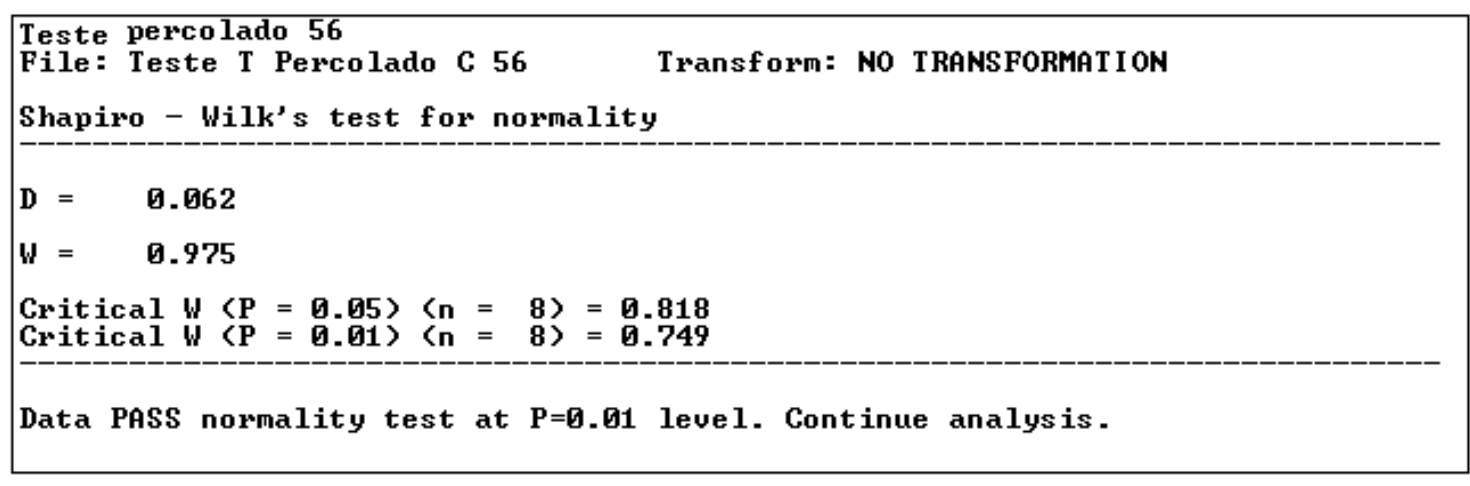

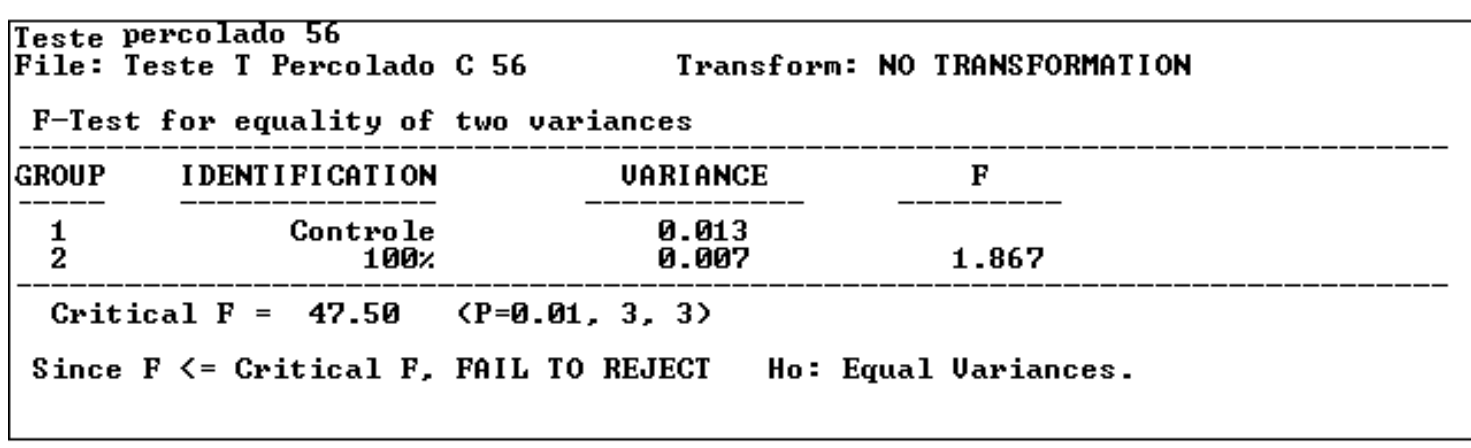

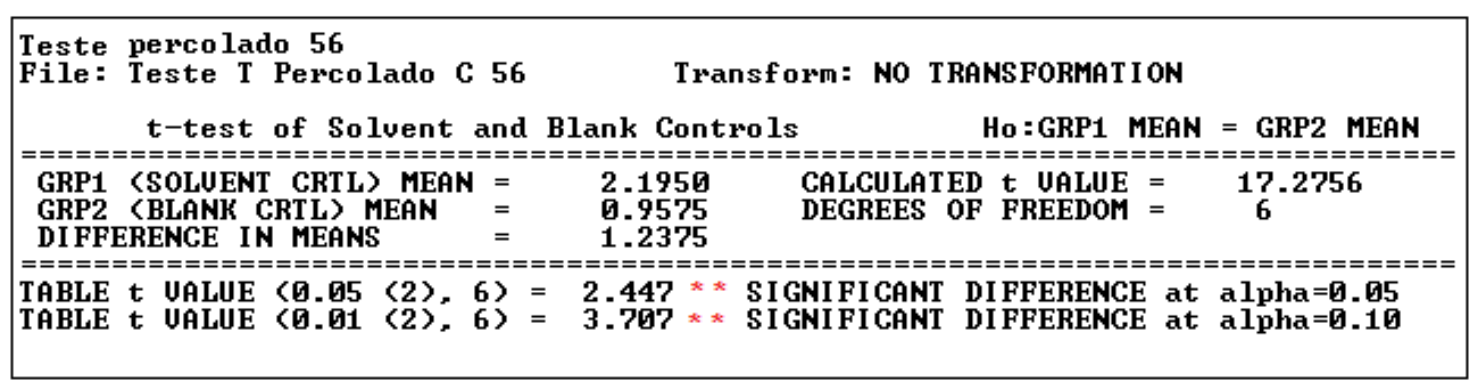


APÊNDICE E (continuação)

Ensaios definitivos

Percolado C 84

\begin{tabular}{|c|c|c|c|c|c|}
\hline \multicolumn{6}{|c|}{$\begin{array}{l}\text { Teste percolado } 84 \\
\text { File: Teste } T \text { percolado C } 84 \\
\text { Chi-square test for normality: }\end{array}$} \\
\hline INTERUAL & $<-1.5$ & -1.5 to $<-0.5$ & -0.5 to 0.5 & $>0.5$ to 1.5 & $>1.5$ \\
\hline $\begin{array}{l}\text { EXPECTED } \\
\text { OBSERUED }\end{array}$ & 0.536 & $\frac{1}{2}^{936}$ & $4^{3.056}$ & $\frac{1}{2}^{936}$ & 0.536 \\
\hline \multicolumn{6}{|c|}{$\begin{array}{l}\text { Calculated Chi-Square goodness of fit test statistic = } \\
\text { Table Chi-Square value (alpha }=0.01 \text { ) }=13.277 \\
\text { Data Pass normality test. Continue analysis. }\end{array}$} \\
\hline
\end{tabular}

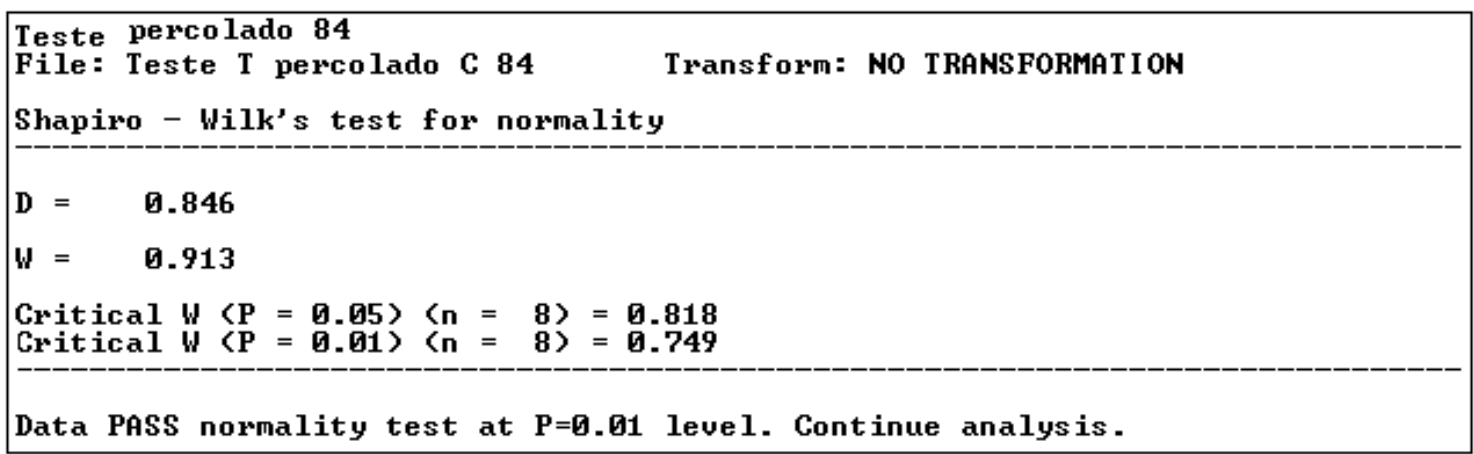

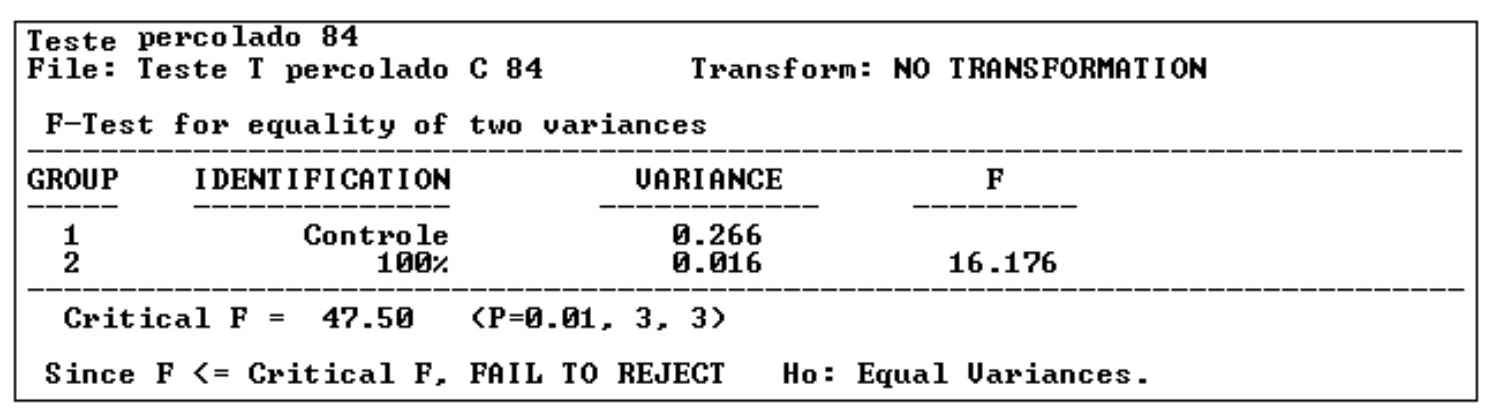

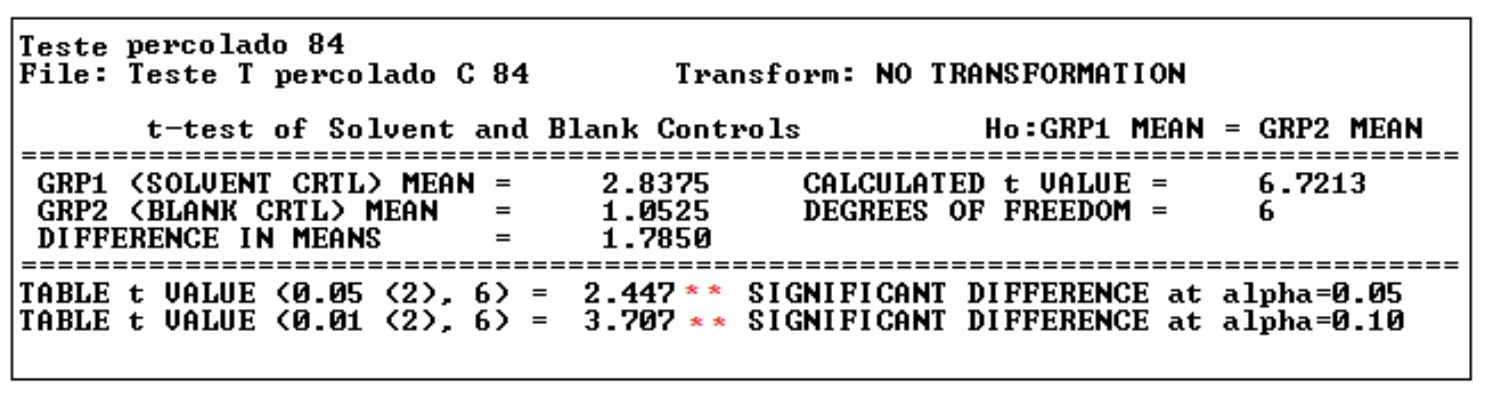


APÊNDICE F - Dados estatísticos para calcular os valores de CENO e CEO dos percolados 28, 56 e 84 da coluna de cinza de carvão nos ensaios definitivos com sementes de $L$. sativa

\section{Percolado 28}

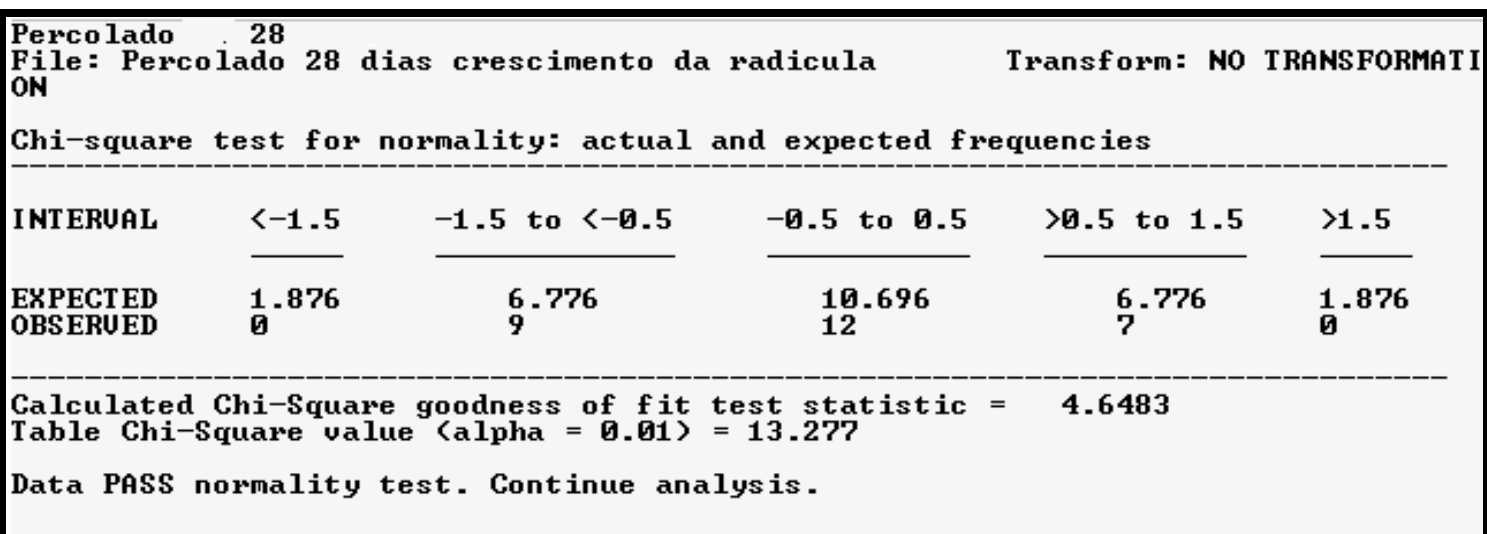

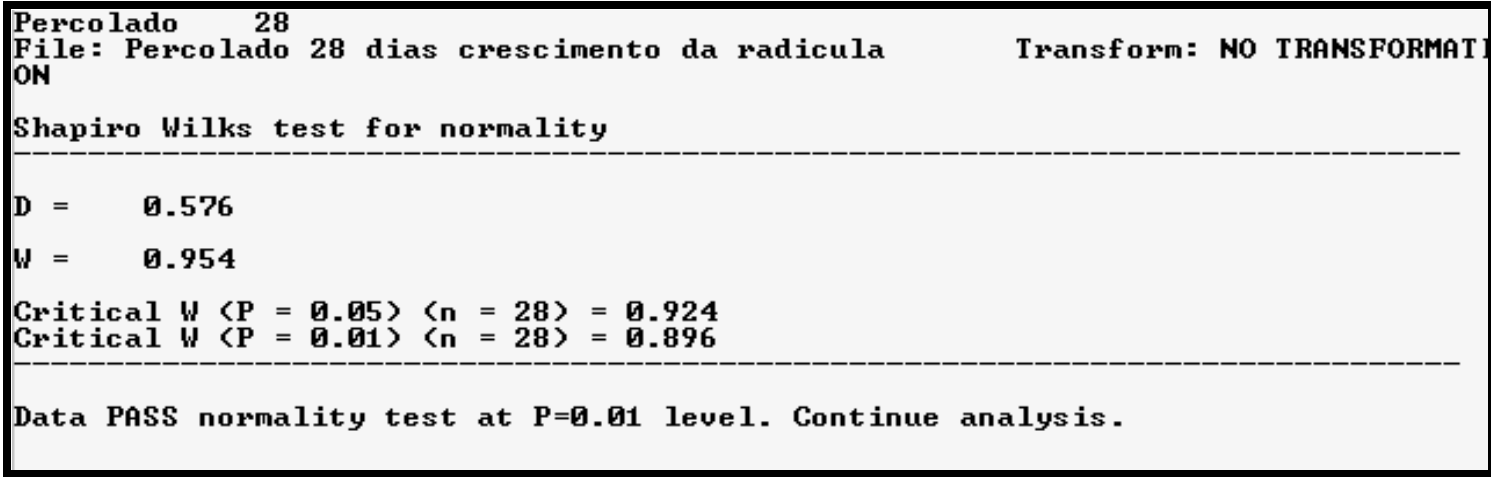

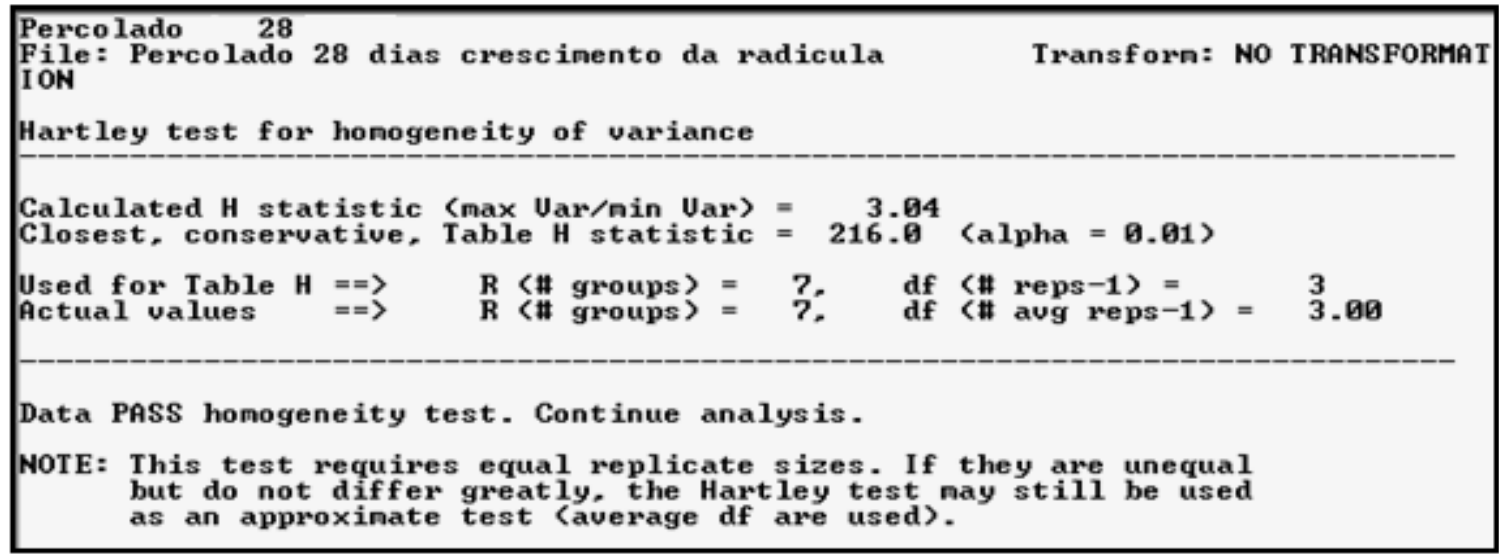


APÊNDICE F (continuação)

\section{Percolado 28}

\begin{tabular}{|c|c|}
\hline $\begin{array}{l}\text { Percolado } 28 \\
\text { File: Percolado } 28 \text { dias crescimento da radicula } \\
\text { ON } \\
\text { Bartletts test for honogeneity of variance }\end{array}$ & Transforn: NO TRANSFORMATI \\
\hline $\begin{array}{l}\text { Calculated B statistic }=\quad 1.11 \\
\text { Table Chi-square value }=16.81 \text { (alpha }=0.01 \text { ) } \\
\text { Table Chi-square value }=12.59 \text { (alpha }=0.05 \text { ) } \\
\text { Average df used in calculation }==\text { > df (aug } n-1 \text { ) } \\
\text { Used for Chi-square table value }==\text { d df (\#groups-1) }\end{array}$ & $\begin{array}{l}=\quad 3.00 \\
=6\end{array}$ \\
\hline
\end{tabular}

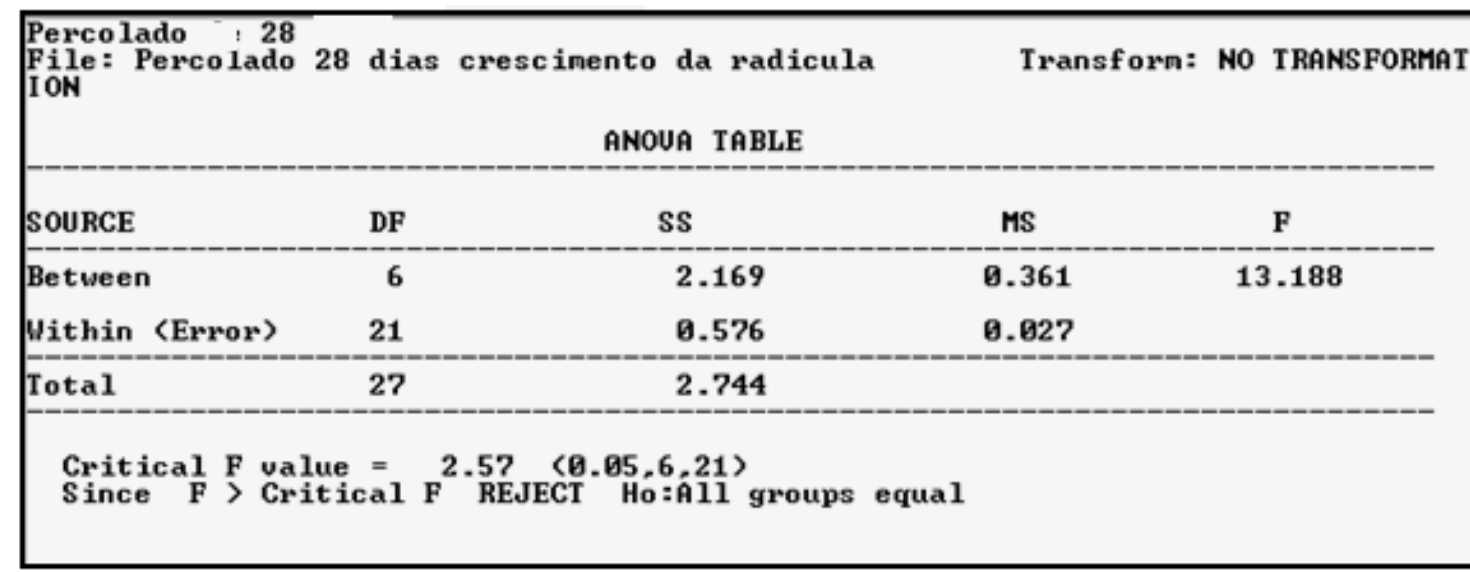

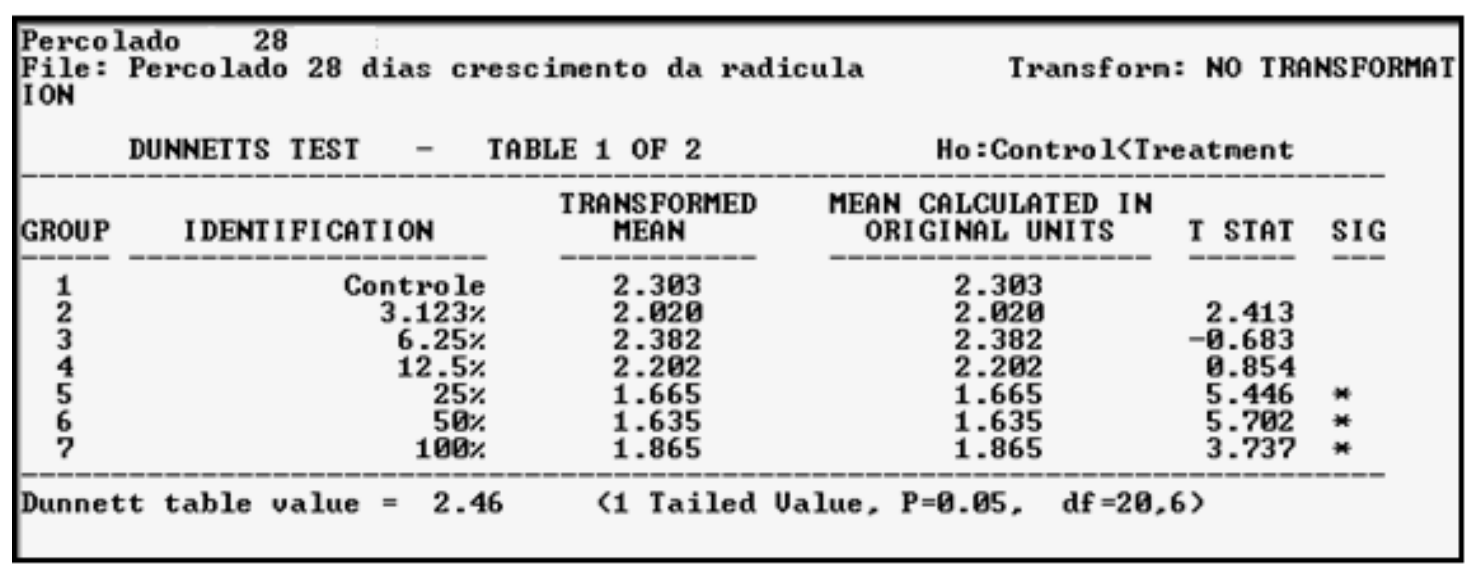


APÊNDICE F (continuação)

\section{Percolado 28}

\begin{tabular}{|c|c|c|c|c|c|c|}
\hline \multicolumn{5}{|c|}{$\begin{array}{l}\text { Percolado } 28 \\
\text { File: Percolado } 28 \text { dias crescimento da radicula } \\
\text { ION }\end{array}$} & \multicolumn{2}{|c|}{$\begin{array}{l}\text { Transforn: NO TRANSFORMAT } \\
\text { Contro } 1<\text { Treatment }\end{array}$} \\
\hline GROUP & I DENT I FI CAT I & $\mathrm{ON}$ & $\begin{array}{l}\text { NUM OF } \\
\text { REPS }\end{array}$ & $\begin{array}{l}\text { Minimun Sig Diff } \\
\text { (IN ORIG. UNITS }\end{array}$ & \%onTROL & $\begin{array}{l}\text { DIFFERENCE } \\
\text { FROM CONTROL }\end{array}$ \\
\hline $\begin{array}{l}1 \\
2 \\
3 \\
4 \\
5 \\
6 \\
7\end{array}$ & & $\begin{array}{r}\text { trole } \\
6.123 \% \\
12.5 \% \\
25 \% \\
50 \% \\
100 \%\end{array}$ & $\begin{array}{l}4 \\
4 \\
4 \\
4 \\
4 \\
4 \\
4\end{array}$ & $\begin{array}{l}0.288 \\
0.288 \\
0.288 \\
\text { ด.288 } \\
\text { ด.288 } \\
\text { ด.288 }\end{array}$ & $\begin{array}{l}12.5 \\
12.5 \\
12.5 \\
12.5 \\
12.5 \\
12.5\end{array}$ & $\begin{array}{r}0.283 \\
-0.080 \\
0.196 \\
0.638 \\
0.668 \\
0.438\end{array}$ \\
\hline
\end{tabular}

\section{Percolado 56}

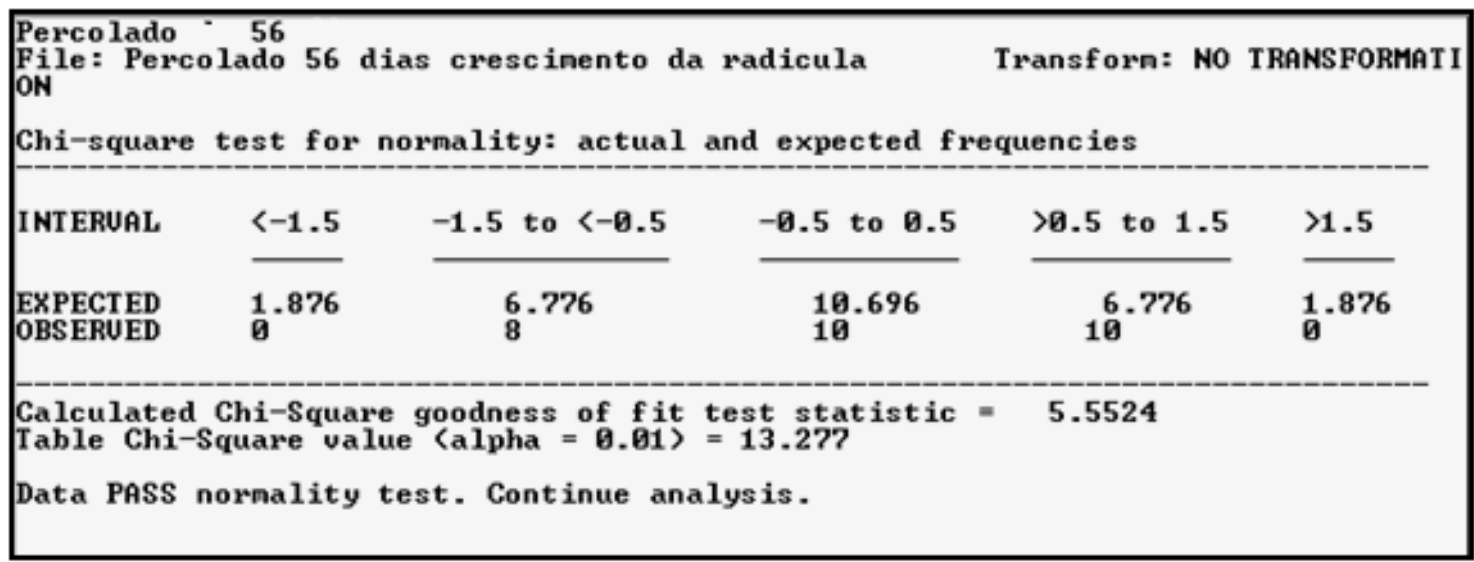

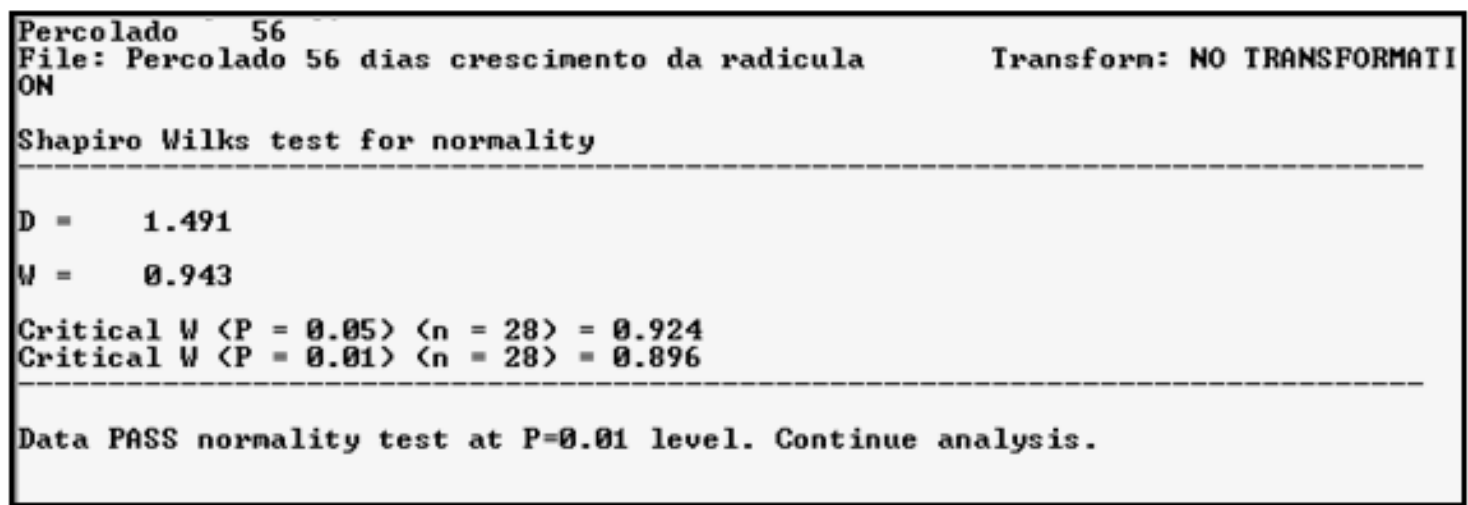


APÊNDICE F (continuação)

\section{Percolado 56}

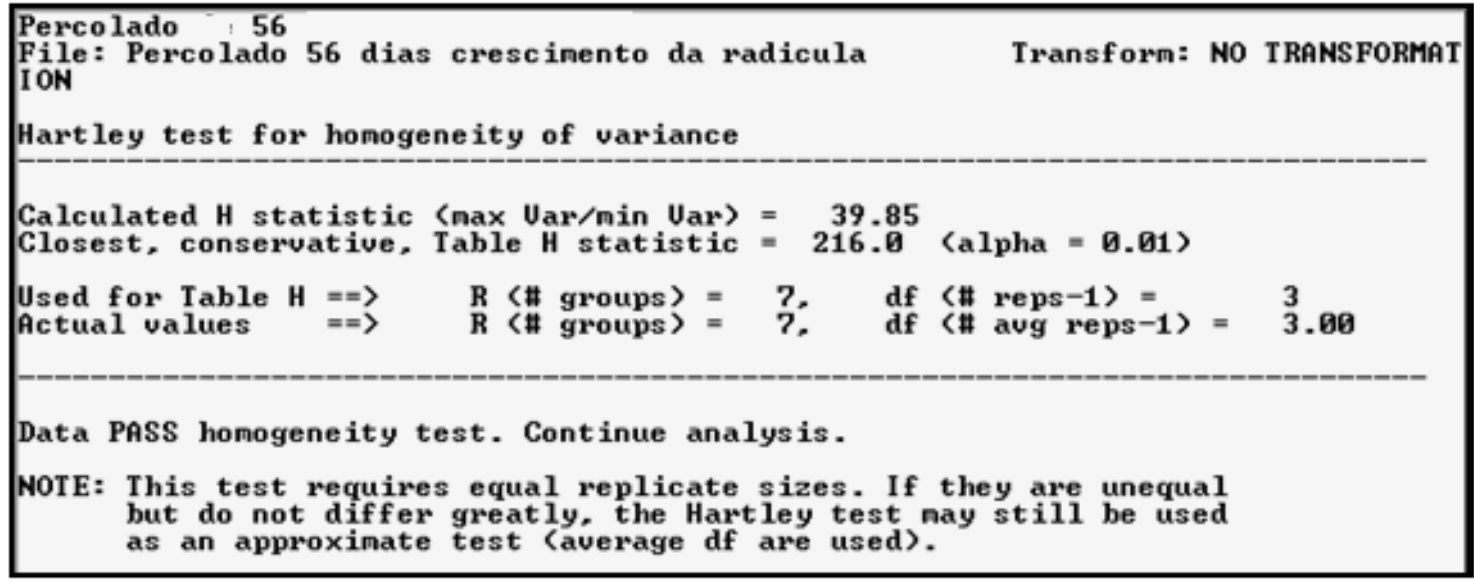

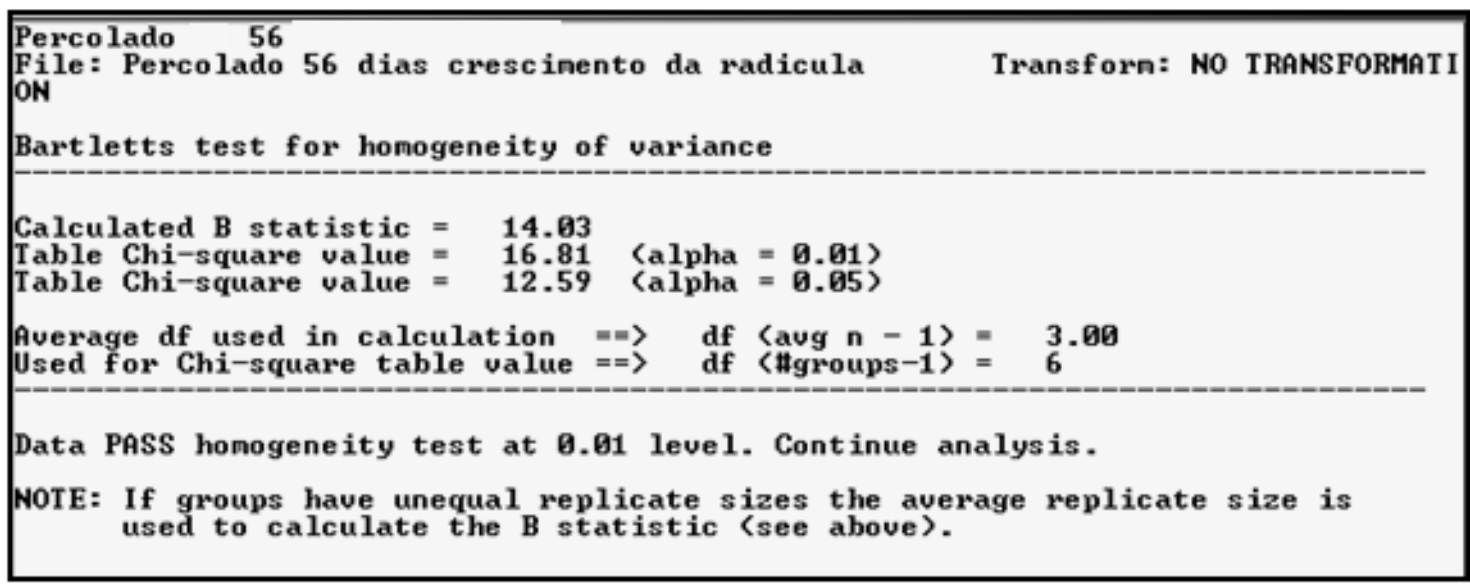

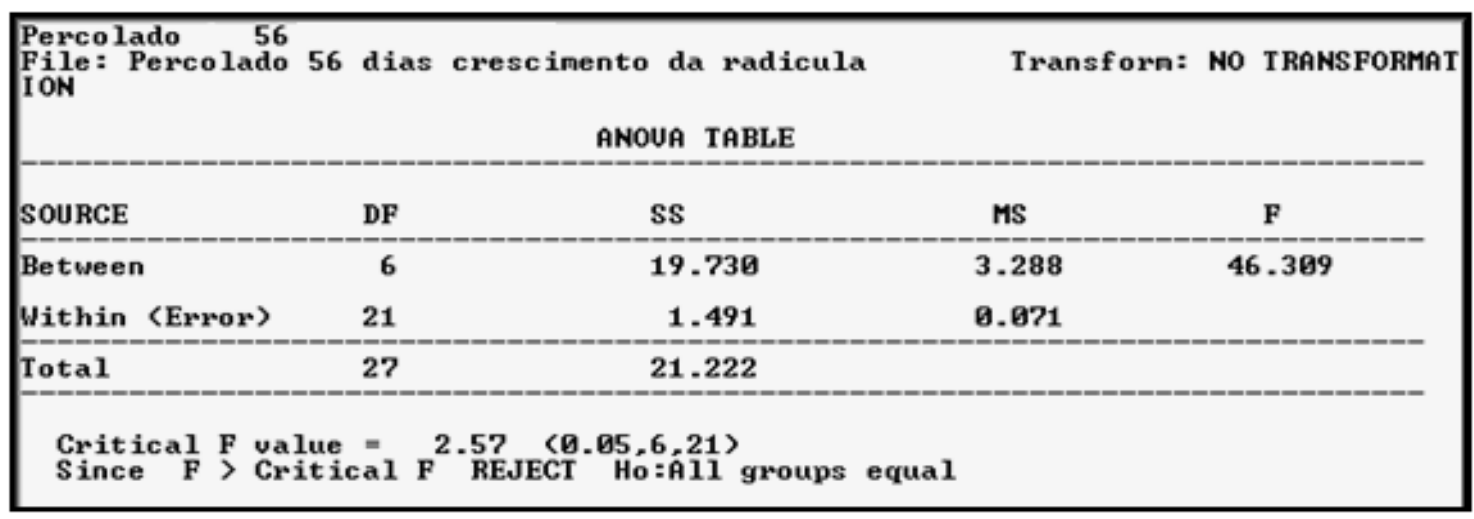


APÊNDICE F (continuação)

\section{Percolado 56}

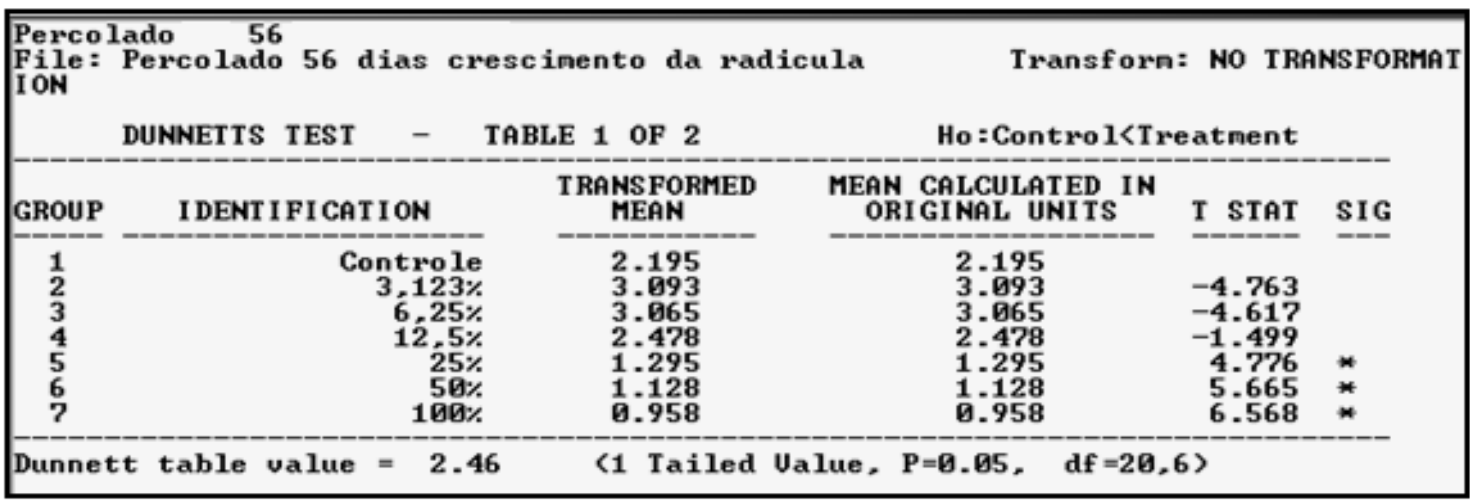

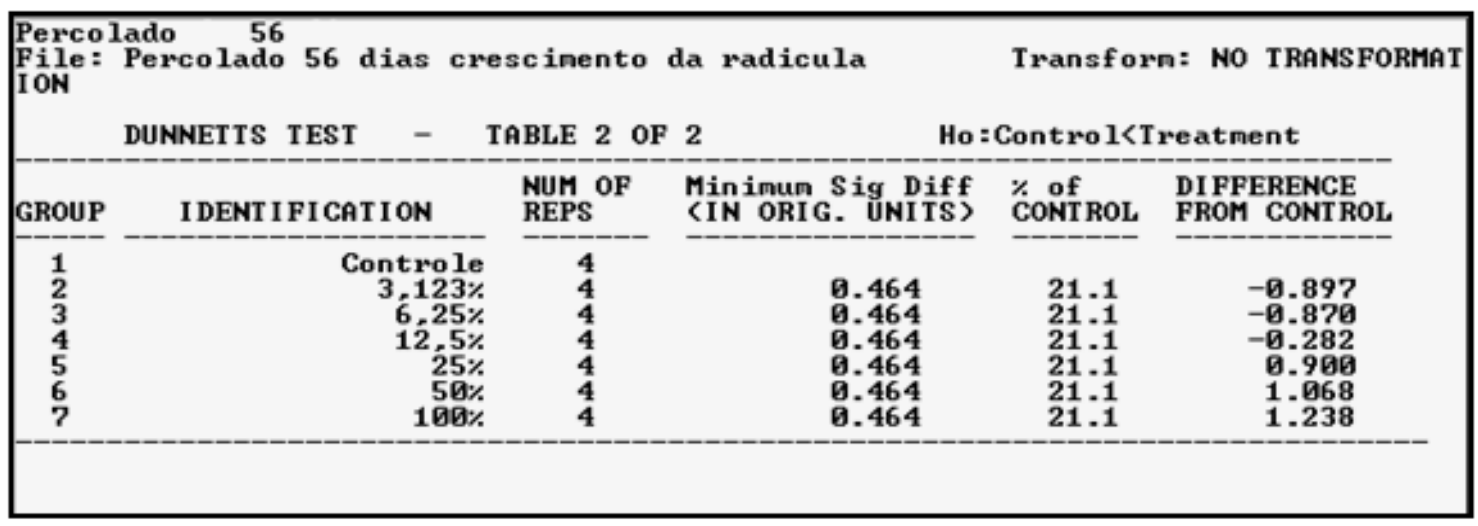

\section{Percolado 84}

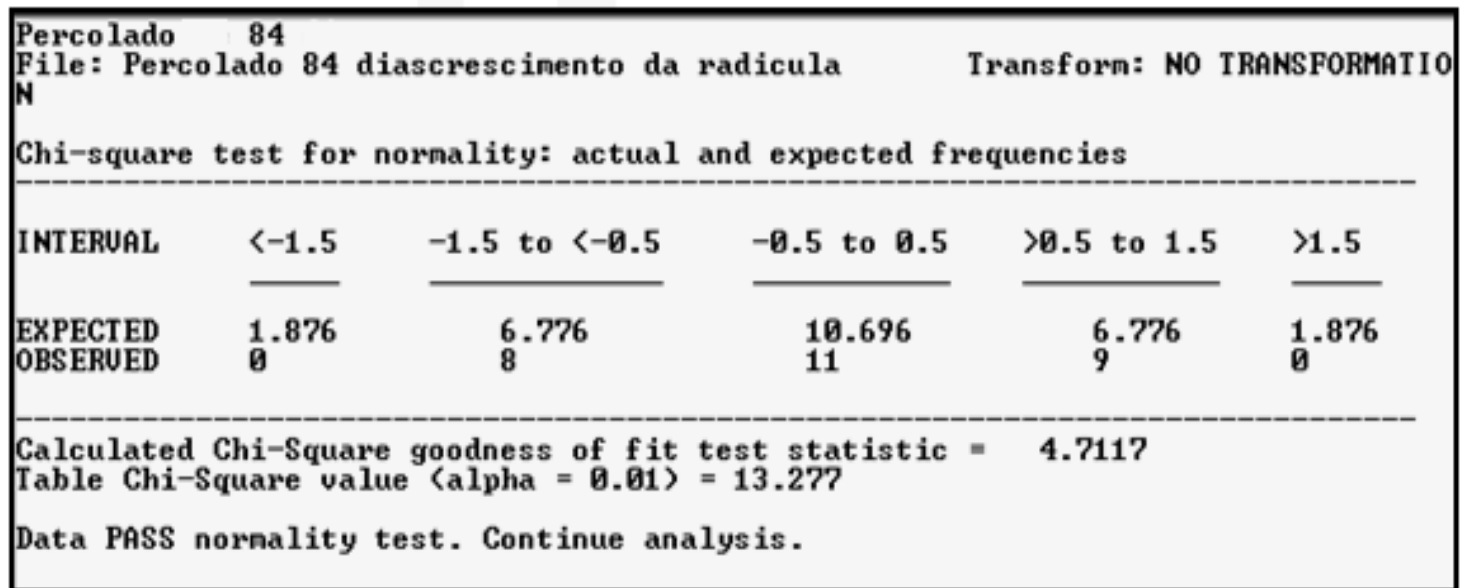


APÊNDICE F (continuação)

\section{Percolado 84}

\begin{tabular}{|c|c|}
\hline $\begin{array}{l}\text { Percolado } 84 \\
\text { File: Percolado } 84 \text { diascrescimento da radicula } \\
\text { N } \\
\text { Shapiro Wilks test for normality }\end{array}$ & Transforn: NO TRANSFORMATIO \\
\hline $\begin{array}{l}D=1.428 \\
W=0.955 \\
\text { Critical } W\langle P=0.65\rangle\langle(n=28\rangle=0.924 \\
\text { Critical } W(P=0.61)\langle(n=28\rangle=0.896\end{array}$ & \\
\hline
\end{tabular}

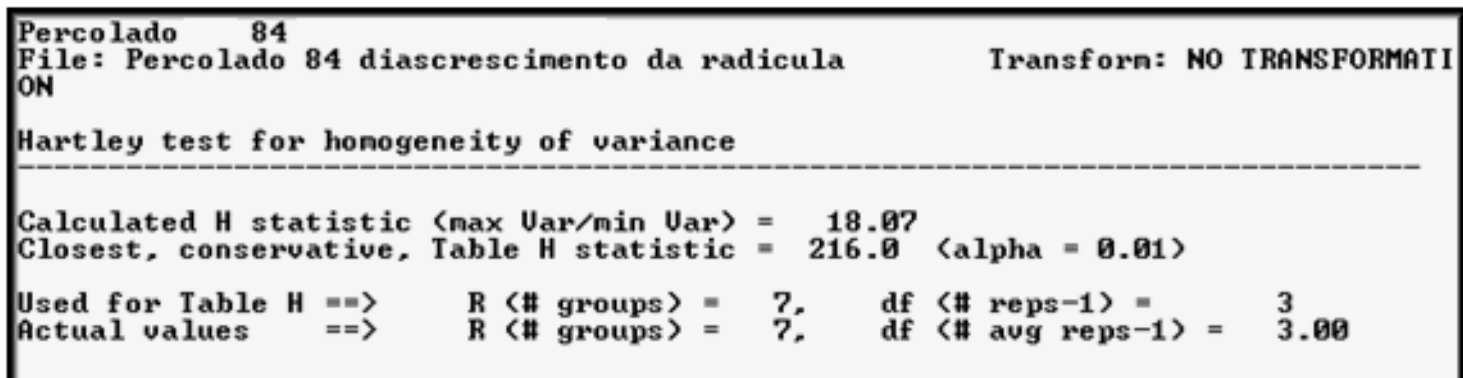

Data PASS honogeneity test. Continue analysis.

NOTE: This test requires equal replicate sizes. If they are unequal but do not differ greatly, the Hartley test nay still be used as an approxinate test (average df are used).

Percolado 84

File: Percolado 84 diascrescinento da radicula N

Transforn: NO TRANSFORMATIO

Bartletts test for honogeneity of variance

Calculated B statistic $=9.87$

Table Chi-square value $=16.81$ (alpha $=0.61$ )

Table Chi-square value $=12.59$ (alpha $=0.65)$

Average df used in calculation $\Rightarrow=>$ df $($ avg $n-1)=3.00$

Used for Chi-square table value $=m$ ) df (\#groups-1) = 6

Data PASS homogeneity test at 0.01 level. Continue analysis.

NOTE: If groups have unequal replicate sizes the average replicate size is used to calculate the $B$ statistic (see above). 
APÊNDICE F (continuação)

\section{Percolado 84}

\begin{tabular}{|c|c|c|c|}
\hline \multicolumn{4}{|c|}{$\begin{array}{l}\text { Percolado de } 84 \text { dias } \\
\text { File: Percolado } 84 \text { diascrescinento da radicula } \\
\text { ON } \\
\text { ANOUA TABLE }\end{array}$} \\
\hline SOURCE & DF & MS & $\mathbf{F}$ \\
\hline Between & 18.161 & 3.627 & 44.566 \\
\hline Within (Error) & 1.428 & 0.068 & \\
\hline Total & 19.589 & & \\
\hline
\end{tabular}

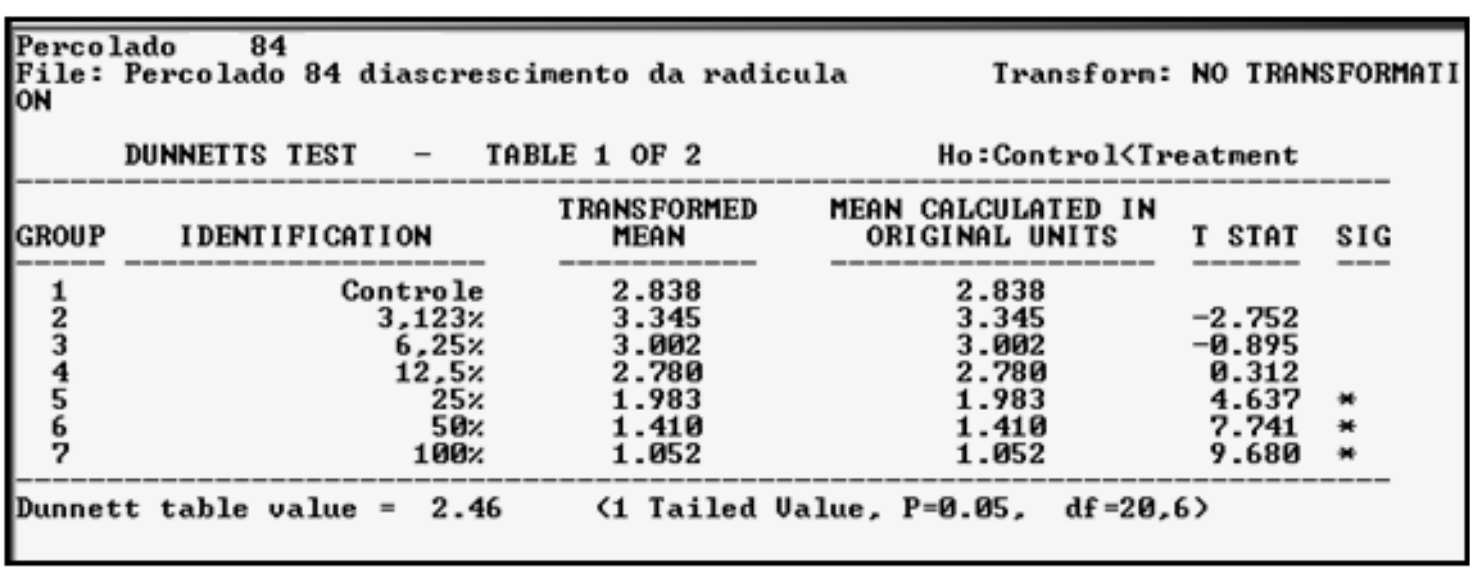

\begin{tabular}{|c|c|c|c|c|c|c|c|}
\hline \multicolumn{6}{|c|}{ 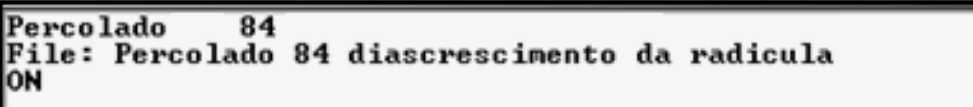 } & \multicolumn{2}{|c|}{$\begin{array}{l}\text { Transforn: NO TRANSFORMATI } \\
\text { :Contro } 1<\text { Treatment }\end{array}$} \\
\hline GROUP & I DENT I FI CAT & ION & $\begin{array}{l}\text { TABLE } 2 \text { c } \\
\text { NUM OF } \\
\text { REPS } \\
\end{array}$ & $\frac{2}{M}$ & $\begin{array}{l}\text { Minimum Sig Diff } \\
\text { (IN ORIG. UNITS) }\end{array}$ & \%ONTROL & $\begin{array}{l}\text { DIFFERENCE } \\
\text { FROM CONTROL }\end{array}$ \\
\hline $\begin{array}{l}1 \\
2 \\
3 \\
4 \\
5 \\
6 \\
7\end{array}$ & & $\begin{array}{r}t r o l e \\
6,123 \% \\
12,5 \% \\
25 \% \\
50 \% \\
100 \%\end{array}$ & $\begin{array}{l}\mathbf{4} \\
4 \\
4 \\
4 \\
4 \\
4 \\
4\end{array}$ & & $\begin{array}{l}0.454 \\
0.454 \\
0.454 \\
0.454 \\
0.454 \\
0.454\end{array}$ & $\begin{array}{l}16.9 \\
16.0 \\
16.0 \\
16.9 \\
16.0 \\
16.0\end{array}$ & $\begin{array}{r}-0.567 \\
-0.165 \\
0.658 \\
0.855 \\
1.428 \\
1.785\end{array}$ \\
\hline
\end{tabular}


APÊNDICE F (continuação)

\section{Percolado 84}

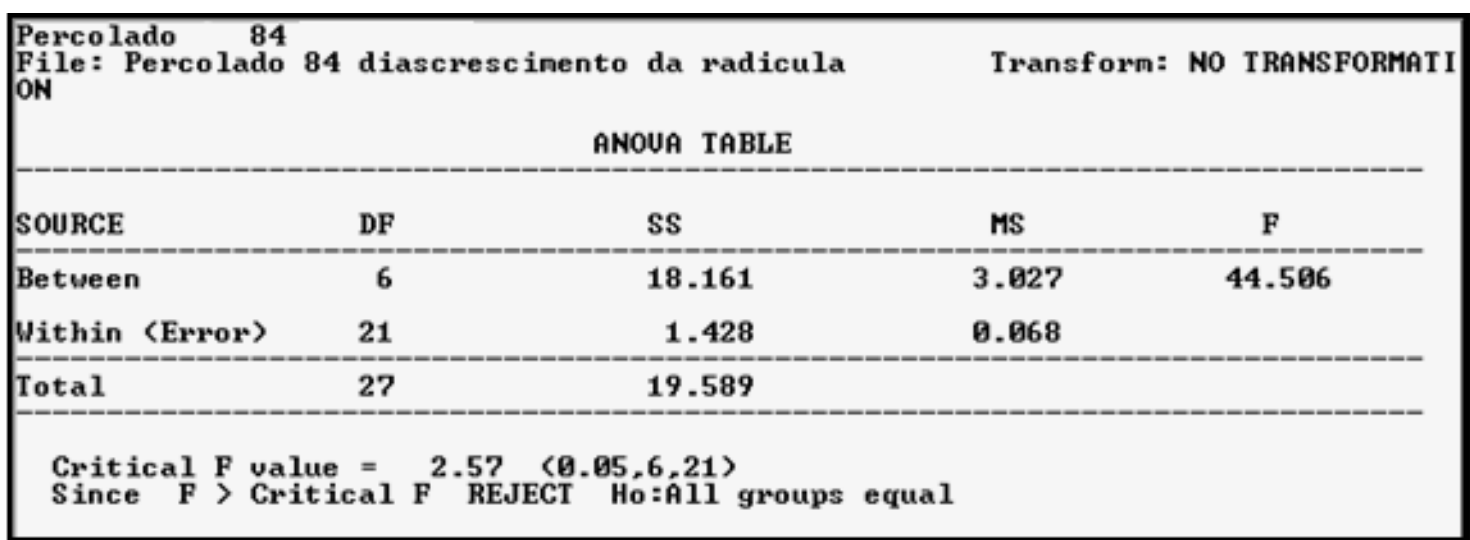


APÊNDICE G - Dados dos ensaios definitivos com $D$. similis para os percolados da coluna de cinza de carvão

Análise de: Percolado 28

Controle negativo: Água de cultivo de $D$. similis

Data do início do ensaio: 06/03/2012 Hora: 10:10

Data do término do ensaio: 08/03/2012 Hora: 10:05

\begin{tabular}{|c|c|c|c|c|c|c|}
\hline \multicolumn{7}{|c|}{ Resultados do teste de toxicidade aguda com Daphnia similis } \\
\hline $\begin{array}{c}\text { Concentrações } \\
\text { (\%) }\end{array}$ & \multicolumn{2}{|c|}{$\begin{array}{c}\mathbf{N}^{\circ} \text { de organismos imóveis por } \\
\text { réplicas }\end{array}$} & $\begin{array}{c}\mathbf{N}^{\circ} \text { acumulado de } \\
\text { organismos mortos ou } \\
\text { imóveis }\end{array}$ & $\begin{array}{c}\text { Medidas } \\
\text { finais }\end{array}$ \\
\hline & $\boldsymbol{R} \mathbf{1}$ & $\boldsymbol{R} \mathbf{2}$ & $\boldsymbol{R} \mathbf{3}$ & $\boldsymbol{R} \mathbf{4}$ & Total & $\boldsymbol{p H}$ \\
\hline Controle & 1 & 0 & 0 & 0 & 1 & 6.98 \\
\hline $\mathbf{3 , 1 2 5}$ & 0 & 0 & 1 & 0 & 1 & 7.10 \\
\hline $\mathbf{6 , 2 5}$ & 0 & 0 & 1 & 1 & 2 & 7.04 \\
\hline $\mathbf{1 2 , 5}$ & 0 & 0 & 1 & 0 & 1 & 7.09 \\
\hline $\mathbf{2 5}$ & 1 & 3 & 2 & 0 & 6 & 7.12 \\
\hline $\mathbf{5 0}$ & 5 & 5 & 5 & 5 & 20 & 6.99 \\
\hline $\mathbf{1 0 0}$ & 5 & 5 & 5 & 5 & 20 & 7.00 \\
\hline
\end{tabular}

Análise de: Percolado 56

Controle negativo: Água de cultivo de $D$. similis

Data do início do ensaio: 28/02/2012 Hora: 9:05

Data do término do ensaio: 01/03/2012 Hora: 9:20

\begin{tabular}{|c|c|c|c|c|c|c|}
\hline \multicolumn{7}{|c|}{ Resultados do teste de toxicidade aguda com Daphnia similis } \\
\hline $\begin{array}{c}\text { Concentrações } \\
\text { (\%) }\end{array}$ & \multicolumn{7}{|c|}{$\begin{array}{c}\mathbf{N}^{\circ} \text { de organismos imóveis por } \\
\text { réplicas }\end{array}$} & $\begin{array}{c}\mathbf{N}^{\circ} \text { acumulado de } \\
\text { organismos mortos ou } \\
\text { imóveis }\end{array}$ & $\begin{array}{c}\text { Medidas } \\
\text { finais }\end{array}$ \\
\hline & $\boldsymbol{R} \mathbf{1}$ & $\boldsymbol{R} \mathbf{2}$ & $\boldsymbol{R} \mathbf{3}$ & $\boldsymbol{R} \mathbf{4}$ & Total & $\mathbf{p H}$ \\
\hline Controle & 0 & 0 & 1 & 0 & 1 & 6.88 \\
\hline $\mathbf{3 , 1 2 5}$ & 1 & 1 & 0 & 0 & 2 & 7.10 \\
\hline $\mathbf{6 , 2 5}$ & 0 & 1 & 0 & 0 & 1 & 6.98 \\
\hline $\mathbf{1 2 , 5}$ & 1 & 1 & 0 & 0 & 2 & 7.20 \\
\hline $\mathbf{2 5}$ & 2 & 0 & 1 & 1 & 4 & 7.00 \\
\hline $\mathbf{5 0}$ & 4 & 3 & 4 & 4 & 15 & 7.19 \\
\hline $\mathbf{1 0 0}$ & 5 & 5 & 5 & 5 & 20 & 7.30 \\
\hline
\end{tabular}


APÊNDICE G (continuação)

Análise de: Percolado 84

Controle negativo: Água de cultivo de $D$. similis

Data do início do ensaio: 13/03/2012 Hora: 9:30

Data do término do ensaio: 15/03/2012 Hora: 9:45

\begin{tabular}{|c|c|c|c|c|c|c|}
\hline \multicolumn{7}{|c|}{ Resultados do teste de toxicidade aguda com Daphnia similis } \\
\hline $\begin{array}{c}\text { concentrações } \\
\text { (\%) }\end{array}$ & \multicolumn{7}{|c|}{$\mathbf{N}^{\circ}$ de organismos imóveis por } & $\begin{array}{c}\mathbf{N}^{\circ} \text { acumulado de } \\
\text { organismos morticas } \\
\text { imóveis }\end{array}$ & $\begin{array}{c}\text { Medidas } \\
\text { finais }\end{array}$ \\
\hline & $\boldsymbol{R} \mathbf{1}$ & $\boldsymbol{R} \mathbf{2}$ & $\boldsymbol{R} \mathbf{3}$ & $\boldsymbol{R} \mathbf{4}$ & Total & $\boldsymbol{p H}$ \\
\hline Controle & 0 & 0 & 1 & 0 & 1 & 7.48 \\
\hline $\mathbf{3 , 1 2 5}$ & 1 & 1 & 0 & 0 & 2 & 7.10 \\
\hline $\mathbf{6 , 2 5}$ & 0 & 1 & 0 & 0 & 1 & 6.98 \\
\hline $\mathbf{1 2 , 5}$ & 1 & 1 & 0 & 0 & 2 & 7.20 \\
\hline $\mathbf{2 5}$ & 2 & 0 & 1 & 1 & 4 & 7.00 \\
\hline $\mathbf{5 0}$ & 4 & 3 & 4 & 4 & 15 & 7.19 \\
\hline $\mathbf{1 0 0}$ & 5 & 5 & 5 & 5 & 20 & 7.04 \\
\hline
\end{tabular}

Análise de: $\underline{\text { Percolado } 112}$

Controle negativo: Água de cultivo de $D$. similis

Data do início do ensaio: 03/04/2012 Hora: 09:10

Data do término do ensaio: 05/04/2012 Hora: 09:50

\begin{tabular}{|c|c|c|c|c|c|c|}
\hline \multicolumn{7}{|c|}{ Resultados do teste de toxicidade aguda com Daphnia similis } \\
\hline $\begin{array}{c}\text { Concentrações } \\
\text { (\%) }\end{array}$ & \multicolumn{7}{|c|}{$\begin{array}{c}\mathbf{N}^{\circ} \text { de organismos imóveis por } \\
\text { réplicas }\end{array}$} & $\begin{array}{c}\mathbf{N}^{\circ} \text { acumulado de } \\
\text { organismos mortos ou } \\
\text { imóveis }\end{array}$ & $\begin{array}{c}\text { Medidas } \\
\text { finais }\end{array}$ \\
\hline & $\boldsymbol{R} \mathbf{1}$ & $\boldsymbol{R} \mathbf{2}$ & $\boldsymbol{R} \mathbf{3}$ & $\boldsymbol{R} \mathbf{4}$ & Total & $\boldsymbol{p H}$ \\
\hline Controle & 0 & 0 & 0 & 1 & 1 & 7.47 \\
\hline $\mathbf{3 , 1 2 5}$ & 1 & 0 & 0 & 0 & 1 & 7.10 \\
\hline $\mathbf{6 , 2 5}$ & 0 & 0 & 0 & 0 & 0 & 7.10 \\
\hline $\mathbf{1 2 , 5}$ & 0 & 0 & 0 & 0 & 0 & 7.06 \\
\hline $\mathbf{2 5}$ & 0 & 0 & 0 & 0 & 0 & 7.00 \\
\hline $\mathbf{5 0}$ & 0 & 0 & 0 & 0 & 0 & 7.18 \\
\hline $\mathbf{1 0 0}$ & 2 & 5 & 2 & 4 & 13 & 6.78 \\
\hline
\end{tabular}


APÊNDICE G (continuação)

Análise de: Percolado 168

Controle negativo: Água de cultivo de $D$. similis

Data do início do ensaio: 25/04/2012 Hora: 09:35

Data do término do ensaio: 27/04/2012 Hora: 09:00

\begin{tabular}{|c|c|c|c|c|c|c|}
\hline \multicolumn{7}{|c|}{ Resultados do teste de toxicidade aguda com Daphnia similis } \\
\hline $\begin{array}{c}\text { Concentrações } \\
\text { (\%) }\end{array}$ & \multicolumn{7}{|c|}{$\begin{array}{c}\mathbf{N}^{\circ} \text { de organismos imóveis por } \\
\text { réplicas }\end{array}$} & $\begin{array}{c}\mathbf{N}^{\circ} \text { acumulado de } \\
\text { organismos mortos ou } \\
\text { imóveis }\end{array}$ & $\begin{array}{c}\text { Medidas } \\
\text { finais }\end{array}$ \\
\hline & $\boldsymbol{R} \mathbf{1}$ & $\boldsymbol{R} \mathbf{2}$ & $\boldsymbol{R} \mathbf{3}$ & $\boldsymbol{R} \mathbf{4}$ & Total & $\boldsymbol{p H}$ \\
\hline Controle & 0 & 0 & 0 & 1 & 1 & 7.50 \\
\hline $\mathbf{3 , 1 2 5}$ & 1 & 0 & 0 & 0 & 0 & 7.34 \\
\hline $\mathbf{6 , 2 5}$ & 1 & 0 & 0 & 1 & 2 & 7.20 \\
\hline $\mathbf{1 2 , 5}$ & 0 & 0 & 1 & 0 & 1 & 7.12 \\
\hline $\mathbf{2 5}$ & 1 & 2 & 0 & 0 & 3 & 7.39 \\
\hline $\mathbf{5 0}$ & 0 & 3 & 1 & 3 & 7 & 7.04 \\
\hline $\mathbf{1 0 0}$ & 3 & 2 & 3 & 3 & 11 & 7.00 \\
\hline
\end{tabular}




\section{APÊNDICE H - Dados estatísticos para calcular os valores de CE50 ${ }_{(48 \mathrm{~h})}$ dos percolados 28, 56, 84, 112 e 168 da coluna de cinza de carvão nos ensaios definitivos com $D$. similis}

\section{Percolado 28}

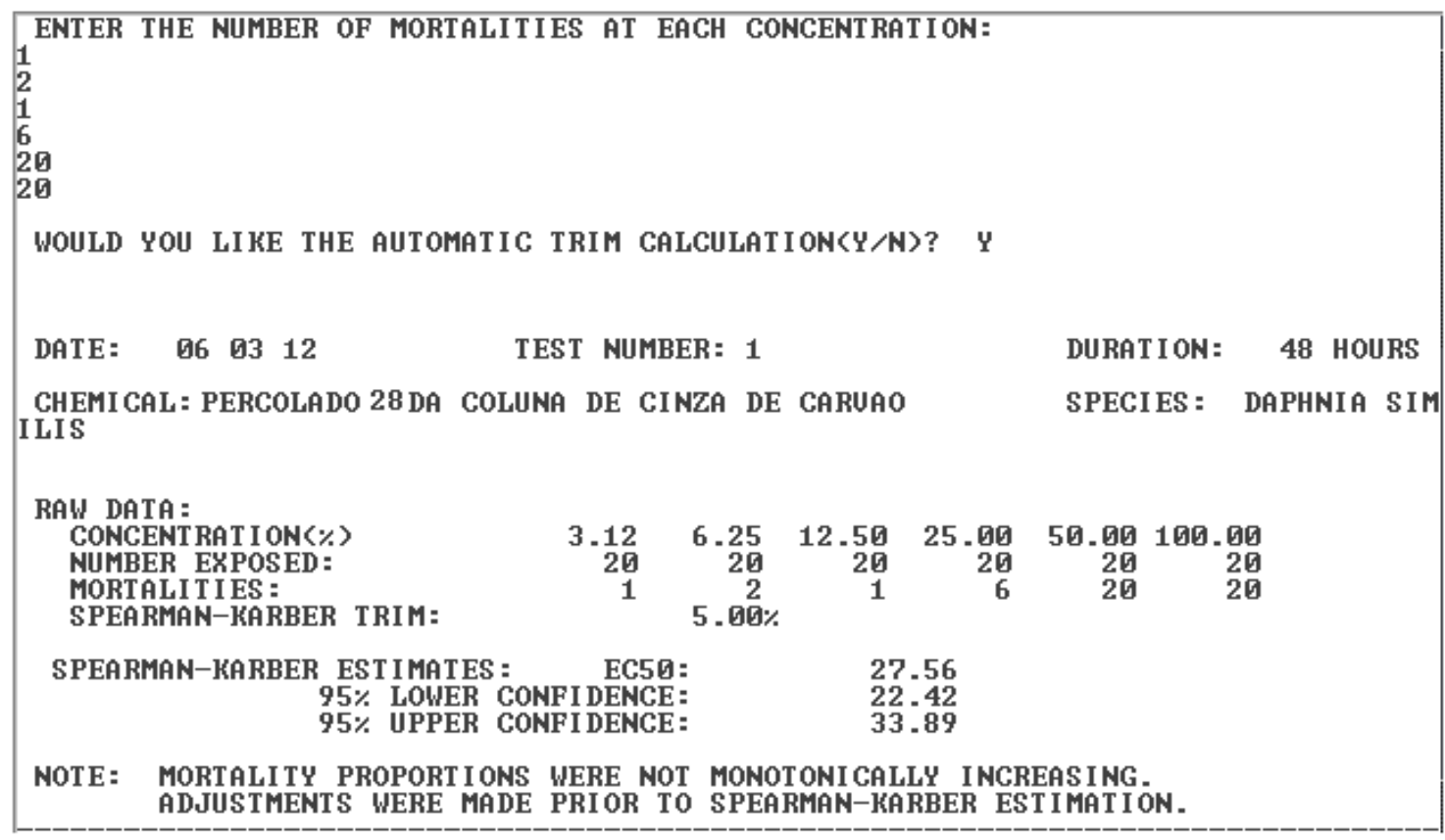

\section{Percolado 56}

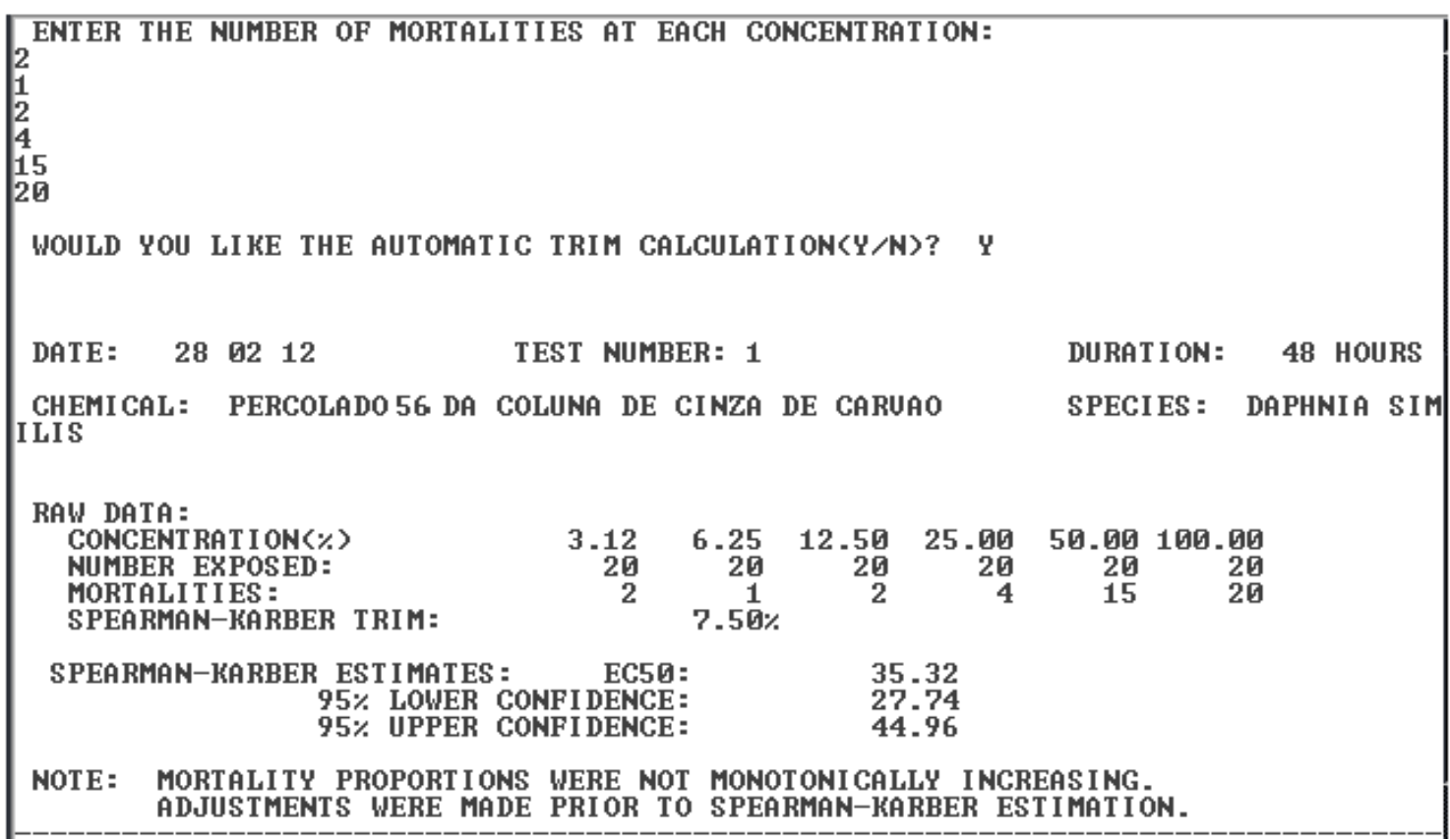


APÊNDICE H (continuação)

\section{Percolado 84}

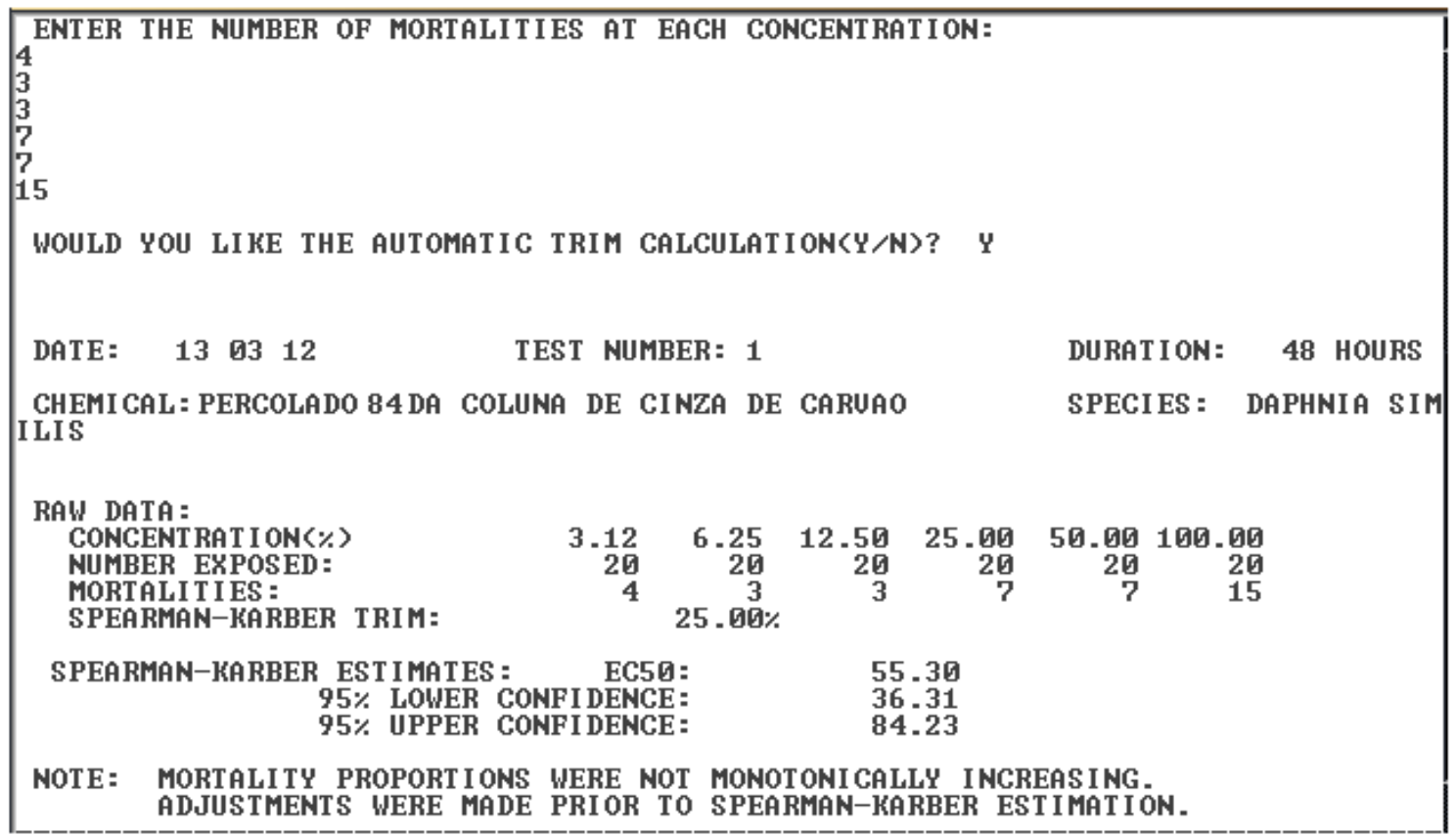

\section{Percolado 112}

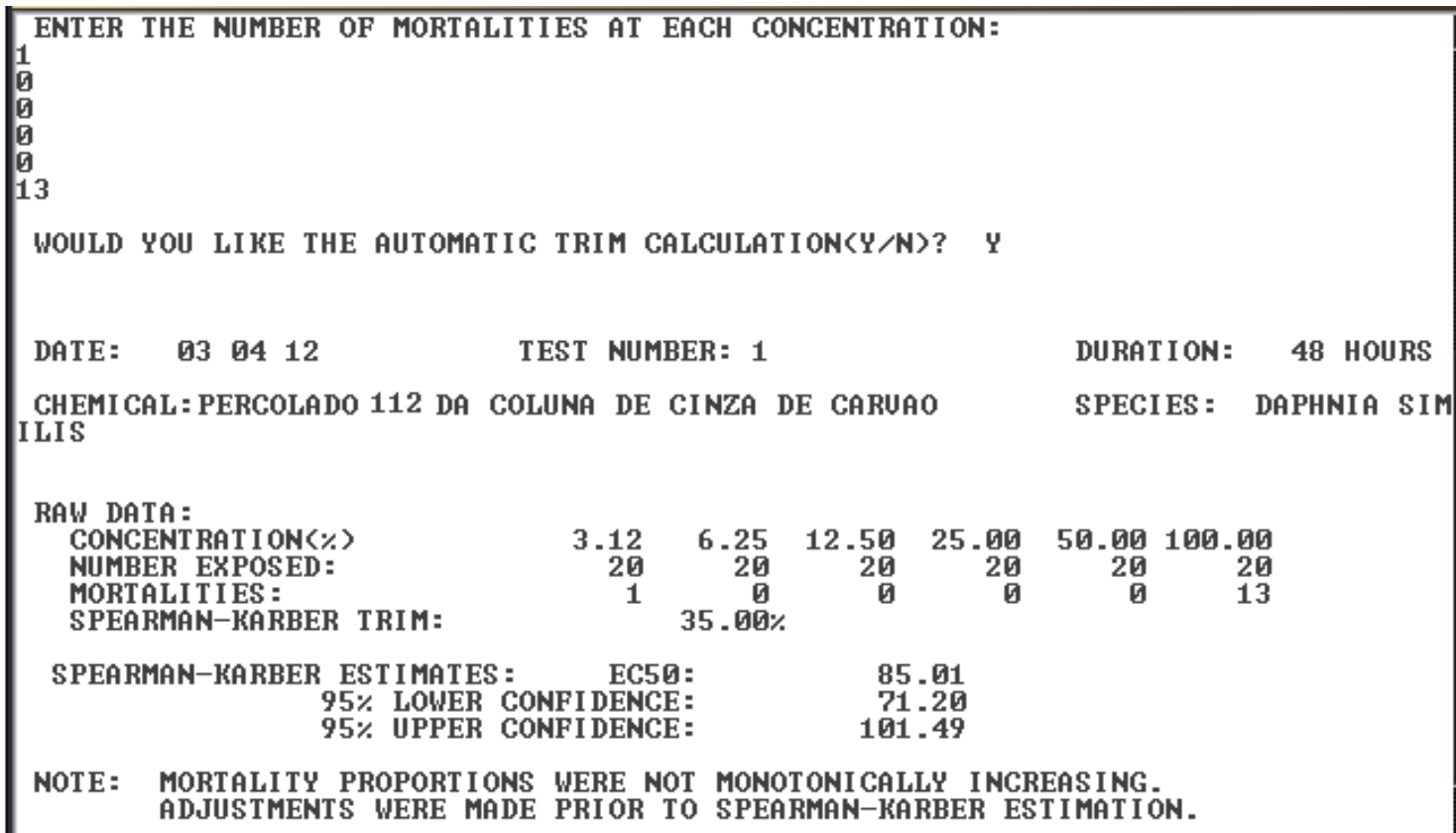


APÊNDICE H (continuação)

\section{Percolado 168}

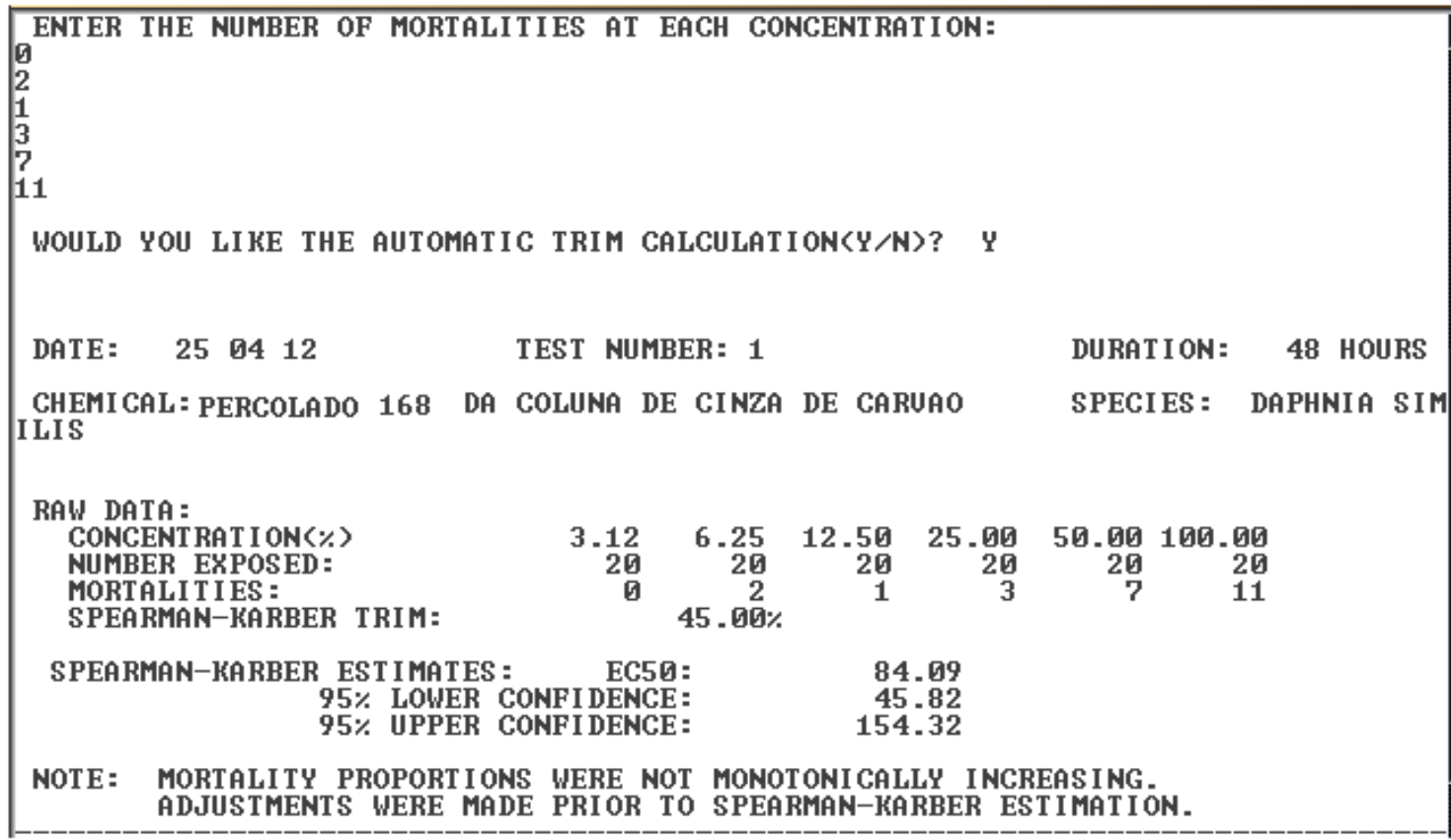




\section{REFERÊNCIAS BIBLIOGRÁFICAS}

ADAMS, W.J.; ROWLAND, C.D. Aquatic Toxicology Test Methods. In HOFFMAN, D.J.; RATTNER, B.A.; BURTON Jr, G.A.; CAIRNS Jr, J. (Editores) Handbook of Ecotoxicology, Washington, D.C.: Lewis Publishers. 2.ed. p. 32 $-58,2002$.

ADRIANO, D. C.; PAGE, A. L.; ELSEEWI, A. A.; CHANG, A. C.; STRAUGHAN, I. Utilization and Disposal of Fly Ash and Other Coal Residues in Terrestrial Ecosystems. J. Environ. Qual., v 9, n.9, p 333-344, 1980.

AGÊNCIA INTERNACIONAL DE ENERGIA - AIE. "Coal's share of global energy mix to continue rising, with coal closing in on oil as world's top energy source by 2017." 2012. Disponível em: <http://www.iea.org>. Acesso em: 15 jan. 2013.

AGÊNCIA INTERNACIONAL DE ENERGIA - AIE. International Energy Outlook. Center for Strategic and International Studies, U.S. Energy Information Administration, Washington, DC: Independent Statistics \& Analysis. 2011. Disponível em: <http://www.iea.org>. Acesso em: 15 jan. 2013.

AGÊNCIA NACIONAL DE ENERGIA ELÉTRICA. ANEEL. 2011. Disponível em: <http://www.aneel.gov.br>. Acesso em: 17 out. 2012.

AMERICAN SOCIETY FOR TESTING AND MATERIALS - Standard practice for conducting early seedling growth tests, ASTM ,1994.( E1598-94).

ARAGÃO, M.A.; ARAÚJO, R.P.A. Métodos de ensaios de toxicidade com organismos aquáticos. In ZAGATTO, P.A.; BERTOLETTI, E. (Editores). Ecotoxicologia Aquática: Princípios e Aplicações, São Carlos, São Paulo: Rima, 2008. p. 117 - 147.

ASSOCIAÇÃO BRASILEIRA DO CARVÃO MINERAL - ABMC. 2011. Disponível em: <http://www.carvaomineral.com.br> . Acesso em: 21 ago. 2012. 
ASSOCIAÇÃO BRASILEIRA DE NORMAS TÉCNICAS. Rochas e solos. Rio de Janeiro: ABNT, 1995. (NBR 6502).

ASSOCIAÇÃO BRASILEIRA DE NORMAS TÉCNICAS, Ecotoxicologia aquática - Toxicidade aguda - Método de ensaio com Daphnia ssp (Cladocera, Crustacea). Rio de Janeiro: ABNT, 2004 (NBR 12713).

AZZOLINI, M. Restauração ecológica de áreas impactadas por cinzas de carvão mineral: contribuição da mamona (Ricinus communis L.) e resposta da espécie a metais pesados. Tese (doutorado). Instituto de Biociências programa de Pós-graduação em Botânica, Porto Alegre, 2008.

BERTOLETTI, E.; ZAGATTO, P.A. Aplicação dos Ensaios Ecotoxicológicos e Legislação Pertinente. In ZAGATTO, P.A.; BERTOLETTI, E. (Editores). Ecotoxicologia Aquática: Principios e Aplicações, São Carlos, São Paulo: Rima, 2008. p. 347 - 379.

BLAISE, C. Introduction to ecotoxicological concenpts. Assessment, Proceedings of Biological Testing and Harzard, Environmental Canada, p. 11 $-47,1984$.

BRADY, N. C. Natureza e propriedades dos solos. 7.ed. Rio de Janeiro: Freitas Bastos, 1989.

BOWERS, N.; PRATT, J.R.; BEESON D.; LEWIS M. Comparative Evaluation of Soil Toxicity using Lettuce Seeds and Soil Ciliates. Environ. Toxicol. Chem., v. 16, n.2, p. 207-213, 1997.

BURTON Jr., G.A.; DENTON, D.L.; HO, K.; IRELAND, D.S. Sediment Toxicity Testing: Issues and Methods. In HOFFMAN, D.J.; RATTNER, B.A.; BURTON Jr, G.A.; CAIRNS Jr, J. (Editores) Handbook of Ecotoxicology, Washington, D.C.: Lewis Publishers. 2.ed. p.124- 164, 2002.

CELERE, M.S.; OLIVEIRA, A.S.; TREVIATO, T.M.B.; MUÑOZ, S.I.S. Metais presentes no chorume coletado no aterro sanitário de Ribeirão Preto, São Paulo, Brasil, e sua relevância para saúde pública. C. Saúde Pública, v. 23, n. 4, p. 939-947, 2007. 
CERUTTI, P.F.; FLORES, F.E.V. Bioindicação da contaminação atmosférica decorrente do uso do carvão In: Canto, M.B. Carvão e meio ambiente, Porto Alegre, Editora da Universidade Federal do Rio Grande do Sul, p. 461 - 469, 2000.

CHANG, A.C.; GRANTO, T.C.; PAGE, A.L. A methodology for establishing phytotoxicity criteria for chromium, copper, nickel and zinc in agricultural land application of municipal sewage sludges. Environ. Qual., v. 21, n. 4, p. 521536, 1992.

CHAPMAN, E.E.V.; DAVE, G.; MURIMBOH. J.D. Ecotoxicological risk assessment of undisturbed metal contaminated soil at two remote lighthouse sites. Ecotox. Environ. Safe., v. 73, n. 5, p. 961-969, 2010.

CIRINO, F.S. Investigação dos níveis de mercúrio total em amostras de solos, sedimentos e águas da região estuarina de Santos e São Vicente, SP. Dissertação (Mestrado) Universidade Católica de Santos, Santos, 2009.

COMPANHIA DE TECNOLOGIA DE SANEAMENTO AMBIENTAL - CETESB. Decisão de Diretoria No 195- 2005-E. São Paulo: CETESB, 2005.

CONAMA - Conselho Nacional do Meio Ambiente Resolução n³57, de 17 de março de 2005. Dispõe sobre a classificação dos corpos de água e diretrizes ambientais para o seu enquadramento, bem como estabelece as condições e padrões de lançamento de efluentes, e dá outras providências.

CONAMA - Conselho Nacional do Meio Ambiente Resolução n³96, de 7 de abril de 2008. Dispõe sobre a classificação e diretrizes ambientais para o enquadramento das águas subterrâneas e dá outras providências.

CONSTITUIÇÃO FEDERAL, Constituição Federativa do Brasil. Brasília, DF: Senado, 1988.

COOK, S.V.; CHU, A.; GOODMAN, R.H. Leachability and toxicity of hydrocarbons, metals and salt contamination from flare pit soil. Water Air Soil Poll., v. 133, n.4, p. 297-314, 2002. 
COSTA, C.R.; OLIVI, P.A.; BOTTA, C.M.R.; ESPÍNDOLA, E.L.G. Toxicidade em ambientes aquáticos: discussão e métodos de avaliação. Revisão. Quím. Nova, v. 31, n.7, p. 1820-1830, 2008.

DOMINGUES, D.F.; BERTOLETTI, E. Seleção, Manutenção e Cultivo de Organismos Aquáticos. In: Zagatto, P.A.; Bertoletti, E. (Editores) Ecotoxicologia Aquática: Principios e Aplicações, São Carlos, São Paulo: Rima, 2008.

DEPOI, F.S.; POZEBON, D.; KALKREUTH, W.D. Chemical characterization of feed coals and combustion by products from Brazilian power plants. Int. J. Coal Geol. v. 76, n.3, p. 227 - 236, 2008.

EI MOGAZI, D.; LISK, D.J.; WEINSTEIN, L.H. A review of physical, chemical, and biological properties of fly ash and effects on agricultural ecosystems. Sci. Total Environ., v. 74, n.1, p 1-37, 1988.

EMPRESA BRASILEIRA DE AGROPECUÁRIA - EMBRAPA - Sistema Brasileiro de Classificação de Solos. Rio de Janeiro, $2^{\circ}$ ed.: Centro Nacional de Pesquisas de Solos, 2006.

EMPRESA BRASILEIRA DE AGROPECUÁRIA - EMBRAPA - 0 silício combate estresses nutricionais. Mato Grosso do Sul, Agropecuária Oeste, 2013.

ENVIRONMENTAL CANADA - Guidance document on control of toxicity test precision using reference toxicants. Report EPS 1/RM/12. p.85, 1990.

ENVIRONMENTAL CANADA - Biological Test Method: Test for Measuring Emergence and Growth of Terrestrial Plants Exposed to Contaminants in Soil. Environmental protection series, EPS 1/ RM/45, 2005.

FAIRBROTHER, A.; WENSTE, R.; SAPPINGTON, K.; WOOD, W. Framework for Metals Risk Assessment. Ecotoxicol. Environ. Safe., v. 68, n.2, p.145-227, $2007 a$. 
FAIRBROTHER, A.; De VITO, S.; MOUNT, D.; SAPPINGTON, K. United States Development of a Framework for Metals Risk Assessment. Environmental Protection Agency. US EPA (120/R-07/001). 2007b. Disponível em: $<$ http/l:www.epa.gov/osa>. Acesso em: 12 jan. 2013.

FAQUIN, V. Nutrição mineral de plantas. Lavras, M.G.: UFLA/FAEPE, 1997. FERREIRA, A.L.N. Exposição de Crómio em alface: acumulação e efeitos na fisiologia e genotoxicidade. Dissertação (Mestrado). Departamento de Biologia Universidade de Aveiro, 2007.

FLUES, M.; SATO, I. M.; COTRIM, M. B.; FIGUEIREDO FILHO, P. M.; CAMARGO, I. M. C. Avaliação da influência da operação da termoelétrica a carvão na concentração dos metais e As no solo de Figueira, PR-Brasil. Quím. Nova. v.31, n.1, p.25-30, 2008.

FUENTES, A., LORÉNS, M.; SÁEZ, J.; AGUILAR, M.I.; PÉREZ-MARÍN, A.B.; ORTUÑO, J.F.; MESEGUER, V.F. Ecotoxicity, phytotoxicity and extractability of heavy metals from different stabilised sewage sludges. Environ Pollut. v.143, n. 2, p. $355-360,2006$.

FURLANI, A.M.C. Nutrição mineral. In Kerbauy, G.B. (Editor) Fisiologia Vegetal. Rio de Janeiro: Guanabara, 2004. p. 40-75.

GAIVIZZO, L.H.B.; VIDOR, C.; TEDESCO, M.J.; MEURER, E. Pollutant potential of coal rejects - chemical characterization of the leached water. Cienc Rural, v. 32, n. 5, p. $771-780,2002$.

GUERRA, R.C. Estudo do lodo gerado em reator biológico, pelo tratamento da água de produção do petróleo, no Terminal Marítimo Almirante Barroso, município de São Sebastião, SP. Visando sua disposição final. Tese (doutorado). Universidade Estadual Paulista, Rio Claro, 2009

GULLEY, D.D.; BOELTER, A.M.; BERGMAN, H.L. TOXSTAT 3.5. Computer Program, 1995. 
HAMILTON, M.A.; RUSSO, R.C.; THURSTON, R.V. Trimmed SpearmanKarber method for estimating median lethal concentrations in bioassays. Environ. Sci Technol., v. 12, n. 4, p.417, 1999.

HAMON, R.; MCLAUGHLIN, M.; LOMBI, E. (Editores). Natural attenuation of trace element availability in soils. Boca Raton: CRC Press, 2007.

HOFFMAN, D.J.; RATTNER, B.A.; BURTON Jr., G.A.; CAIRNS Jr., J. Introduction. In HOFFMAN, D.J.; RATTNER, B.A.; BURTON Jr, G.A.; CAIRNS Jr, J. (Editores) Handbook of Ecotoxicology, Washington, D.C.: Lewis Publishers. 2.ed.p. $15-32,2002$.

IZIDORO, J.C. Estudos sobre a remoção de íons metálicos em água usando zeólitas sintetizadas a partir de cinzas de carvão. Dissertação (Mestrado). Instituto de Pesquisas Energéticas e Nucleares, São Paulo, 2008.

LAMEIRA, V. Estudo dos efeitos letais e subletais (reprodução e teratogênese) do fármaco triclosan para Daphnia similis, Ceriodaphnia dubia, Ceriodaphnia silvestrii (Cladócera, Crustacea). Dissertação (Mestrado). Instituto de Pesquisas Energéticas e Nucleares, São Paulo, 2008.

LANGE, C.N. Contaminação do solo e mobilidade de $\mathrm{As}, \mathrm{Cd}$, Mo, $\mathrm{Pb}$ e Zn em colunas de solo franco arenoso com cinza de carvão. Dissertação (Mestrado). Instituto de Pesquisas Energéticas e Nucleares, São Paulo, 2012.

LARSON, R.; FARBER, B. Estatística aplicada. São Paulo, Pearson Education do Brasil, 4 edição, 2011.

LEFFA, D.D. Avaliação do potencial genotóxico do rejeito de carvão mineral através do molusco Helix aspersa (Müller 1774). Bacharel (Ciências Biológicas) Universidade do Extremo Sul Catarinense, Santa Catarina, 2008.

LEPSCH, I.F. Formação e conservação dos solos. São Paulo: Oficina de Textos, 2002.

LU, S.G.; CHEN, Y.Y.; SHAN, H.D.;. BAI, S.Q. Mineralogy and heavy metal leachability of magnetic fractions separated from some Chinese coal fly ashes. J. Hazard. Mater., v.169, p. 246-255, 2009. 
MARTENS, D.C.; BEHAM, B.R. Growth of plants in fly ash amended soils. Inter. Ash Util. Symp, St. Louis, MO, v. 26, p. 657- 64, 1976.

MARTINS, R.S.L. Avaliação da toxicidade de águas de chuva a organismos aquáticos. Dissertação (Mestrado). Instituto de Pesquisas Energéticas e Nucleares, São Paulo, 2009.

MAZOYER, M.; ROUDART, L. História da agricultura no mundo. São Paulo : UNESP, 2010.

MCBRIDE, M.B. Environmental Chemistry of Soils. New York: Oxford University Press, 1994.

MEZA, J.C.S.; SALAZAR, V.F.P.; SILVA, T.B.P.; GARCÍA, V.G.G.; GONZÁLEZ, C.J.A.; GARCÍA, P.G. Toxicity assessment of a complex industrial wastewater using aquatic and terrestrial bioassays Daphnia pulex and Lactuca sativa. J. Environ. Sci. Health Part A, v. 42, n. 10, p. 1425-1431, 2007.

MINISTÉRIOS DAS MINAS E ENERGIA - MME - Martiz Energética Nacional 2030, Brasília, 2007.

MOZETO, A.A.; ZAGATTO, P.A. Introdução de agentes químicos no ambiente. In: ZAGATTO P.A.; BERTOLETTI E. Ecotoxicologia Aquática: Principios e Aplicações, São Carlos, São Paulo: Rima, 2008. p. 15-36.

NASCIMENTO, I.A.; PEREIRA, S.A.; LEITE, M.B.N.L. Biomarcadores como instrumentos preventivos de poluição. In: Zagatto, P.A.; Bertoletti, E. Ecotoxicologia Aquática: Princípios e Aplicações, São Carlos, São Paulo: Rima, 2008. p. 413 - 429.

ORGANIZATION FOR ECONOMIC COOPERATION AND DEVELOPMENT OECD - Terrestrial Plant Test: 208: Seedling Emergence and Seedling Growth Test. Guideline for the Testing of Chemicals Proposal for Updating Guideline 208, 2003.

PLAA, G.L. Present status: toxic substances in the environment. Can. J. Physiol. Pharm., v.60, p.1010-1016, 1982. 
POSTHUMA, L.; SUTER, G.W. TRAAS, T.P. Species Sensitivity Distributions in Ecotoxicology. Boca Raton, Florida: CRC Press, 2002.

PRINTES, L.B.; BOHRER, M.B.C.; PORTELA, C.M.S.; GÜNTZEL, C.E. Biomonitoramento da área sob influência da exploração carbonífera através de testes de toxicidade com cladocera (Crustacea; Branchiopoda). In: Canto, M.B. (Editor) Carvão e o meio ambiente, Porto Alegre, Editora da Universidade Federal do Rio Grande do Sul, 2000.

PROCHNOW, T.R.; PORTO. M.L. Avaliação de uma área de rejeitos da mineração de carvão com vistas a bioindicadores vegetais para metais pesados. In: Canto, M.B. Carvão e o meio ambiente,. Porto Alegre, Editora da Universidade Federal do Rio Grande do Sul, p. 673 - 695, 2000.

RODGHER, S.; ESPÍNDOLA, E.L.G.; LOMBARDI, A.T. Suitability of Daphnia similis as an alternative organism in ecotoxicological tests: implications for metal toxicity. Ecotoxicol., v. 19, n. 6, p. $1027-1033,2010$.

ROHDE, G. M.;. RODRIGUEZ, M.T.R. Diagnóstico ambiental das cinzas de carvão. In: Canto, M.B. Carvão e meio ambiente, Porto Alegre, Editora da Universidade Federal do Rio Grande do Sul, p. 461 - 469, 2000.

ROHDE, G.M.; ZWONOK, O.; CHIES, F.; SILVA, N.I.W.L. Cinzas de Carvão Fóssil no Brasil - Aspectos técnicos e ambientais. Porto Alegre: CIENTEC, 2006.

ROONEY, C.P.; ZHAO, F-J.; MCGRATH, S.P. Phytotoxicity of nickel in a range of European soils: Influence of soil properties, $\mathrm{Ni}$ solubility and speciation. Environ. Poll., v. 145, n. 2, p. 596 - 605, 2007.

SECO, J.I.; FERNANDEZ-PEREIRA,C.; VALE, J. A study of the leachate toxicity of metal-containing solid wastes using Daphnia magna. Ecotoxicol. Environ. Safe., v. 56, n. 3, p. 339-350, 2003.

SILVA, J.C. Mobilidade de As, Cd, Mo, Pb e Zn em colunas de latossolo argiloso com cinza de carvão e contaminação do solo. Dissertação (Mestrado). Instituto de Pesquisas Energéticas e Nucleares, São Paulo, 2013. 
SILVA, N.I.W.; CARLAGE, L.M.; CHIES, F.; MALLMANN, J.E.; ZWONOK, O. Caracterização de cinzas volantes para aproveitamento cerâmico. Cerâmica, v. 45, n. 296, p. $184-187,1999$.

SCHNEIDER, P.; KÄMPF, N.; GIASSON, E. Solos. In: Canto, M.B. Carvão e meio ambiente, Porto Alegre, Editora da Universidade Federal do Rio Grande do Sul, p. $461-469,2000$.

SOBRERO, M.C.; RONCO, A. Ensayo de toxicidad aguda con semillas de lechuga (Lactuca sativa L). In: Morales, G.C. Ensayos toxicológicos y métodos de evaluación de calidad de aguas: Estandarización, intercalibración, resultados y aplicaciones, IMTA, p. 63 -72., 2004.

SPOSITO, G. The Chemistry of soils. New York: Oxford University Press, 1989

SUKANDAR, T.; PADMI, M.; TANAKA, E.; AOYAMA, I. Chemical stabilization of medical waste fly ash using chelating agent and phosphates: Heavy metals and ecotoxicity evaluation. Waste Manage., v. 29, n. 7, p. 2065 - 2070, 2009.

UNITED STATES ENVIRONMENT CANADA. Guidance document on control of toxicity test precision using reference toxicants, p.85, 1990.

UNITED STATES ENVIRONMENTAL PROTECTION AGENCY - US EPA Methods for measuring the acute toxicity of effluents and receiving waters to freshwater and marine organisms. Environmental Monitoring Systems Laboratory, Cincinnati - Ohio, 1993.

UNITED STATES ENVIRONMENTAL PROTECTION AGENCY - US EPA Seed Germination/ Root Elongation Toxicity Tests." Ecological Effects Tests Guidelines, 1996.

VALAVANIDIS, A.; VLACHOGIANNI, T. Metal Pollution in Ecosystems Ecotoxicology Studies and Risk Assessment in the Marine Environment. Sci. Adv. Environ. Toxicol. and Ecotoxicol. Issues. v.1, p. 57-84, 2010.

WANG, W. Root elongation method for toxicity of organic and inorganic pollutants. Environ. Toxicol. Chem., v.6, n. 5, p. 409-414, 1987. 
WARD, N.I. Trace Elements. In Fifield F.W.; Haines, P.J. (Editor) Environmental Analytical Chemistry, London, Blackwell Science, 1995. p. 360-392.

WATER QUALITY COMMITTEE. Overview: metal toxicity. 2010.

WONG, M. H, E BRADSHAW, A. D.. A Comparison of the toxicity of heavy metals, using root elongation of Rye grass, Lolium perenne. New Phytology, v. 91, n. 2, p. 255-261, 1982.

WORLD ENERGY COUNCIL. Survey of Energy Resources. London: Regency House, 2007.

WU, S.G.; HUANG, L.; HEAD, J.; CHEN, D-R.; KOMG, I.C.; TANG, Y.J. Phytotoxicity of Metal Oxide Nanoparticles is Related to Both Dissolved Metals Ions and Adsorption of Particles on Seed Surfaces. J. Petr. Environ. Biotech., v. 3, n.4, p. 2157-7463, 2012.

$\mathrm{YU}, \mathrm{M}-\mathrm{H}$. Environmental Toxicology: Biological and Health Effects of Pollutans. Boca Raton, Florida: CRC Press, 2004.

ZAGATTO, P.A. Ecotoxicologia Aquática: Princípios e Aplicações In: ZAGATTO, P.A.; BERTOLETTI, E. (Editores) Ecotoxicologia. São Carlos, São Paulo: Rima, 2008. p. 3-15. 